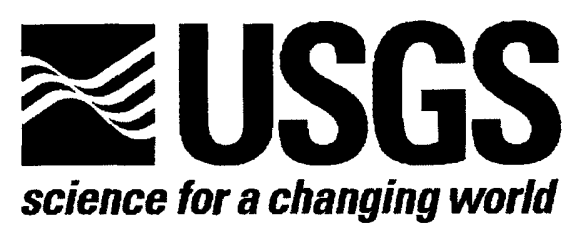

\title{
GEOELECTRICAL STUDIES \\ OF A TRENCHED LINE ACROSS THE ANIMAS RIVER, SAN JUAN COUNTY, COLORADO
}

\author{
by David L. Campbell ${ }^{1}$ and J. Christopher Eckhart ${ }^{1}$
}

Open-File Report 00-112

2000

This report is preliminary and has not been reviewed for conformity with U.S. Geological Survey editorial standards and stratigraphic nomenclature. Any use of trade, product, or firm names is for descriptive purposes only and does not imply endorsement by the U.S. Govemment.

\section{U.S. DEPARTMENT OF THE INTERIOR U.S. GEOLOGICAL SURVEY}

${ }^{1}$ Denver, Colorado 


\title{
GEOELECTRICAL STUDIES OF A TRENCHED LINE ACROSS THE ANIMAS RIVER, SAN JUAN COUNTY, COLORADO
}

\author{
by David L. Campbell and J. Christopher Eckhart
}

\section{INTRODUCTION}

In Summer, 1998, the U.S. Bureau of Land Management commissioned the U.S. Geological Survey to study a site on the upper Animas River where a trench was to be dug across the river valley. Part of that work included geophysical studies along the trench line to be done ahead of trenching, so as to test the ability of those methods to distinguish features seen in the trench walls. In particular, it was hoped that it might be possible to locate units of fluvially redistributed mine tailings that might be present in the valley. The geophysical methods we used were magnetics, multifrequency electromagnetic, spectral induced polarization, and ground penetrating radar.

\section{COORDINATE SYSTEM}

The trench line (fig. 1) crosses the valley of the Animas River about 1 mile below the abandoned townsite of Eureka, Colorado. It trends $287 \mathrm{~m}$ in a southeasterly direction across the valley from the rubble slope on the northwest to a gravel road on the southeast. The line changes direction by about $5^{\circ}$ to the left at a point $150 \mathrm{~m}$ from its northwest end, on the northwest bank of the main strand of the Animas River. The Animas River is braided in the study area, and the trench line crosses several other of its strands as well.

The zero point of our coordinate system is on the extension of the trench line at the northwest edge of an abandoned haulage road that follows the northwest edge of the valley. We spaced wooden stakes $20 \mathrm{~m}$ apart along the line where the trench was to be dug ("Center Line"), and numbered them increasing to the southeast, our nominal "east". Lines parallel to the Center Line were also laid out $20 \mathrm{~m}$ "north" (that is, northeast) and $20 \mathrm{~m}$ "south" (southwest) of it; these lines also have stakes spaced $20 \mathrm{~m}$ apart along them and are called "Line 20N" and "Line 20S", respectively. All the stakes, and several permanent features like telephone poles, were surveyed using an EDM. A map showing locations of staked points, stream strands, and surface sedimentary units was prepared by Kirk Vincent of the U.S. Geological Survey. That map is at a scale of $1 \frac{1 / 4}{4}$ inches $=20 \mathrm{~m}$; several of the figures in this report are made to that scale for ready correlation with it. All geophysical measurements were made on the surveyed lines as nearly as possible. The trench was subsequently dug using a backhoe with its "north" edge flush against the surveyed Center Line, and Kirk prepared a map of features seen in that wall of that trench. That map is at a scale of $16 \mathrm{~cm}=10 \mathrm{~m}$ in order to show all the detail revealed by trenching. Kirk's geological maps are intended to be published as a U.S. Geological Survey WaterResources Investigations Report entitled "The response of the upper Animas River below Eureka, Colorado, to the discharge of ore-mill tailings," by K.R. Vincent and J.G. Elliott. This present report describes only the geophysical aspects of the study. The detailed 
geophysical cross sections in this report are done at a scale of $5 \mathrm{~cm}=10 \mathrm{~m}$. They all have southeast to the right, and so are looking upstream.

\section{SELECTED STRATIGRAPHIC UNITS}

For a proper description of the units Kirk Vincent mapped in the walls of the trench, you must read his report (Vincent and Elliott, work in progress). For reference, however, here is a list of some particular units he mapped that turn out to have strong geophysical signatures:

BlkCSG - Blackened and cemented sandy gravel. High IP polarizability. BrnSS - Brown sandy silt. High electrical conductivity. Good radar reflector. Peat - a thin lens of peat within the BrnSS at $\sim 65-67 \mathrm{E}$ was a very strong radar reflector. YBrnSCT - Yellowish brown and olive thickly laminated to very thinly bedded silty clay tailings. Located $\sim 143-147 \mathrm{E}$. High electrical conductivity.

\section{MAGNETOMETER PROFILES}

Magnetic fields were measured along Lines 20N, Center Line, and Line 20S using a GeoMetrics G-858 magnetometer. The sensor was carried only about $1 \frac{1}{2}$ feet above the surface (a mistake, in retrospect, because this meant it saw every stray scrap of iron, such as old barrel hoops). The data was taken with the instrument continuously recycling and recording to memory at 1 -second intervals. At the operator's normal walking pace, this resulted in about 4 readings every 5 meters. Marks were entered into the data stream as the sensor passed the 20-m stakes, and data was stretched evenly in between. The average magnetic field in the study area was found to increase to the nominal east along the lines by $0.7566 \mathrm{nT} / \mathrm{m}$, and this trend as well as a background value of $52,495 \mathrm{nT}$ was subtracted from the observed data to give the residual magnetic values shown in Fig. 2.

We think that most or all of the high-amplitude local anomalies seen on Fig. 2 are due to ferrous metal junk on the surface or shallowly buried under the lines. On Line 20S, for example, the more-than-1000-nT doublet at about coordinate 70E was due to half of a steel 55-gal drum that was bogged in the sand at that place. The huge low at about $20 \mathrm{~S}$ $33 \mathrm{E}$ is probably due to another artifact, buried under a shallow slough. Its size, found by "hemstitching" around it with the magnetometer, suggests its source may be a sheet of metal roofing. We probed down a few feet here and there with a rod but couldn't find it. Local high-magnetic fields at the ends of the three lines are probably due to rhyolite blocks on the hillslope and in the road metal. Most of the remaining features on the line have amplitudes of $50 \mathrm{nT}$ or less. One of these, on Center Line at $150-155 \mathrm{~m}$, just west of the main strand of the Animas River, and inside a bend of it, is due to a foot or more of magnetic black sands deposited there. Such sands are visible in the stream banks, are well cemented, and attract a hand magnet. They are known to be the source for some magnetic features seen there and elsewhere; in particular, they can give rise to lows if the sensor, held near the ground, is below their outcrop in a stream bank (e.g., 20N 100E). One interesting unexplained magnetic feature is the paired high and low anomaly at $240-260 \mathrm{E}$ 
on line $20 \mathrm{~N}$. This feature is at a stream (the high) and nearby young gravel bars (lows). There is a telephone pole just north of the line at about $260 \mathrm{E}$.

Generally speaking, magnetic features in the study area are bland and hard to correlate between the 20 - $\mathrm{m}$-apart lines. They do not help in any obvious way to trace buried stratigraphic units.

\section{ELECTROMAGNETIC PROFILES}

Electromagnetic data was taken along Line 20N, Center Line, and Line 20S using a multifrequency 2-loop unit, the GEM-2, manufactured by Geophex Ltd, Raleigh NC 27603. The unit measured InPhase and Quadrature components at frequencies of 2430 , 7430 , and $15120 \mathrm{~Hz}$. It continuously cycled and wrote to memory as the operator walked the lines. As with the magnetometer, the operator added a mark to the data stream as he passed each $20-\mathrm{m}$ stake and the data was later stretched evenly between these known points. The combination of operator's walking pace and instrument's repetition rate resulted in sets of 6 readings (InPhase and Quadrature at each of the 3 frequencies) spaced about every $12-15 \mathrm{~cm}$.

We expected to be able to invert the multifrequency EM data to make depth sections under each of the three lines. Using computer programs such as that by Anderson (1992), one could find a 3-layer best fit to the 6 observed values at each observation point. This was not possible, because the GEM-2 unit, a product recently put on the market, turned out to be uncalibrated. The manufacturer has promised to try to correct this problem in the future.

Fig. 3 shows the GEM-2 data along the 3 lines. The plotted data has been somewhat smoothed by taking a running 5-point average of the recorded data points. McNiell (1996) states that InPhase values should not change much as one sweeps through the frequencies that the GEM-2 uses; Fig. 3 shows that to be so. For "low-induction-number" instruments with fixed loop-spacing like the GEM-2, the InPhase component may reflect additional phase lags due to magnetic materials in the ground (McNiell, 1996). Comparing Figs. 2 and 3, we see that this also seems true, in an inverse sense -- InPhase values are generally higher where magnetic fields are lower, and vice-versa. This phenomenon was first noted by Fraser (1981). A striking example of it occurs at coordinate $32-38$, Line $20 \mathrm{~S}$.

For instruments of the GEM-2 type, the Quadrature component is directly proportional to the electrical conductivity of the ground (Won and others, 1996). Using an equation derived from their chart (Won and others, 1996), the Quadrature values were converted to conductivities before plotting in Fig 3. At the time we did the survey, we thought (as likely did most geophysicists) that this effective conductivity would be a weighted average (higher weights nearer the surface) of the true conductivities distributed through a block of ground under the instrument whose thickness would be a large fraction of the "skin depth" there. For ground of $2 \mathrm{mS} / \mathrm{m}$ conductivity, skin depths are $92 \mathrm{~m}$ at $15120 \mathrm{~Hz}, 131$ 
$\mathrm{m}$ at $7430 \mathrm{~Hz}$, and $228 \mathrm{~m}$ at $2430 \mathrm{~Hz}$. We therefore assumed that the GEM-2 data would reflect ground conductivities quite deep under the trench line.

A recent publication (Reid and Macnae, 1999) shows our above assumptions about depth were wrong. Using a graph in that paper, we find the "local source skin depths" for the electric field are only about $1.4 \mathrm{~m}$ for the GEM-2's $15120 \mathrm{~Hz}$ component, $1.7 \mathrm{~m}$ for its $7420 \mathrm{~Hz}$ component, and $2.0 \mathrm{~m}$ for its $2430 \mathrm{~Hz}$ component. Therefore, according to Reid and Macnae (1999), the GEM-2 frequencies investigated to about trench depths, but not much deeper.

Fig. 3 shows that, in many parts of the 3 lines, the $7420 \mathrm{~Hz}$ Quadrature value is lowest, the 15120 value is a little higher, but similar, and the 2430 value is much higher. It is likely that the $2430 \mathrm{~Hz}$ values reflect higher conductivity values below the water table. Comparison with the SIP conductivity profile (Plate 1, upper panel), shows a general correlation between conductivitiy patterns measured using the two different systems. The GEM-2 conductivity values at $7430 \mathrm{~Hz}$ generally agree well with those found using the SIP gear. The $15210 \mathrm{~Hz}$ values are too low, actually negative in many places, while those at $2430 \mathrm{~Hz}$ are perhaps a little high. This probably reflects the fact, mentioned above, that the GEM-2 was poorly calibrated -- its electronic package apparently amplified signals at some frequencies relatively more than those at other frequencies.

\section{GROUND-PENETRATING RADAR}

\section{Data collection and processing}

Two men collected the GPR data in about 6 hours on 19 August, 1998. The equipment we used was manufactured by Geophysical Survey Systems Incorporated (GSSI), North Salem NH 03073, and consisted of a Model SIR-10A+ unit (Fig. 4) and Model 3205 antennas. These antennas have a nominal center frequency of $300 \mathrm{MHz}$ (their frequency in air, which loads down to around $150 \mathrm{MHz}$ on dirt). The transmitter and receiver antennas were mounted $1.4 \mathrm{~m}$ apart in a rigid frame (Fig. 5), and were pulled on the ground along the surveyed center line where the trench was to be dug. To avoid water damage to the antennas, they were stopped and carried across streams with their bottoms just above the water level. Marks were entered on the record every $20 \mathrm{~m}$ and at other known points. The entire line was covered with 5 overlapping segments. Two channels of data were recorded on each segment -- channel 1 , from $0-100$ nanoseconds (ns; $1 \mathrm{~ns}=10^{-}$ ${ }^{9}$ second), planned to get near surface detail; and channel 2, 0-300 ns, to see as deep as possible. The deep limit, $300 \mathrm{ns,}$, was determined on site by experimenting with the equipment; no signals were detected for times after that.

The GPR data was processed in the office using programs by Jeffrey E. Lucius, USGS (1999, written commun.; these programs are available via anonymous ftp from musette.cr.usgs.gov in the directory/pub/lucius/software). The processing steps were: 
Snip out any record segments where the antennas were stopped, as at stream edges.

Rescale gains as needed to bring up faint arrivals and tone down too-strong ones.

Adjust zero time as needed to coincide with firing of the transmitter antenna.

Compare overlapping segments and choose the better one.

Flip the segments end-for-end so that coordinates increase to the right (the data had been collected going the other direction).

"Rubber-sheet" the lines; e.g., stretch the data between marks at known positions to get a true horizontal scale.

Plot the data to scale.

At this point, we found that all features on Channel 1 also appeared just as well on Channel 2, so the Channel 1 data was dropped.

\section{Comments about GPR data}

Fig. 6 is a plot of two-way travel time versus horizontal distance, plotted to the scale 1 $1 / 4^{\prime \prime}=2 \mathrm{~m}$ to match Kirk Vincent's sketch maps of stratigraphic details in the trench wall (Vincent and Elliott, work in progress). The plots are truncated at $250 \mathrm{~ns}$, because there was only noise after that.

Wherever the antennas were carried, rather than dragged on the ground, the initial arrival is earlier and stronger. This happens at coordinates 0-9 (where there were big boulders that would have hung up the antenna sled), and at all stream crossings (coordinates 9-19, 25-29, 156-162, 225-130, 246-255, and 269-277).

Several features on Fig. 6 arise from radar waves in the air, and do not indicate ground geology. GPR waves travel $30 \mathrm{~cm} / \mathrm{ns}$ (the speed of light) in air, but slower than that in the ground. A good example of this effect is shown on Fig. 7, where late arrivals trace out a $30 \mathrm{~m}$-wide hyperbola centered at about $262 \mathrm{~m}$. That coordinate is where the metal-cased GPR console was located: apparently the GPR waves were reflecting from it. This console was a little offset from the line per se, so as to give a hyperbolic form to the arrivals. The limbs of the hyperbola have a (two-way travel time) slope of $15 \mathrm{~cm} / \mathrm{ns,}$ confirming that this arrival is indeed an air wave. These arrivals are much stronger where the antennas were carried across streams. Apparently picking up the antennas only a few $\mathrm{cm}$ so as to clear the water greatly changed their ground coupling characteristics. The result was to defocus the antenna beam from vertically downward into a diffuse beam, part of which transmitted sideways and reflected from the console.

Even antennas lying flat on the ground have beams with some side lobes, however. The diffuse apparent west-dipping hazy zones at coordinates 185-215 represent reflections from the inside bight of the antenna cable as it trailed behind the sled. There is also a double set of faint apparent east-dipping arrivals at the far western end of the section (about coordinates 4-25) that probably represent reflections from the steep northwestern 
bank of the northwesternmost channel of the Animas River. These arrivals all have airwave velocities.

\section{Translating GPR time-sections to depth-sections}

The speed of GPR waves, V, in a material is affected by the material's relative dielectric permittivity (RDP), conductivity, and magnetic permeability, but the principal one of these is RDP. To a fair approximation

$$
\mathrm{V}=30 / \mathrm{SQRT}(\mathrm{RDP})[\mathrm{cm} / \mathrm{ns}]
$$

Sen and others (1981) developed a way to calculate the RDP of different mixtures of materials. Their result, the "BHS equation", is now widely used in geophysics. For a mixture of sand and water, BHS predicts that a fully water-saturated sand of $40 \%$ porosity will have $\mathrm{RDP} \sim 25$. This suggests the trench-line GPR waves may have $\mathrm{V} \sim 6 \mathrm{~cm} / \mathrm{ns}$, so that a feature at the bottom ( $250 \mathrm{~ns}$ ) of our (two-way) time section is at about $7.5 \mathrm{~m}$ depth. This velocity was assumed in making the depth sections of Figs. 8. These figures have a horizontal scale of $1: 2000(10 \mathrm{~cm}=20 \mathrm{~m})$ and a vertical exaggeration (VE), if the above calculation is right, of $2: 1$.

The depths on Figs. 8 are very approximate. For one thing, different geological units will have different GPR velocities, and we do not know these in detail. Furthermore, any full reflected waveform is at least a triplet (typically, a low-high-low if reflected from a material of higher RDP; high-low-high if from one of lower RDP) of about 5 ns duration for the antenna frequency we used. The true depth of the reflector is that to the top of the triplet, but the triplet itself covers perhaps $30 \mathrm{~cm}$ of apparent depth. Notice that GPR may see reflections from the top of thin units but it may not be possible to resolve the thickness of units thinner than about $30 \mathrm{~cm}$ (using $300 \mathrm{MHz}$ antennas, at least) -- the reflection from the unit's bottom may be masked by the triplet signature from its top.

\section{Interpretation of GPR depth-sections}

The many intertwined GPR wave packets we see on figs. 7 and 8 resemble stratigraphy, and we want to interpret them as such. GPR waves are, indeed, sensitive to lithology, so that many of those wave packets truly do represent reflections from lithologic interfaces. To that extent, "GPR stratigraphy" correlates with mapped stratigraphy. However, GPR waves are also highly sensitive to amounts of porewater in the media through which they propagate. Therefore, other GPR wave packets may represent reflections from relatively wet or dry subunits; caused for example by variations in the coarseness of sand grains and the extent to which interstices between the coarser grains are filled by finer grains or by porewater. Such variations probably could be mapped in a trench wall, but they aren't significant to our objectives. Still, they show up on GPR sections. Result: "GPR stratigraphy" is an amalgam, in which useful stratigraphic information is heavily overprinted by less-significant detail. 
Interpreting GPR sections is a specialty (see van Overmeeren, 1998) similar to interpreting seismic stratigraphy (see, for example, Tucker and Yorston, 1973). In principle, one defines particular wave packets and follows them laterally so as to outline different units. It helps to view the record obliquely, in order to outline places where one set of wave packets truncates another. Very bright arrivals can indicate edges where a reflecting horizon has been cut off laterally -- particularly so if the bright spot is concave down with hyperbolic tails off to the sides. Remember that some arrivals may be coming from features out of the plane of the section. Not everything on the display is in its correct vertical position, in other words.

Nevertheless, there are many features on Figs. 8 that correlate with units mapped in the trench walls (Vincent and Elliott, work in progress). In particular, the tops and (sometimes) bottoms of the sandy silt unit can apparently be identified in many places (e.g., coordinates 205-246). If our identification of these interfaces is correct, however, it implies that GPR velocity in sandy silt is even slower than the assumed $6 \mathrm{~cm} / \mathrm{ns}$. This leads to a problem, for it implies that the RDP of the material above the interface has to be so high as to be physically unlikely.

\section{SPECTRAL INDUCED POLARIZATION}

\section{Data collection and processing}

SIP data was collected during two trips. On July 23,1998 , we took data using $2 \mathrm{~m}$ dipoles between coordinates $128-152$ and $160-200$. There is a fast-flowing strand of the Animas River between coordinates 152 and 160 , precluding data collection in that interval. During August 17-19, 1998, we took data using $2 \mathrm{~m}$ dipoles between coordinates 102-126 and using $4 \mathrm{~m}$ dipoles between coordinates 8-124 and 188-284. Streams in all these intervals were shallow and slow enough to let us emplace electrodes on their bottoms and work on through them (Fig.10). The data was collected using dipole-dipole arrays to $\mathrm{N}=5$ (one transmitter dipole and 5 receiver dipoles, in-line, for each setup). The two-man crew was able to measure 24-30 setups a day. The equipment used was a Zonge GDP-32 receiver/data processer and a battery-driven Zonge NT-20 transmitter. For each dipole we measured spectral response of the ground (electrical conductivity and IP amplitude and phase) in the band from $1 / 8 \mathrm{~Hz}$ to $72 \mathrm{~Hz}$.

Fig. 10 plots observed spectra in pseudosection form. A few spectra, those with obvious errors, have been deleted from the display. These are working charts, useful for checking data quality and for quick characterization of the ground at each place. Long spectra that curl downward indicate "EM coupling" -- this means the operator probably laid the current cables too close to the potential cables. Flat lines usually mean the ground is not polarizable--sand will give such signatures. Note the preponderance of such flat spectra in Fig. 10. The spectra we are especially looking for here appear as small humps, for these can indicate high sulfide content; hence, potentially toxic mine tailings. There are, however, few of these on Fig. 11. 
Data was processed using the computer software package Zonge supplies with their gear. The electrical conductivity and 3-point phase values were interpreted using the computer program DCIP2D, written by geophysicists at the University of British Columbia. DCIP2D takes raw data measured along the surface and produces a cross-section that shows how the SIP properties may be distributed with depth. Three-point phase is a measure of IP response that tries to minimize electromagnetic inductive effects (that is, effects due to electrical conductivity structures in the ground). The hope, therefore, is to have one cross-section that shows how electrically conductive the ground is, and another cross-section that shows how polarizable it is.

Interpretation of SIP data

We had expected that the IP parameter would pick out mine waste, but it did not. Instead, the high IP reponses correlate most strongly with BlkCSG, the blackened cemented sandy gravel unit.

\section{CONCLUSIONS}

The objective of the geophysical work reported herein was to find out what methods might be most effective at predicting units in the upper Animas River valley that might be encountered by excavation equipment. In particular, we hoped to devise a strategy for locating pockets of fluvially redistributed mine waste, especially mine waste with high, potentially toxic, levels of metals.

\section{$\underline{\text { Magnetics }}$}

We encountered one clearly magnetic unit in the study area, a well-indurated black sand. This black sand unit, however, appears to be thin, and seems to give rise to a magnetic signature only where it is very shallow or outcropping. Our magnetic survey did not help map buried units in the study area. It did, of course, find many scraps of ferrous metal.

\section{Electromagnetics}

Our particular EM survey failed to give depth information because the equipment we used had not been properly calibrated in the factory. However, the survey was fast and easy to do, and it gave excellent horizontal resolution. Analogous airborne surveys, done using calibrated gear, are routinely interpreted nowadays to give maps of electrical resistivity at different depths, and it should be possible to do that here. BrnSS, the brown sandy silt unit (Vincent and Elliott, work in progress), appears to be a good electrical conductor, and probably can be mapped, at least roughly, using multifrequency EM. Because BrnSS lies below later mine tailings, this should help give maximum thickness estimates of any possible fluvial tailings deposits.

\section{Induced Polarization}


Our work elsewhere (Campbell and others, 1998) has shown that mine waste with high sulfide content will usually have high SIP phase values. On the trench line, we used $2 \mathrm{~m}$ and $4 \mathrm{~m}$ dipoles in our SIP work. This means that we were measuring blocks of ground of the order of $2 \mathrm{~m}$ and $4 \mathrm{~m}$ on a side. The SIP method, therefore, can certainly be expected to detect pods of mine waste of that size, as well as blocks containing smaller pods that are rich and large enough to effect overall block properties. The interpretation program we use divides the ground into still smaller blocks for its modeling, $0.5 \mathrm{~m}$ on a side for the $2 \mathrm{~m}$ dipoles and $1.0 \mathrm{~m}$ on a side for the $4 \mathrm{~m}$ dipoles, and uses a statistical procedure to assign best-fit values to each model block. In this way it tries to pull out possibly-rich sub-blocks that may be of interest. Our $2 \mathrm{~m}$-dipoles definitely picked out a highly electrically conducting unit of mine tailings (YBrnSCT) that was about $30 \mathrm{~cm}$ thick and very near the surface (at 142E-147E). The resolution of any such dipole-dipole geoelectrical work will drop off as the depth of the target unit increases and its thickness and sulfide content decreases.

Our SIP work is an example of a classic engineering trade-off. To get good resolution we must use smaller dipoles, while to cover the ground at a good rate we must use larger dipoles. For this study we measured complete spectra for each dipole pair, but that seems unnecessary. Finding only one of any standard IP measure of polarity (e.g., chargeability, percent frequency effect, raw phase, 3-point phase, or any other) should adequately index the polarizable blocks of ground, as well as substantially speed up operations. Even so, IP work seems cumbersome and relatively expensive for this application. There probably is a better way (below).

\section{Ground penetrating radar}

Our GPR profile showed much stratigraphic detail. One of the reflecting units was the silty sand (Vincent and Elliott, work in progress; cf. electromagnetics section, above). GPR profiles do not give much information on composition of the units they detect, however, and they do not seem able to pick out mine tailings at all. Therefore, they need auxillary information to interpret them reliably.

Translating GPR time-sections into depth-sections is important, but it appears the standard BHS mixing rule doesn't apply very well for fluvial units in the upper Animas River valley. Units on the depth-section (Fig. 8) seem too deep by about a factor of 2 . Better: devise an empirical conversion factor, and drop the theoretical BHS scheme that our interpretation package uses.

\section{RECOMMENDATIONS}

Should it be decided to go ahead with excavation in the upper Animas River valley, the following geophysical strategy should help avoid bad ground:

First, use a magnetometer to sweep for ferrous junk (e.g., sheets of steel roofing). Put the sensor at the top of the pole, head-high or a little more. It isn't necessary to make an 
accurate magnetic map; rather, one just needs to sweep along lines spaced 10-20 m apart and flag the edges of big ( $>200 \mathrm{nT}$, say) anomalies, so that the excavating machinery can avoid possible ferrous junk buried in those places.

Second, run GPR profiles on the possible excavation path, along lines oriented approximately perpendicular to the path and spaced $10-20 \mathrm{~m}$ apart. It should be possible to use playouts of the field records directly, without going to advanced processing.

An alternative, preferrably adjunct, to the above step would be to sweep along lines spaced 10-20 m apart with a multifrequency EM unit that continuously cycles and records to memory. Typical commercial units allow use of up to 6 frequencies at a time, and one should use at least 3 frequencies. The exact frequencies to pick should be determined by modeling to make sure the survey will see deeper than the machinery will dig. The results should be interpreted using a standard airborne EM package to give a maps of electrical conductivity at various depths. Typical turnaround time for such processing will probably be a few weeks.

Third, choose a preliminary excavation path through places where the EM and/or GPR stratigraphy is as flat and bland as possible. Then use a post-hole digger, plus/minus vibracore or penetrometer sampling, to identify GPR reflecting units and check for tailings units.

Forth, iterate on the above steps as necessary.

\section{ACKNOWLEGEMENTS}

We thank Ahmed Zamzami and Yahya Tarabulsi, visitors from the USGS Mission in Saudi Arabia, for helping us with data collection and processing.

\section{REFERENCES}

Anderson, Walter L., 1992, Interactive inversion of dipole loop-loop electromagnetic data for layered earth models using numerical integration and complex image theory (Version 1.0): U.S. Geological Survey Open-file Report 92-553A (text) and B (diskettes), 42 p.

Campbell, D.L., Fitterman, D.V., Hein, A.S., and Jones, D.P., 1998, Spectral induced polarization studies of mine dumps near Silverton, Colorado (extended abstract): Proceedings of the Symposium on the Application of Geophysics to Engineering and Environmental Problems, March 23-27, 1998, Chicago, Illinois, p. 761-769.

Fraser, Douglas C., 1981, Magnetite mapping with a multicoil airborne electromagnetic system, Geophysics, v. 46, no.11, p. 1579-93. 
McNiell, J.D., 1996, Why doesn't Geonics Limited build a multi-frequency EM31 or EM38?: Technical Note TN-30, Geonics Ltd., 1745 Meyerside Dr. Unit 8, Mississauga, Ontario, Canada L5T $1 \mathrm{C6}$.

Reid, James E., and Macnae, James C., 1999, Doubling the effective skin depth with a local source: Geophysics, v. 64 , no. 3, p. 732-738.

Sen, P.N., Scala, C., and Cohen, M.H., 1981, A self-similar model for sedimentary rocks with application to the dielectric constant of fused glass beads: Geophysics, v. 46, no. 5, p. 781-795.

Tucker, P.M., and Yorston, H.J., 1973, Pitfalls in seismic interpretation: Tulsa, OK, Society of Exploration Geophysicists Monograph Series No. 2, 50 p.

van Overmeeren, R.A., 1998, Radar facies of unconsolidated sediments in The Netherlands: a radar stratigraphy interpretation method for hydrogeology: Journal of Applied Geophysics, v. 40, p. 1-18.

Won, I.J., Keiswetter, Dean A., Fields, George R.A., and Sutton, Lynn C., 1996, GEM-2: a new multifrequency electromagnetic sensor: Journal of Environmental \& Engineering Geophysics, v. 1, issue 2, p.129-138. 


\section{FIGURES}

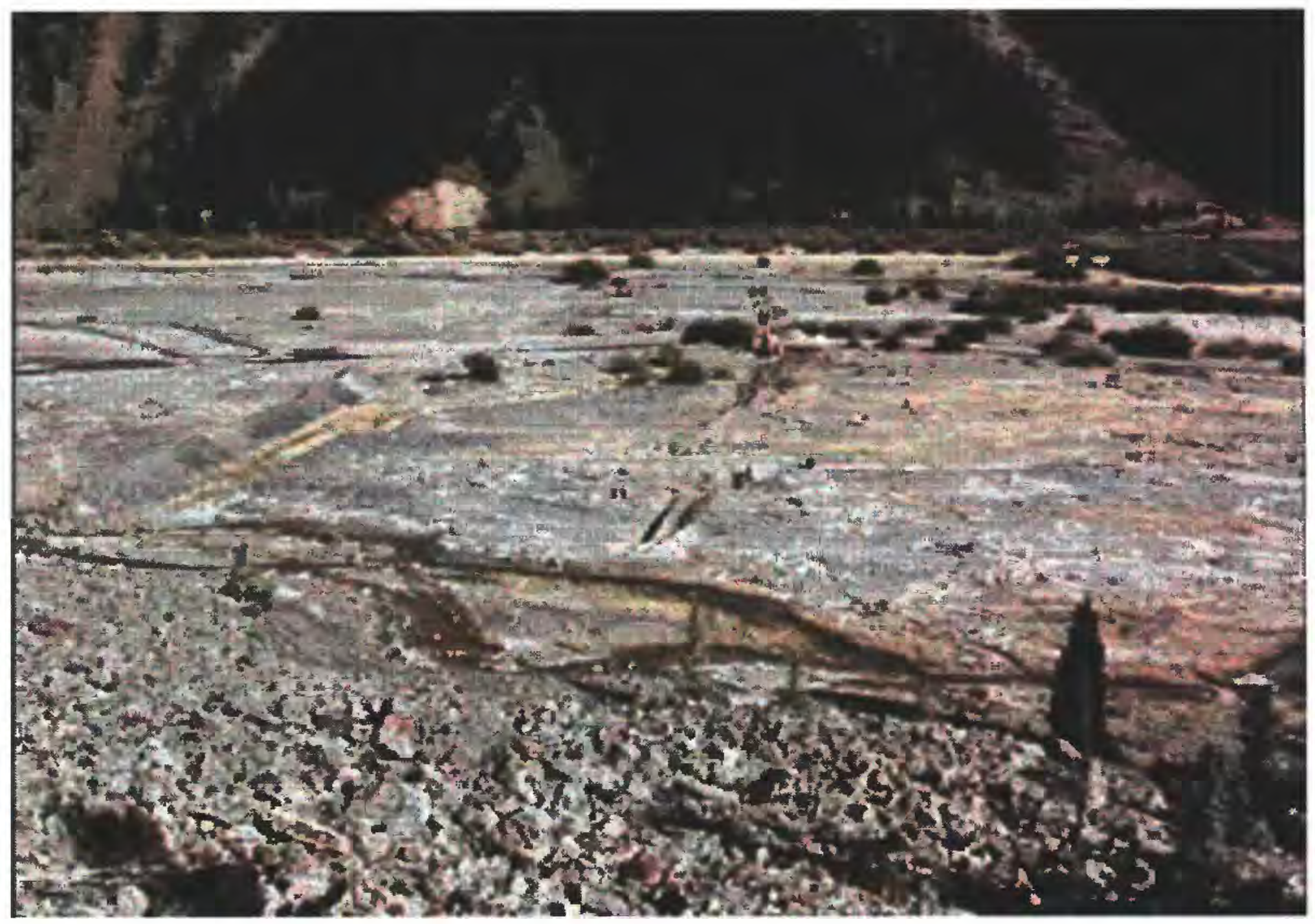

Fig. 1.-- Photograph of the trench line, looking southeast from the hillside, taken

September 16, 1998. Note the slight bend in the trench line and the backhoe at work. 
Fig. 2.-- Residual Magnetic data along 3 parallel lines. Center Line equals trench line.

This figure consists of 9 separate pages, which directly follow this page. There are 3 pages each for Line 20N, Center Line, and Line 20S. Scale is about $1.25^{\prime \prime}$ to $20 \mathrm{~m}$, to match Kirk Vincent's plan map. Though this figure is on separate pages for OF

reproduction, it is intended that the pages be pasted together end to end so as to easily compare with other data. 


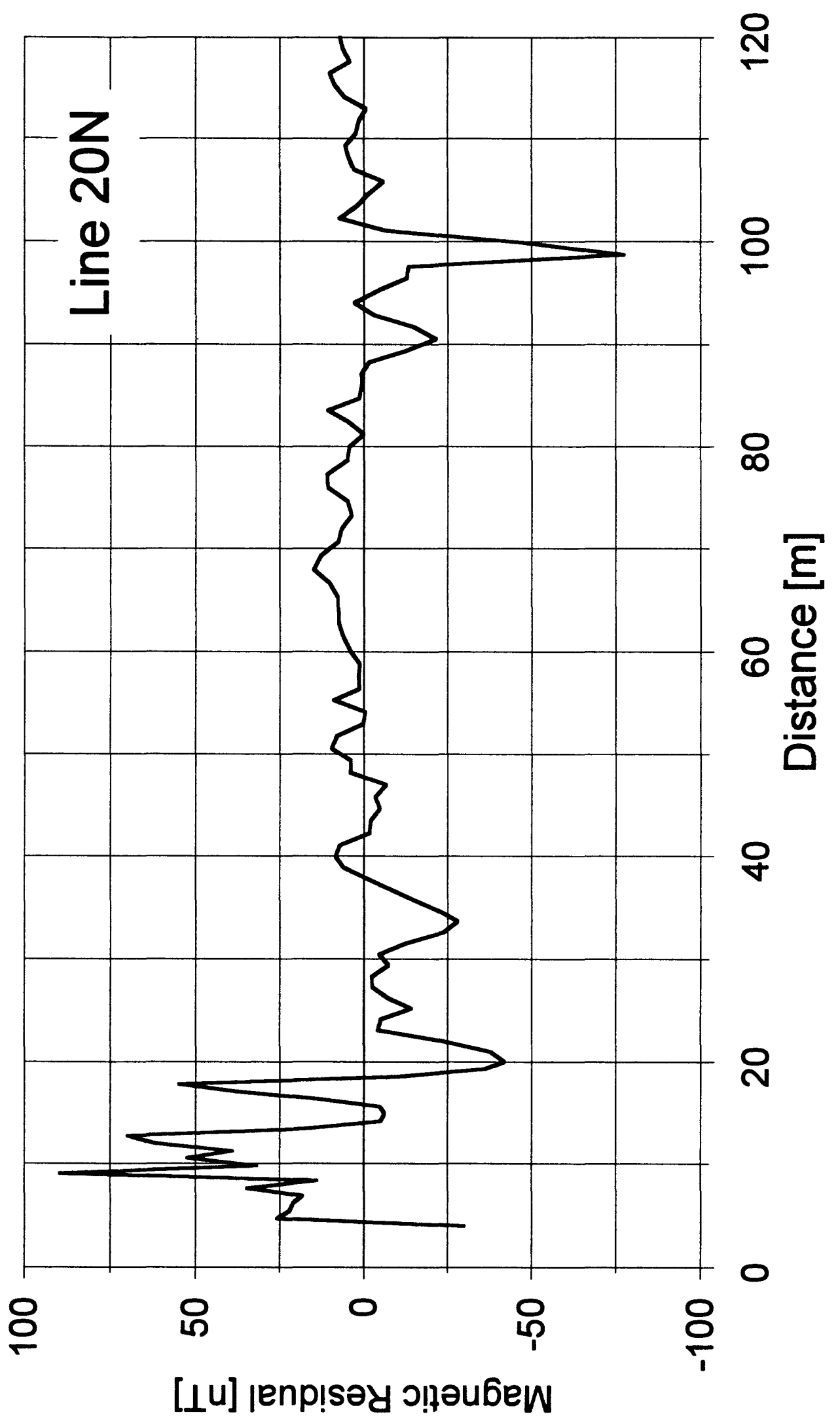




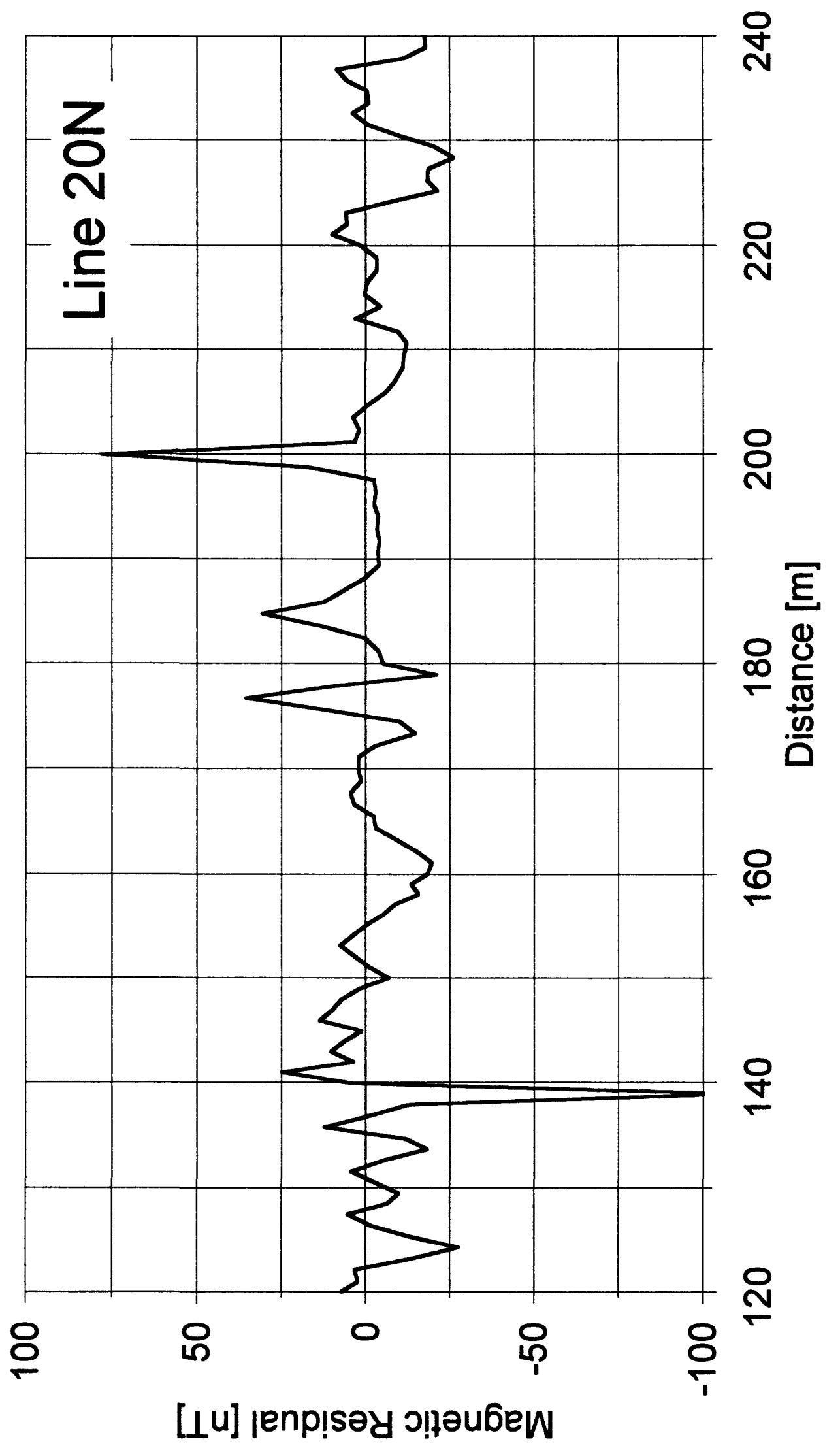




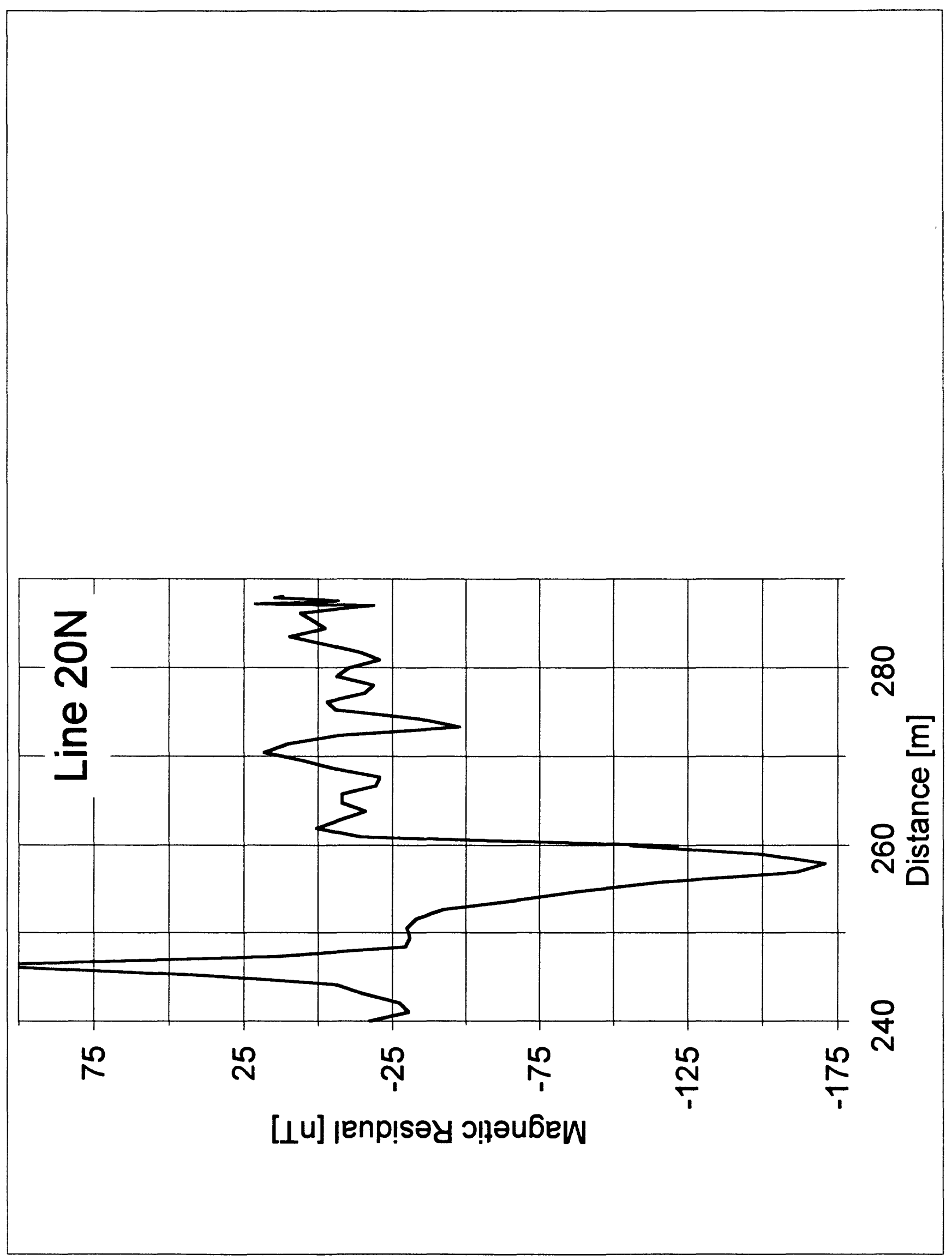




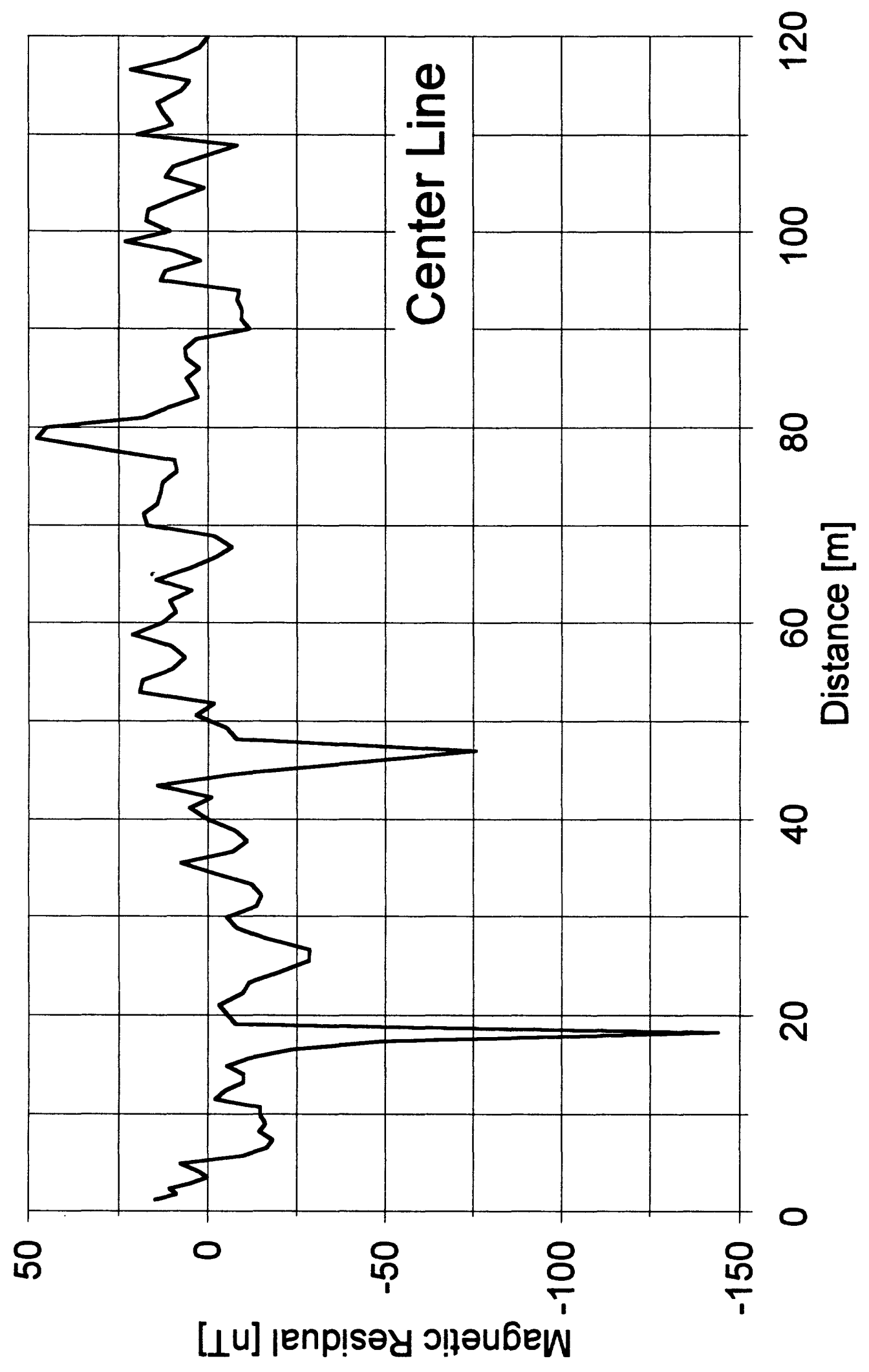




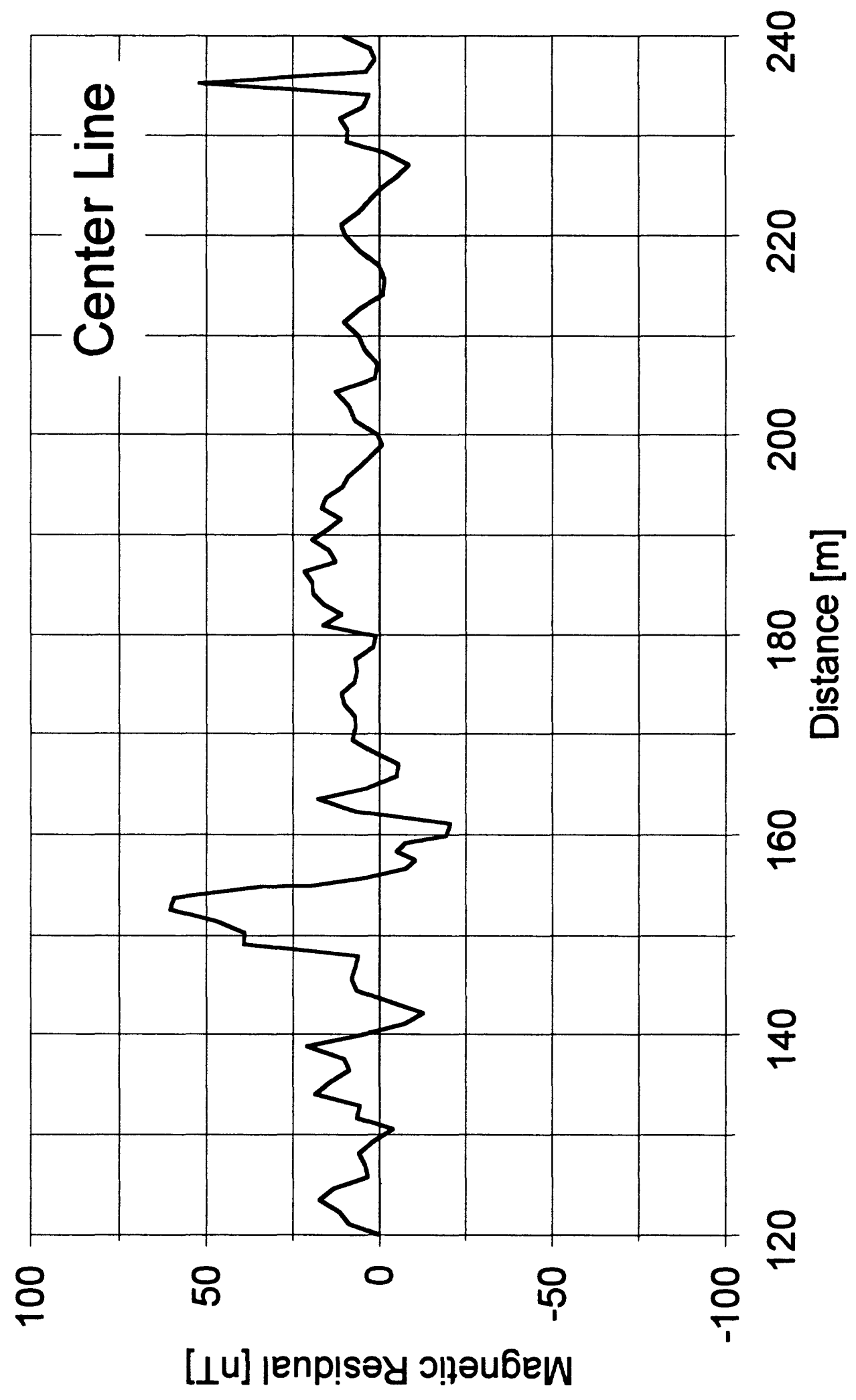




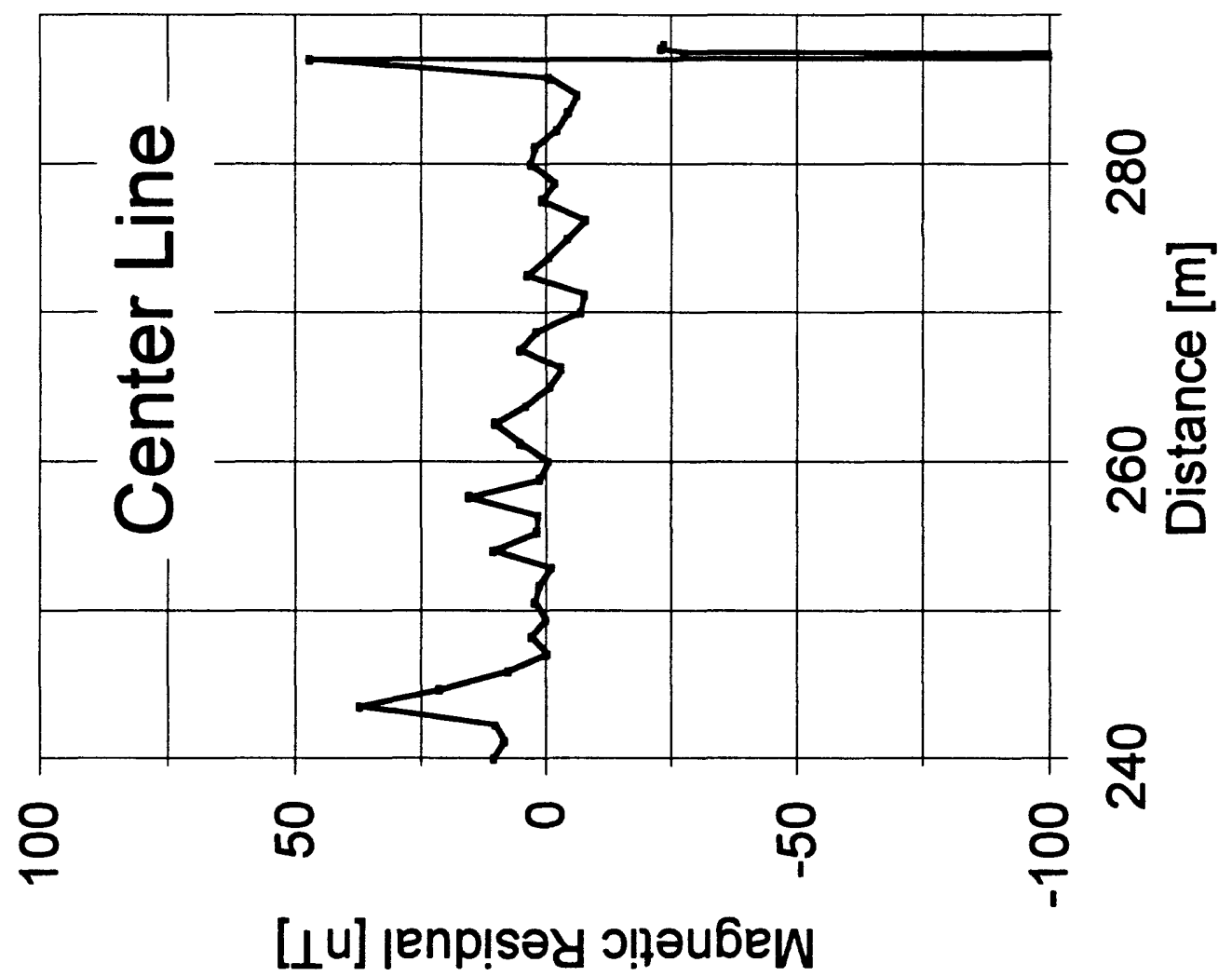




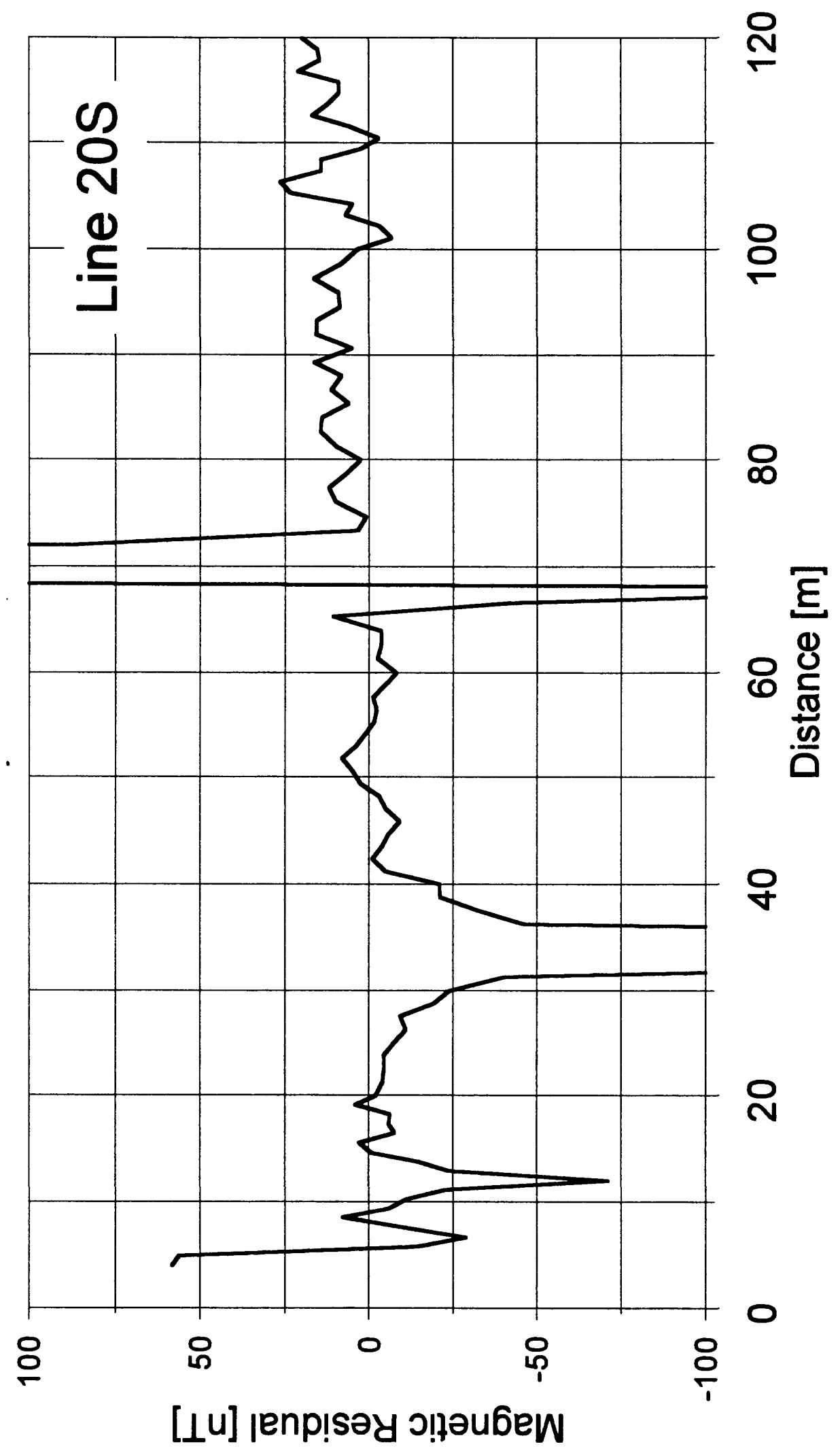




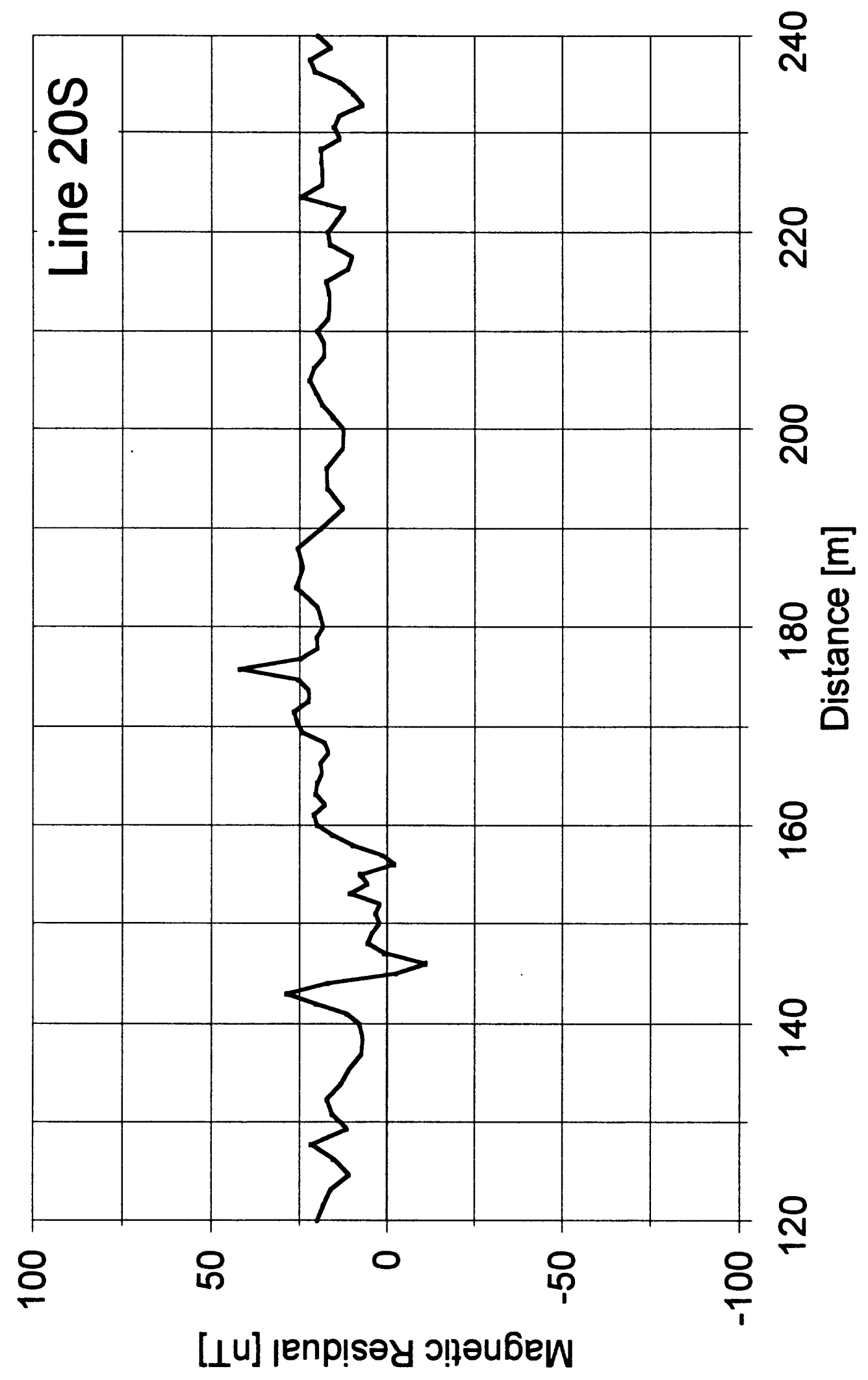




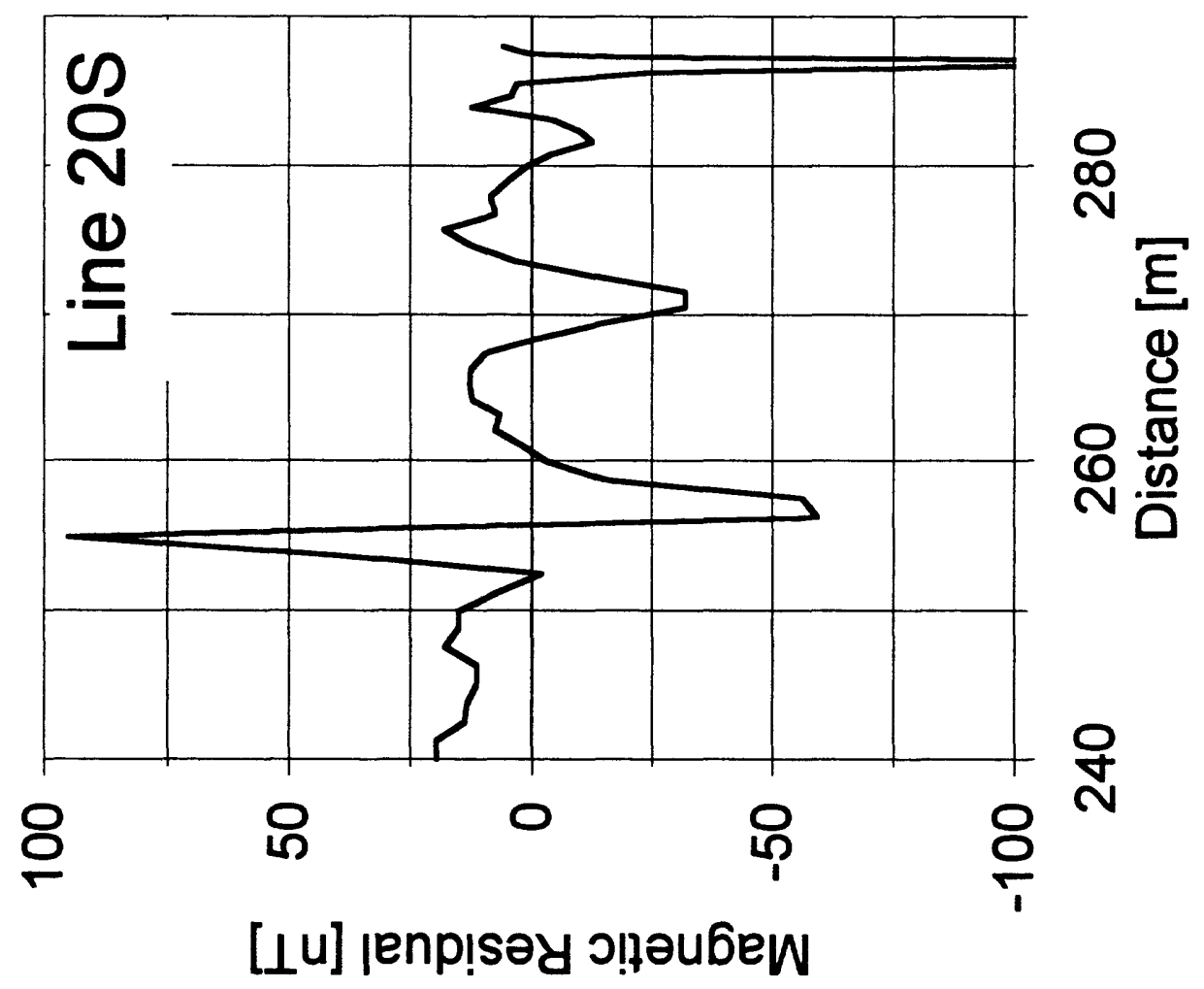


Fig. 3.-- EM data at 3 frequencies along the center line.

This figure consists of 48 separate pages which directly follow this page. There are 8 pages each for InPhase on Lines 20N, Center, and 20S; and 8 each for Quadrature on Lines $20 \mathrm{~N}$, Center Line, and 20S. The Quadrature values are presented as equivalent conductivities, in $\mathrm{mS} / \mathrm{m}$. Scale is close to $10 \mathrm{~cm}$ for $20 \mathrm{~m}$, so as to match the scale of the GPR and SIP plots. Though this figure is on separate pages for Open-File reproduction, it is intended that the pages be pasted together end to end so as to easily compare with the other data. 


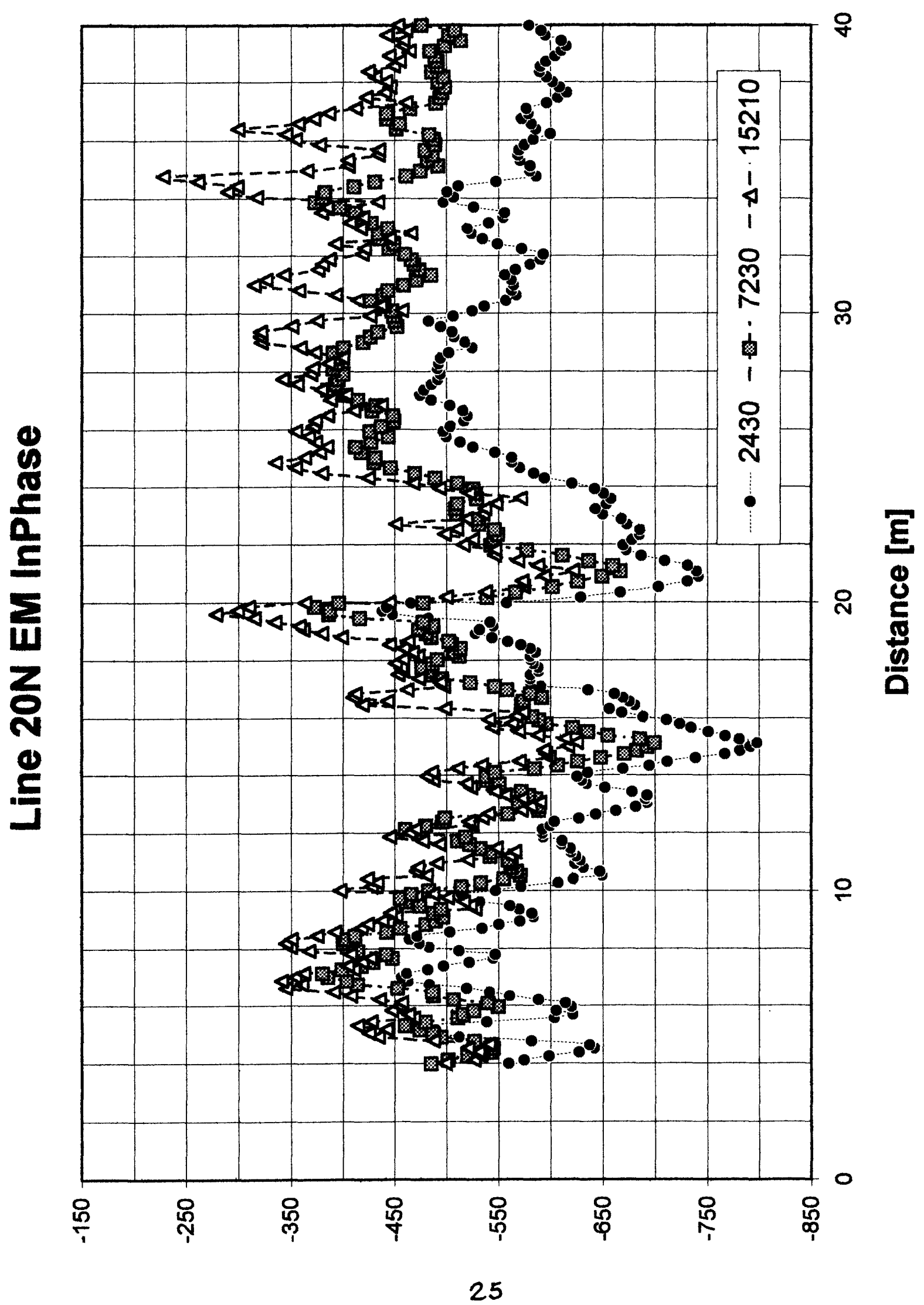




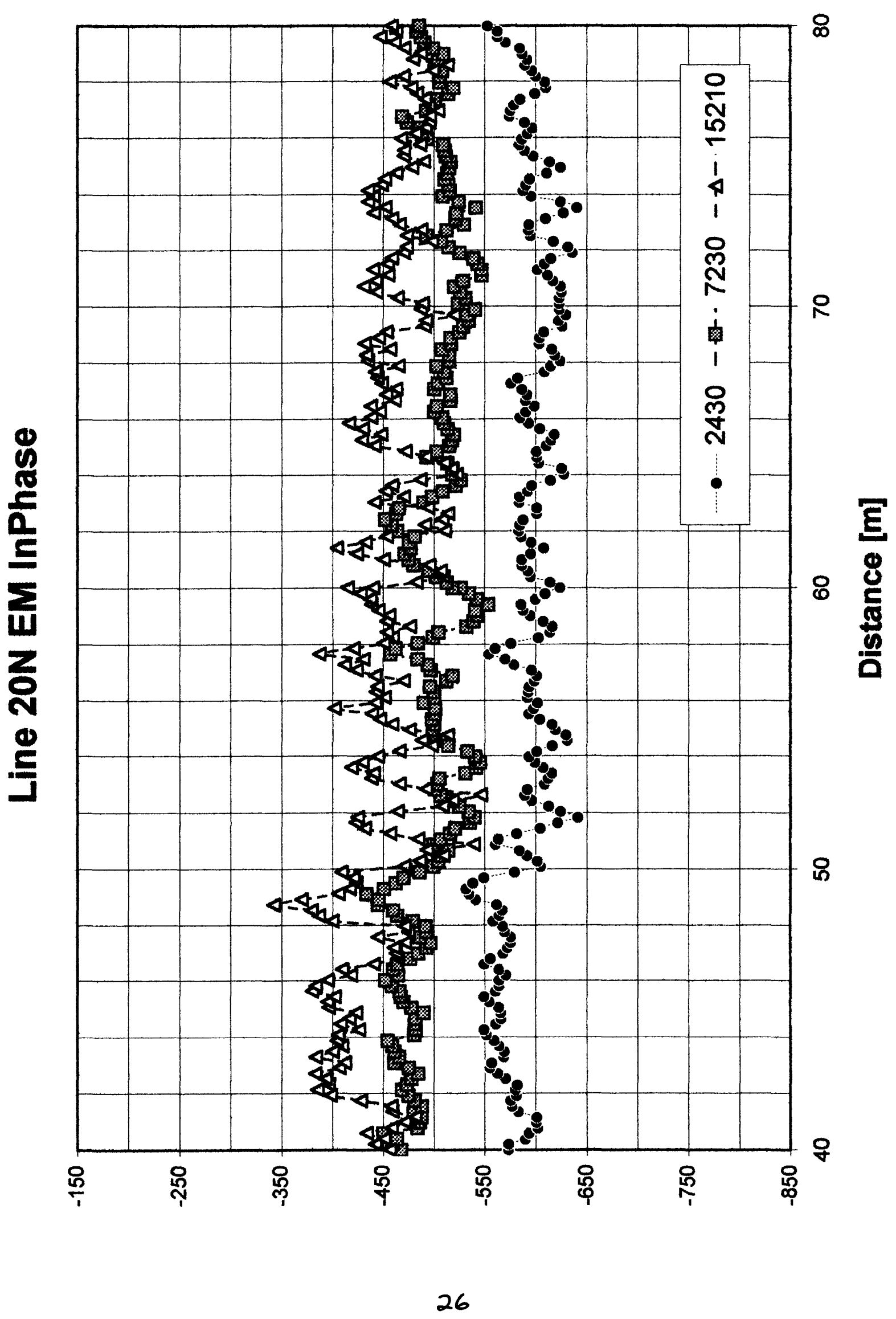




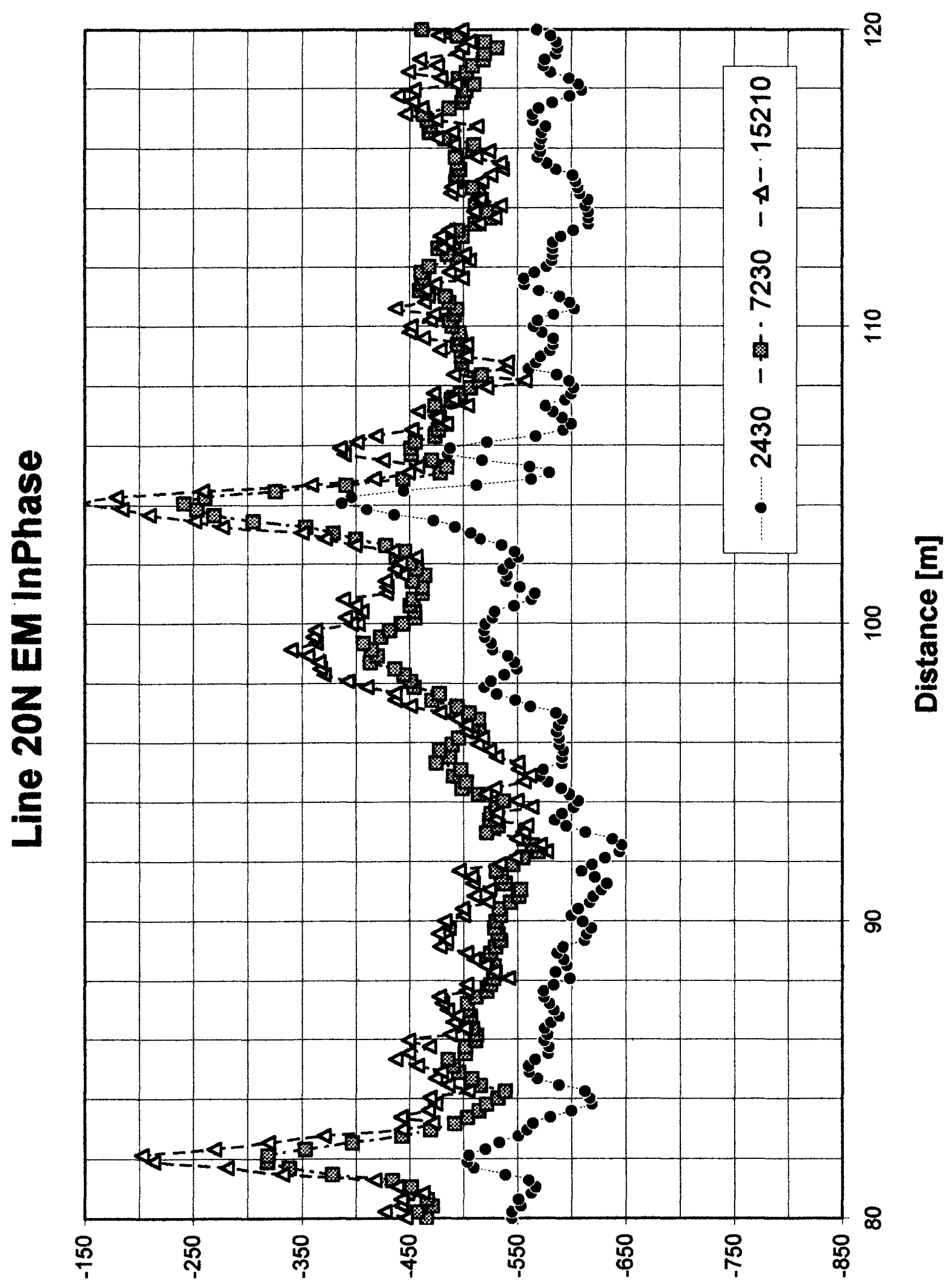




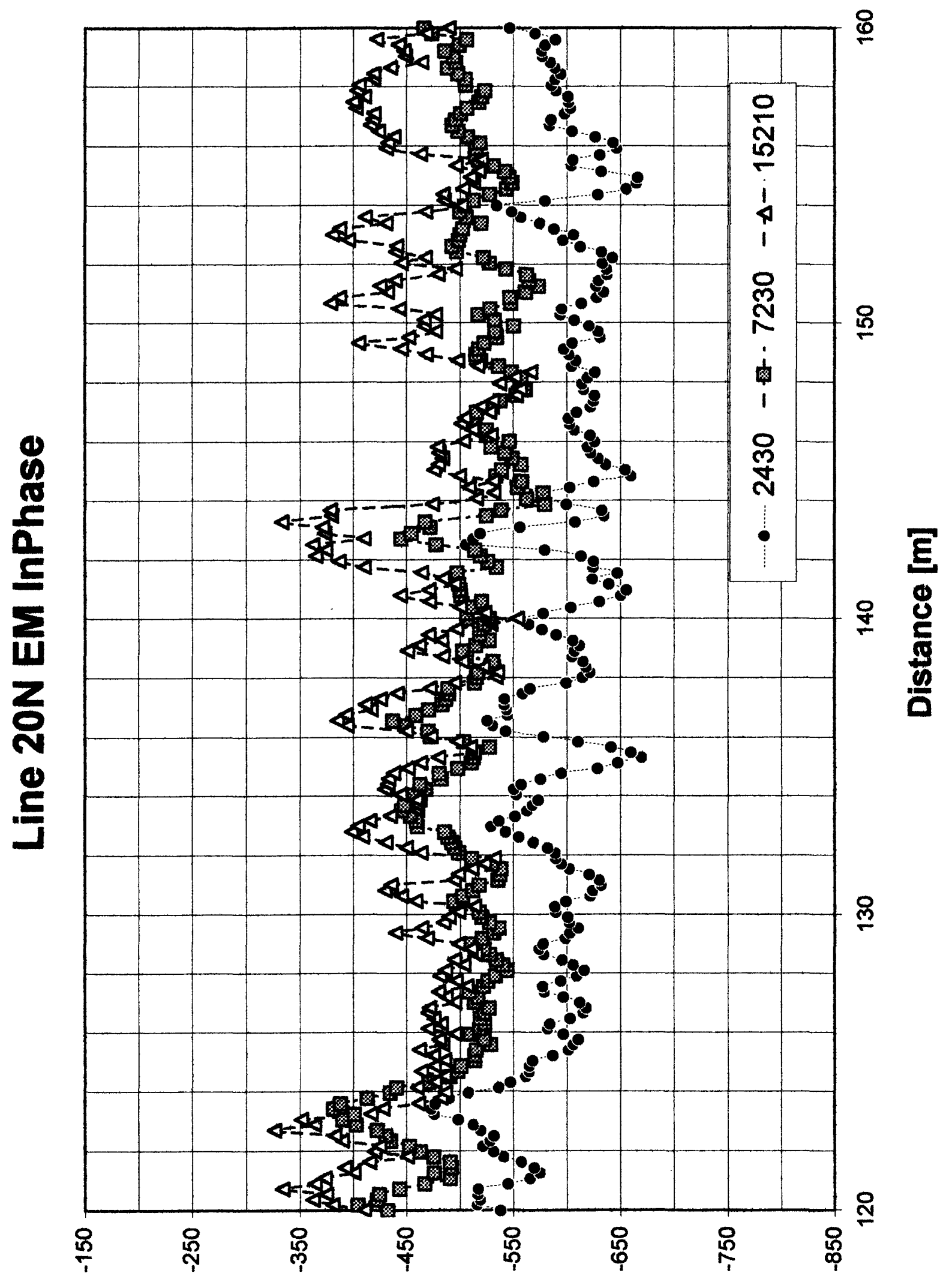




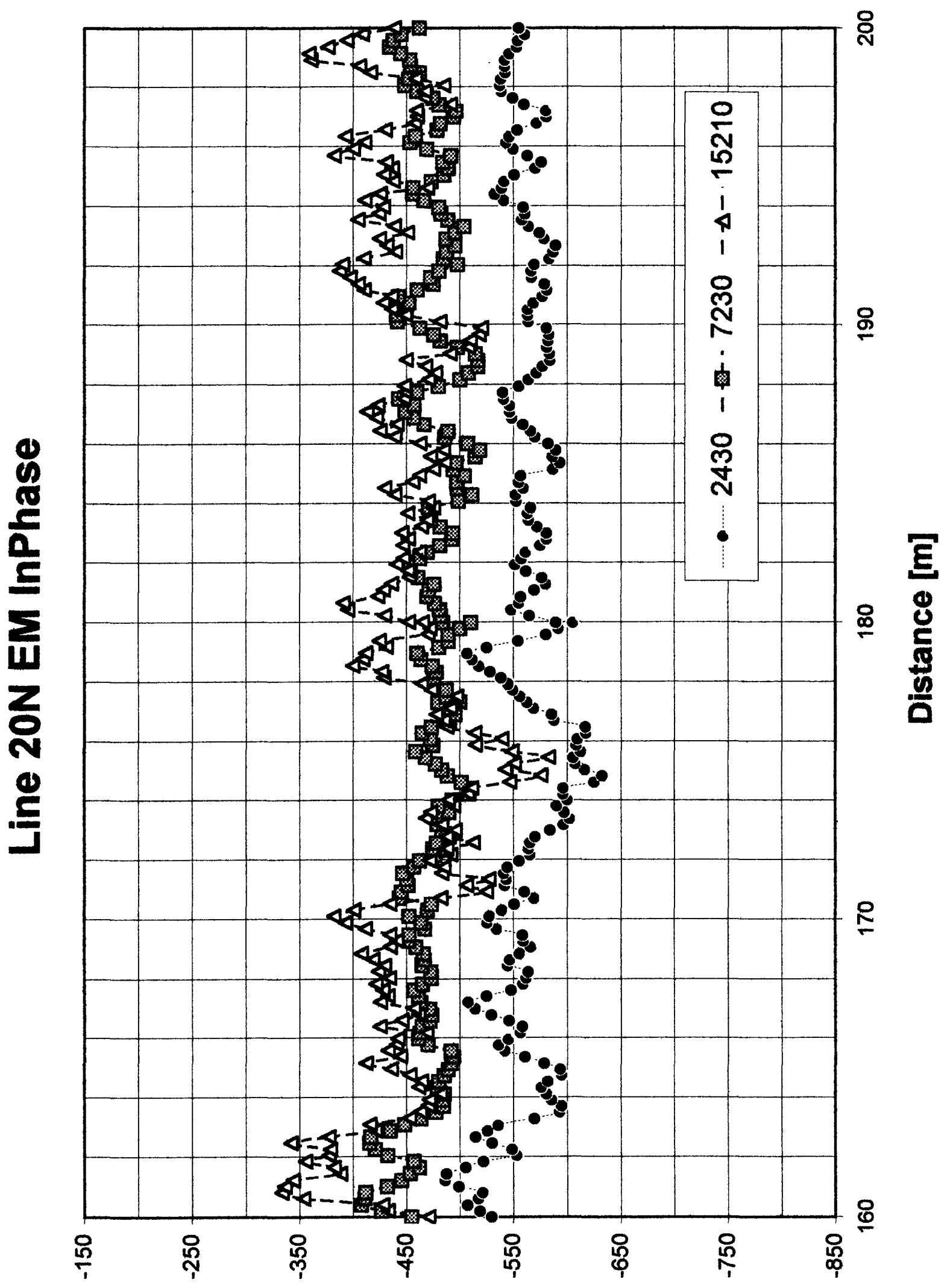




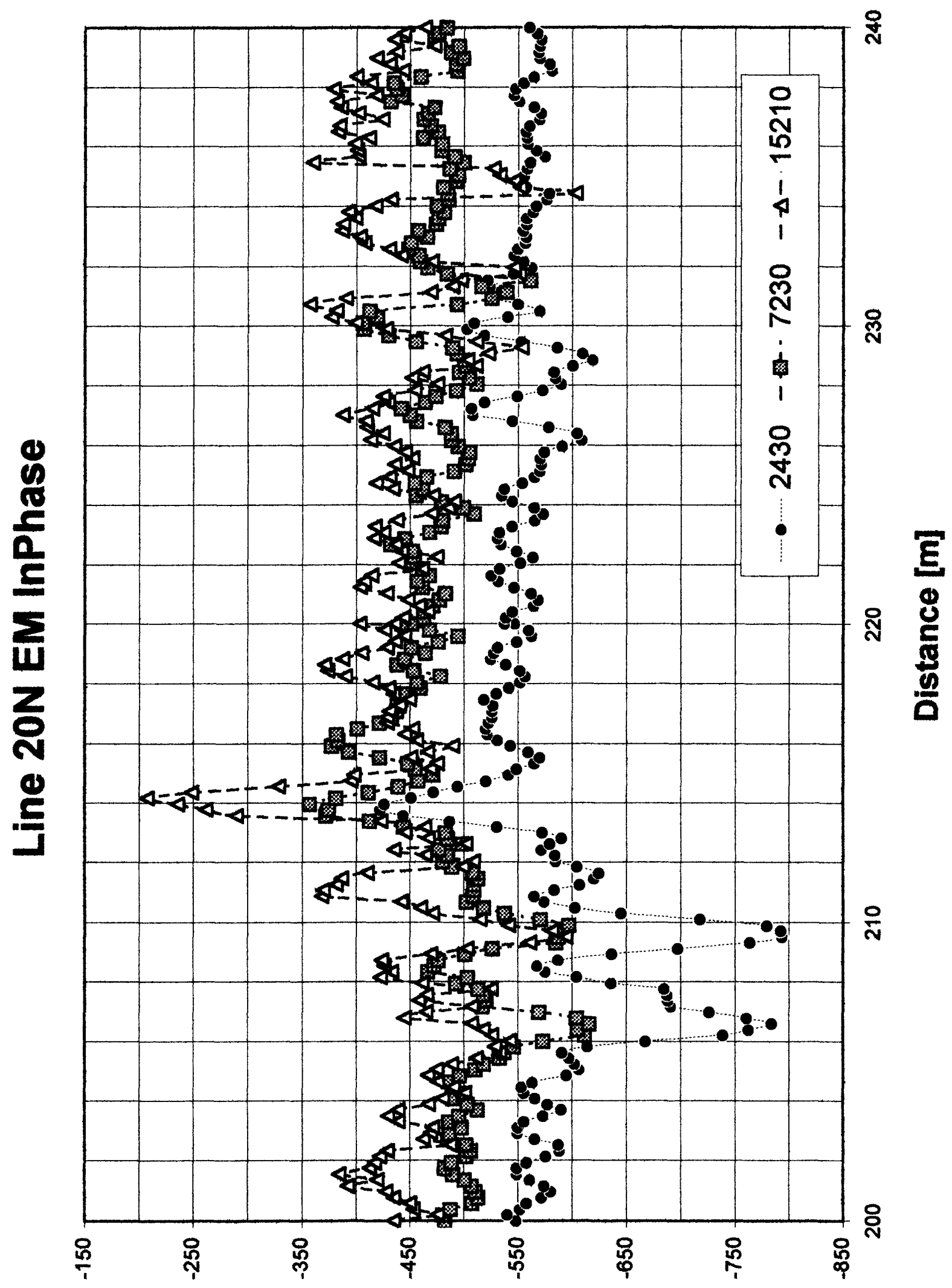




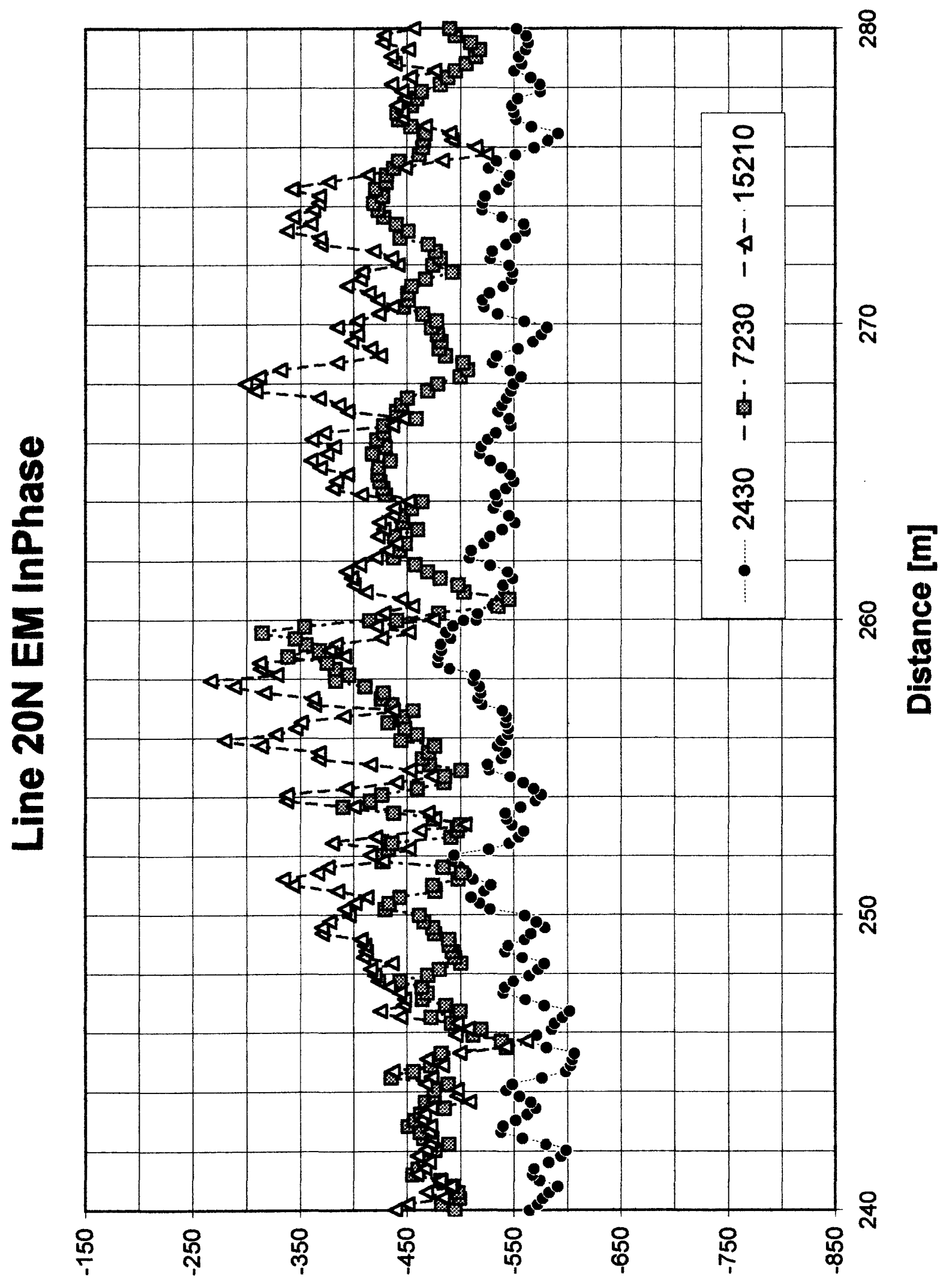




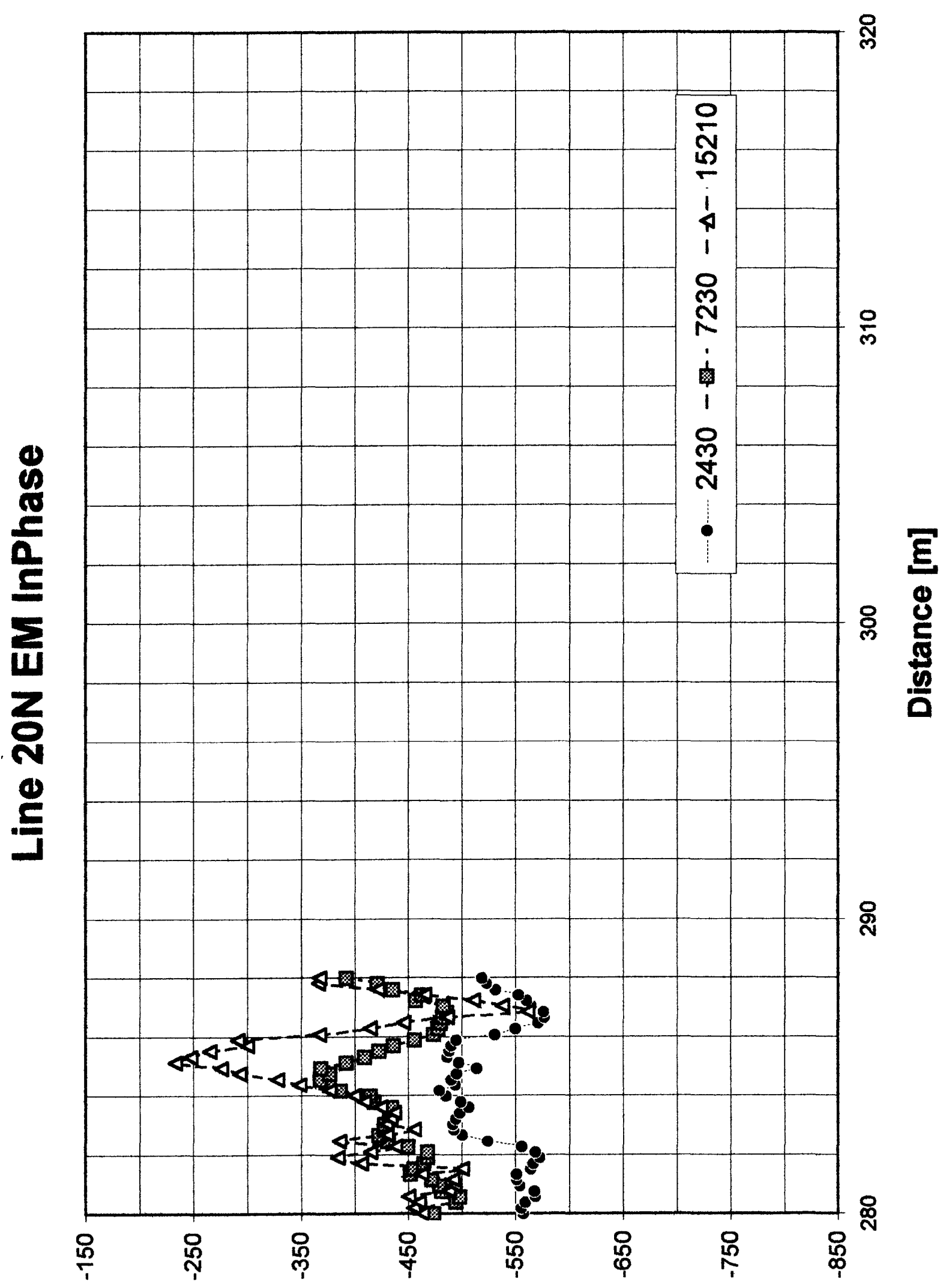




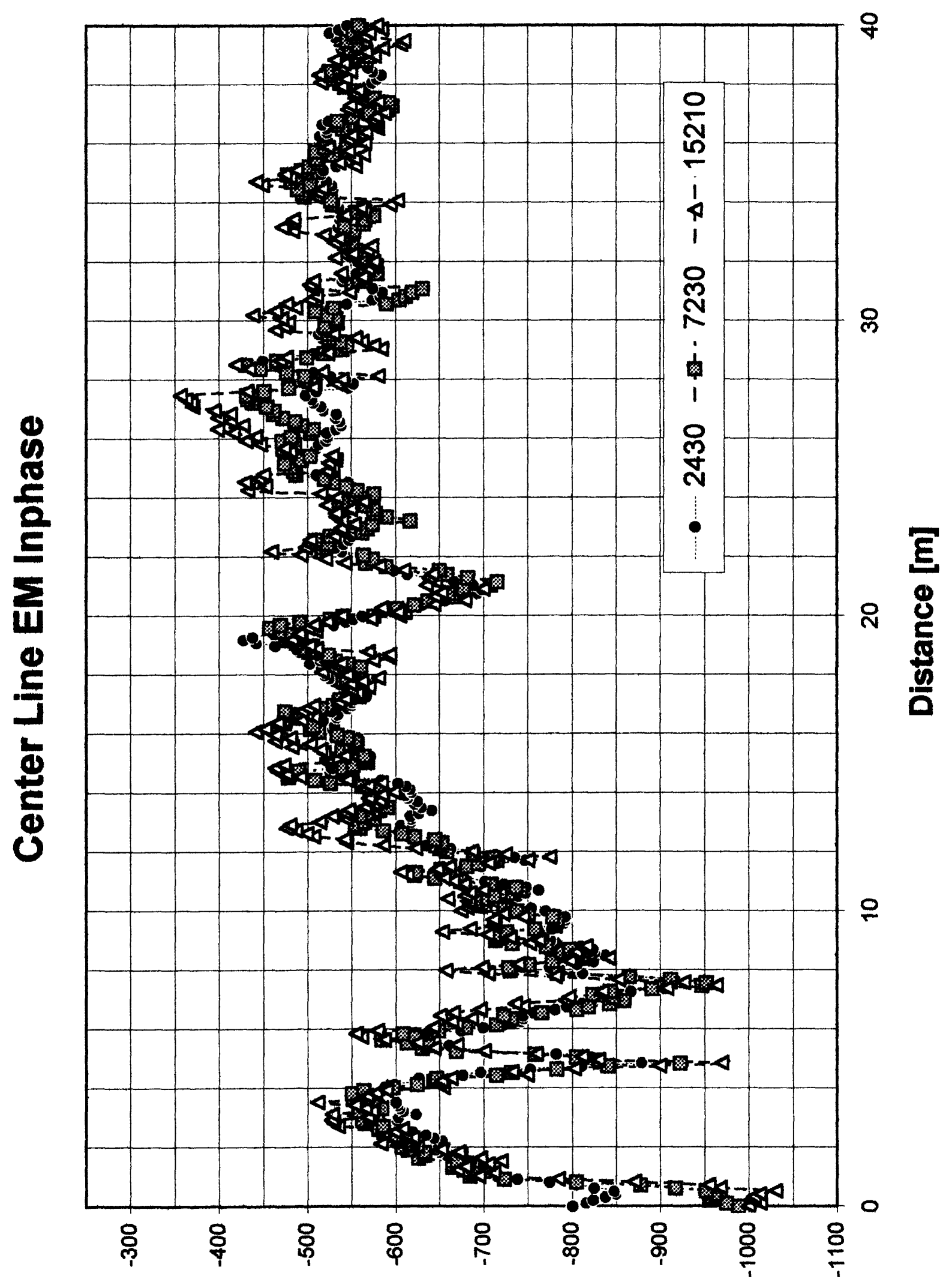




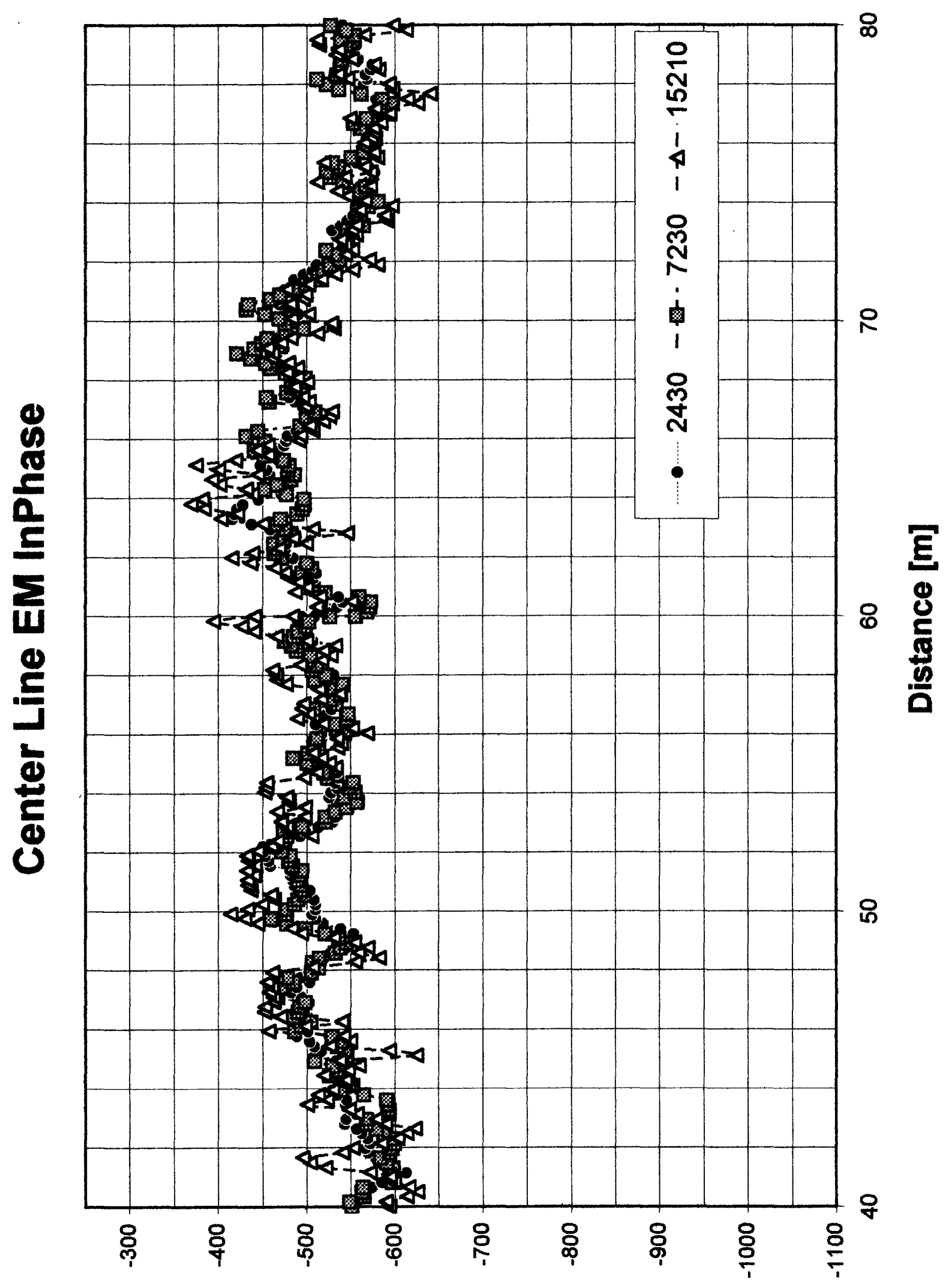




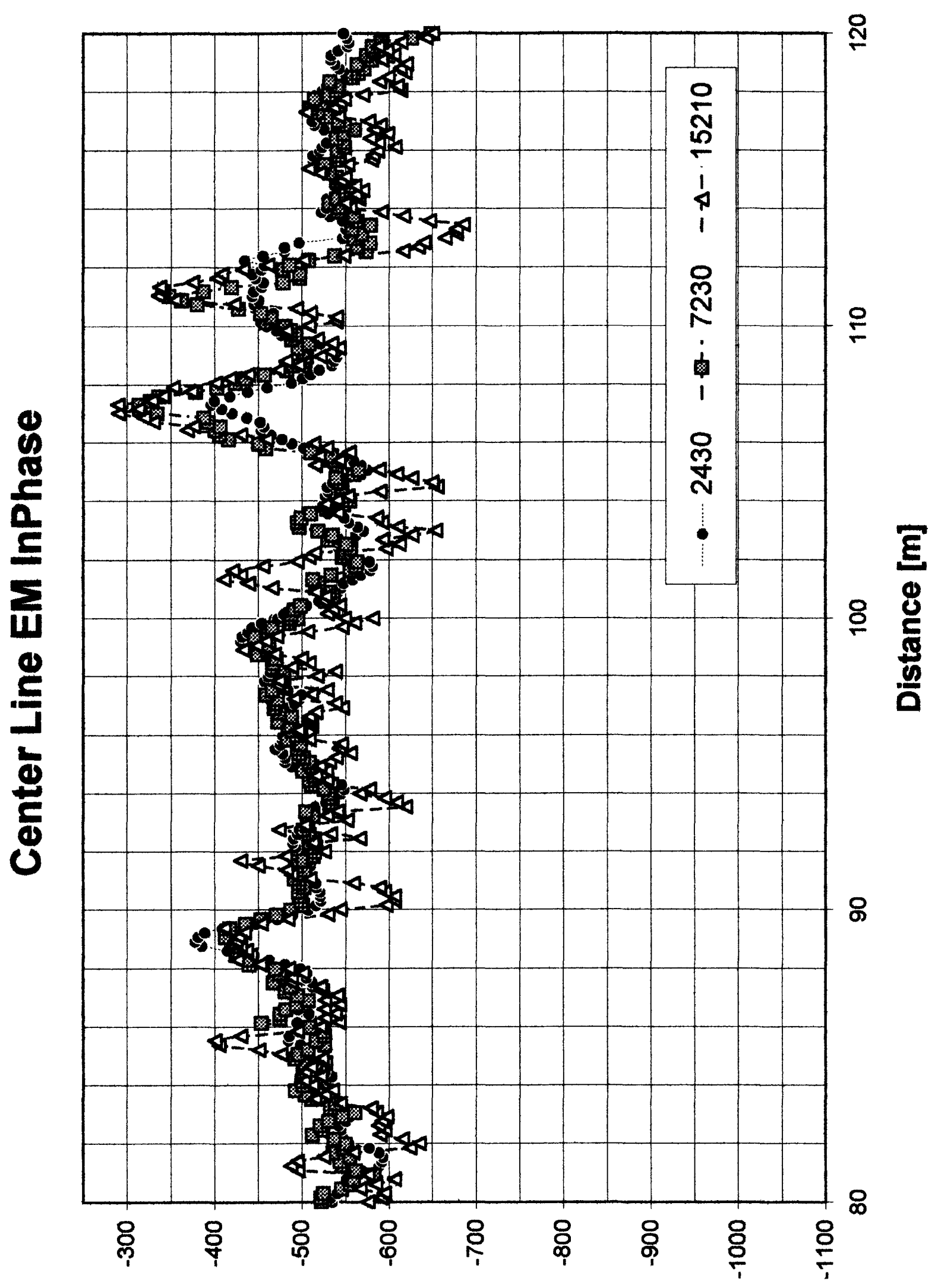




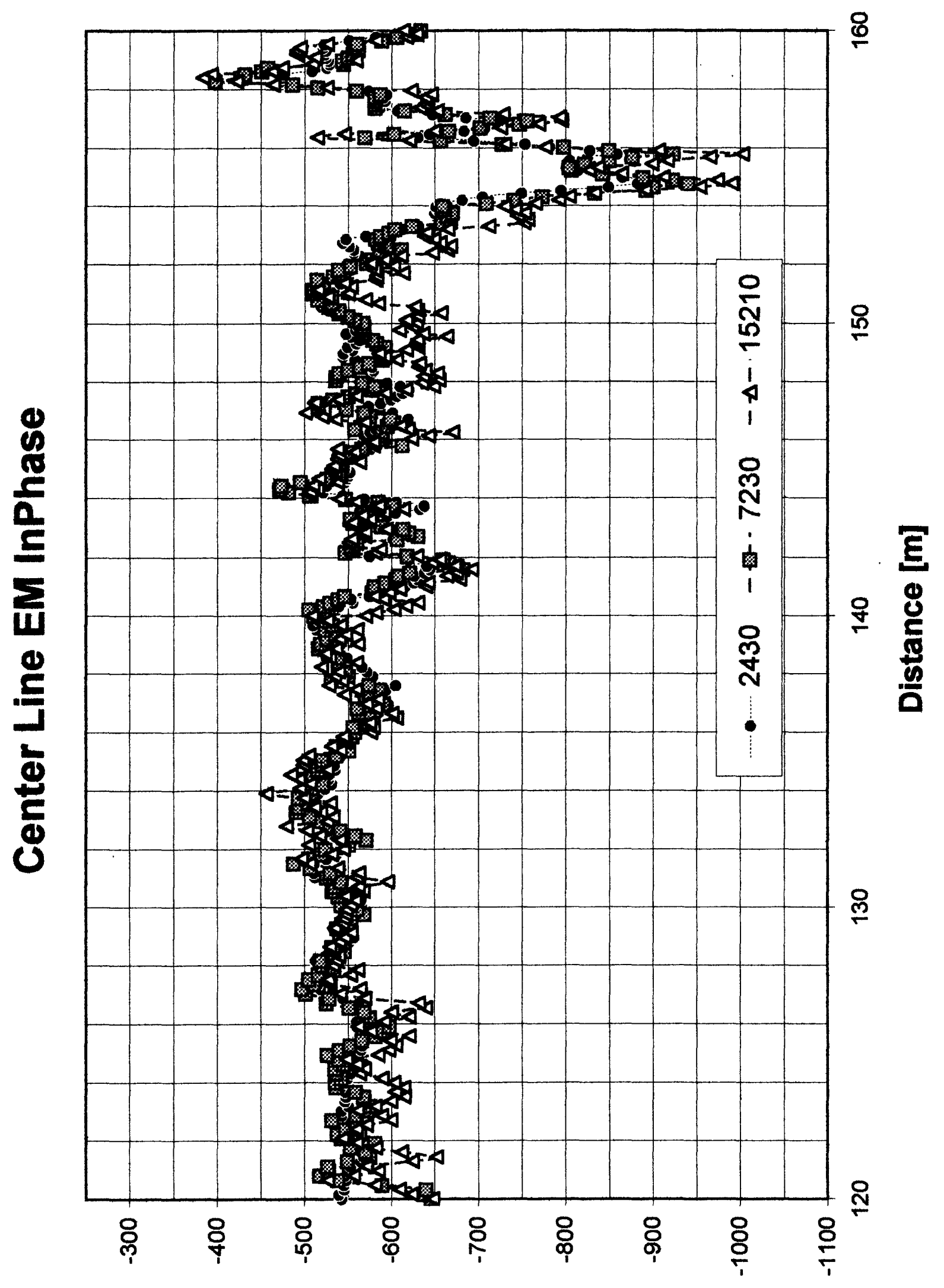




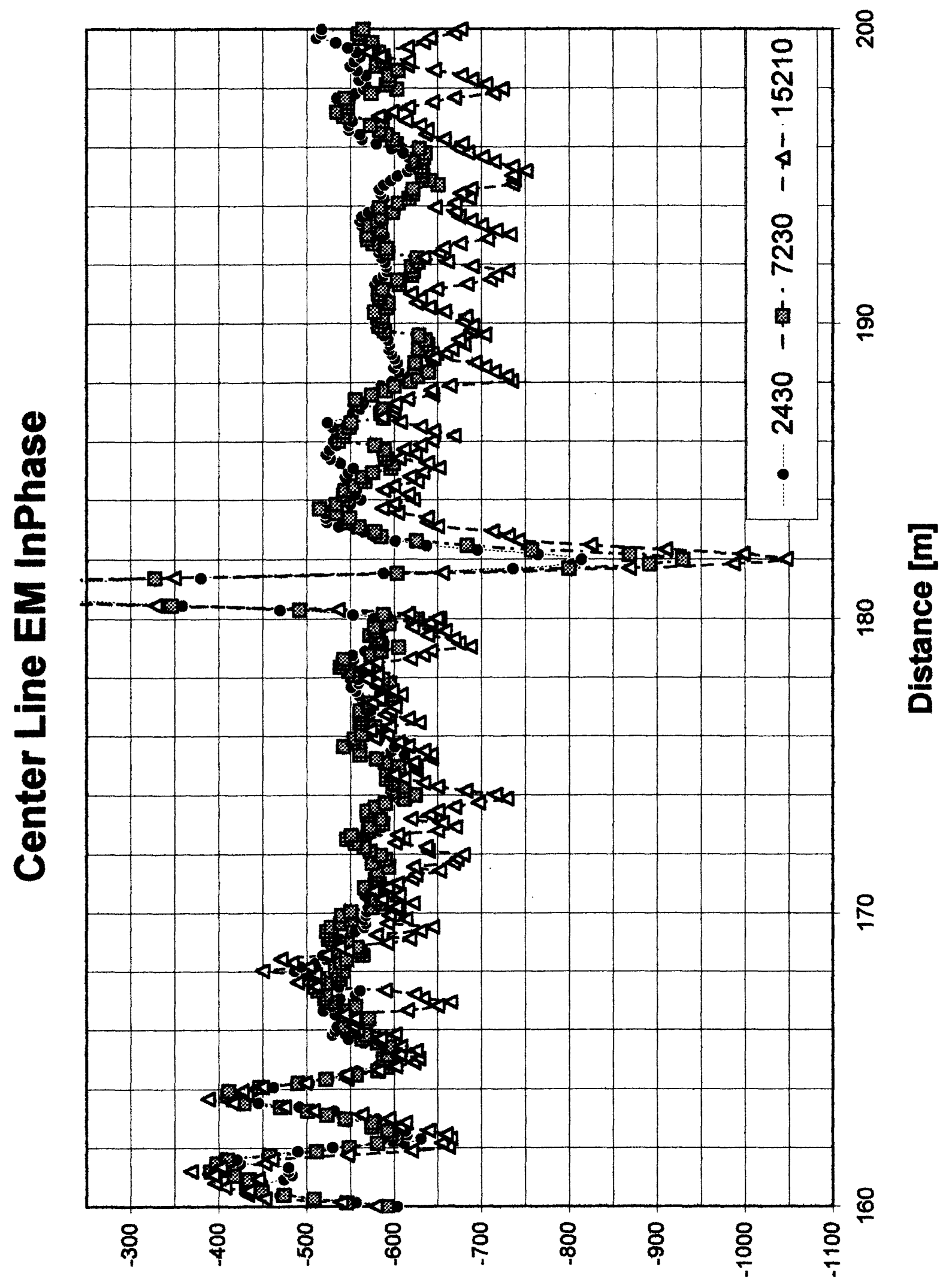




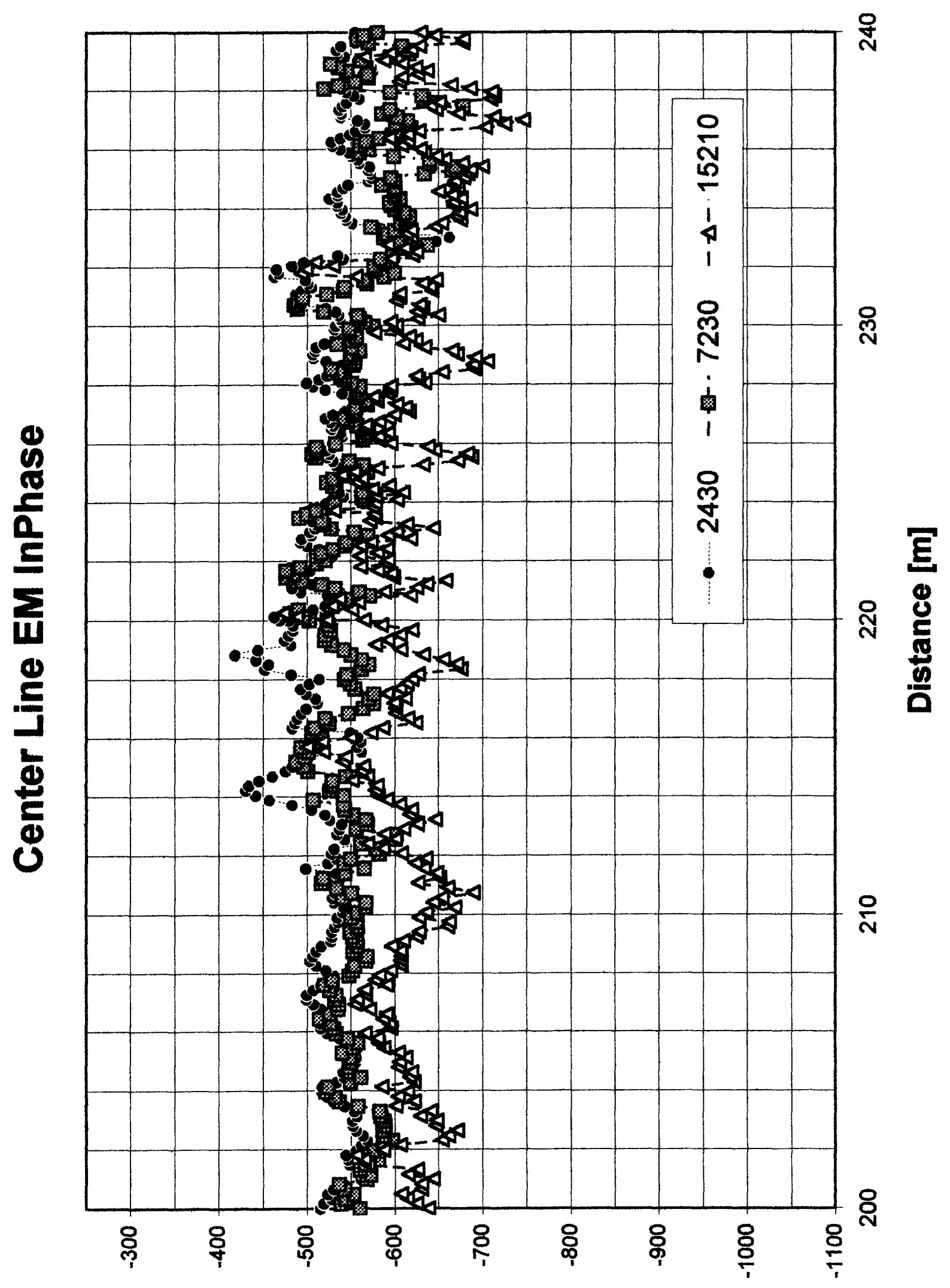




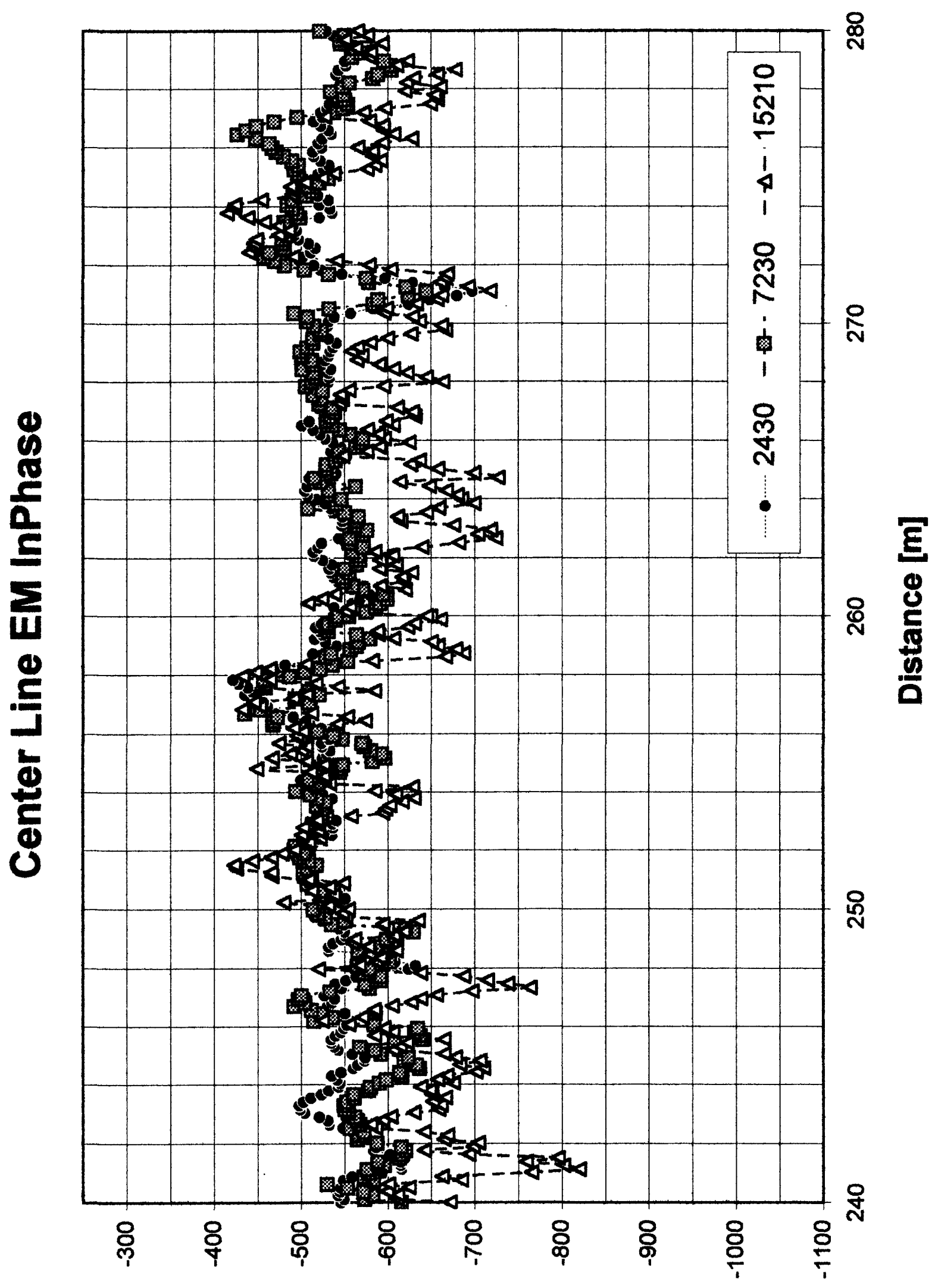




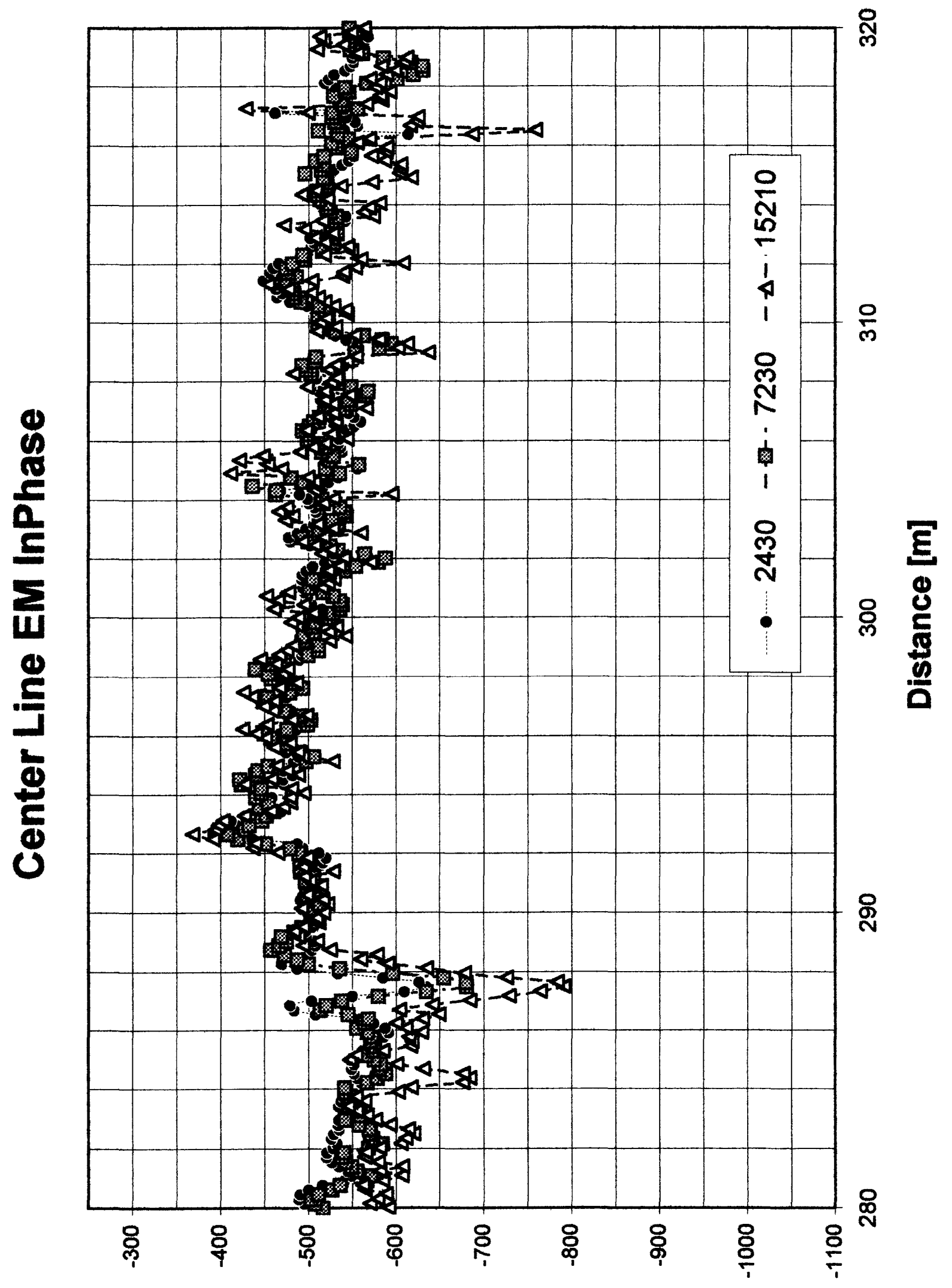




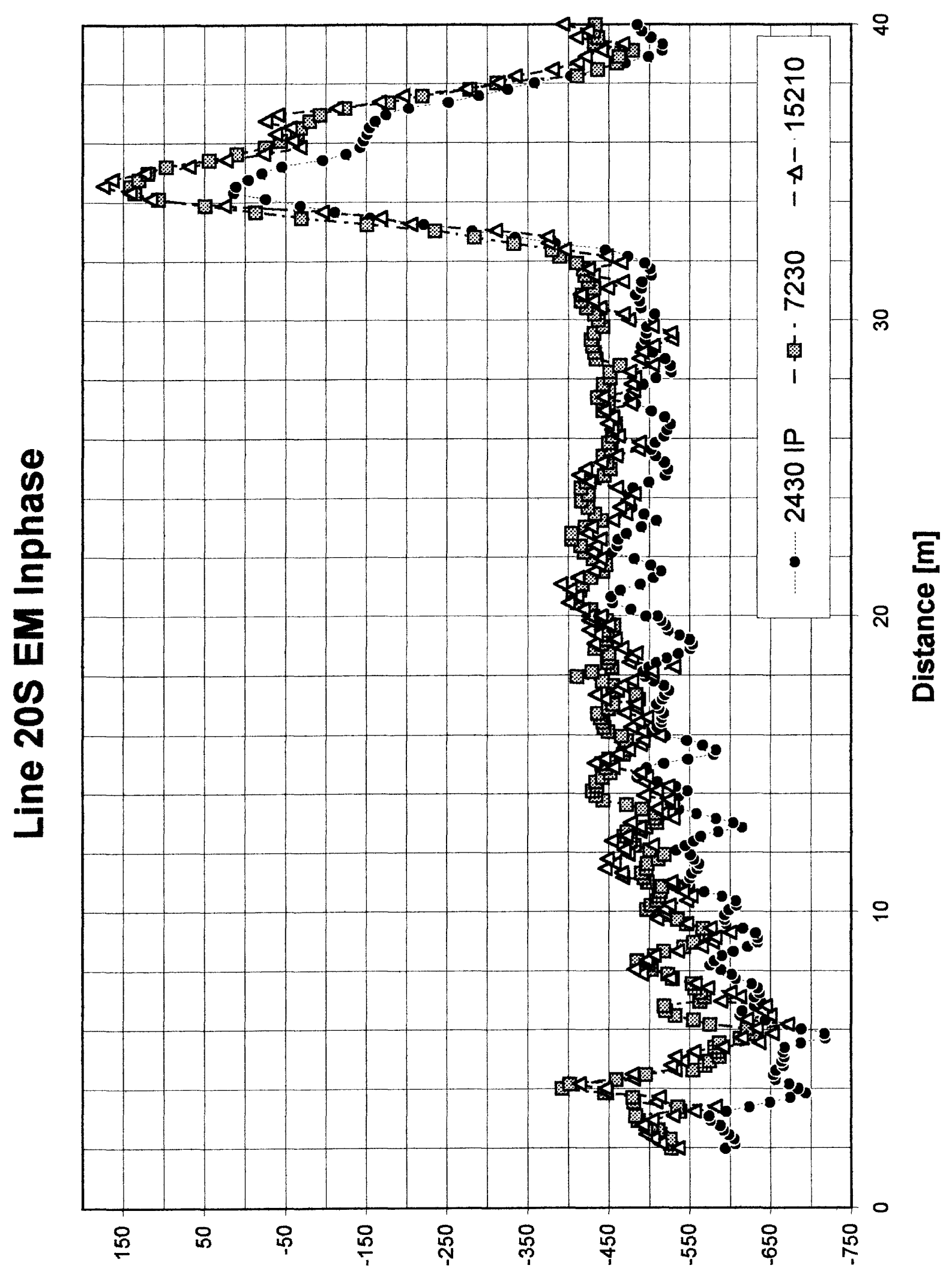




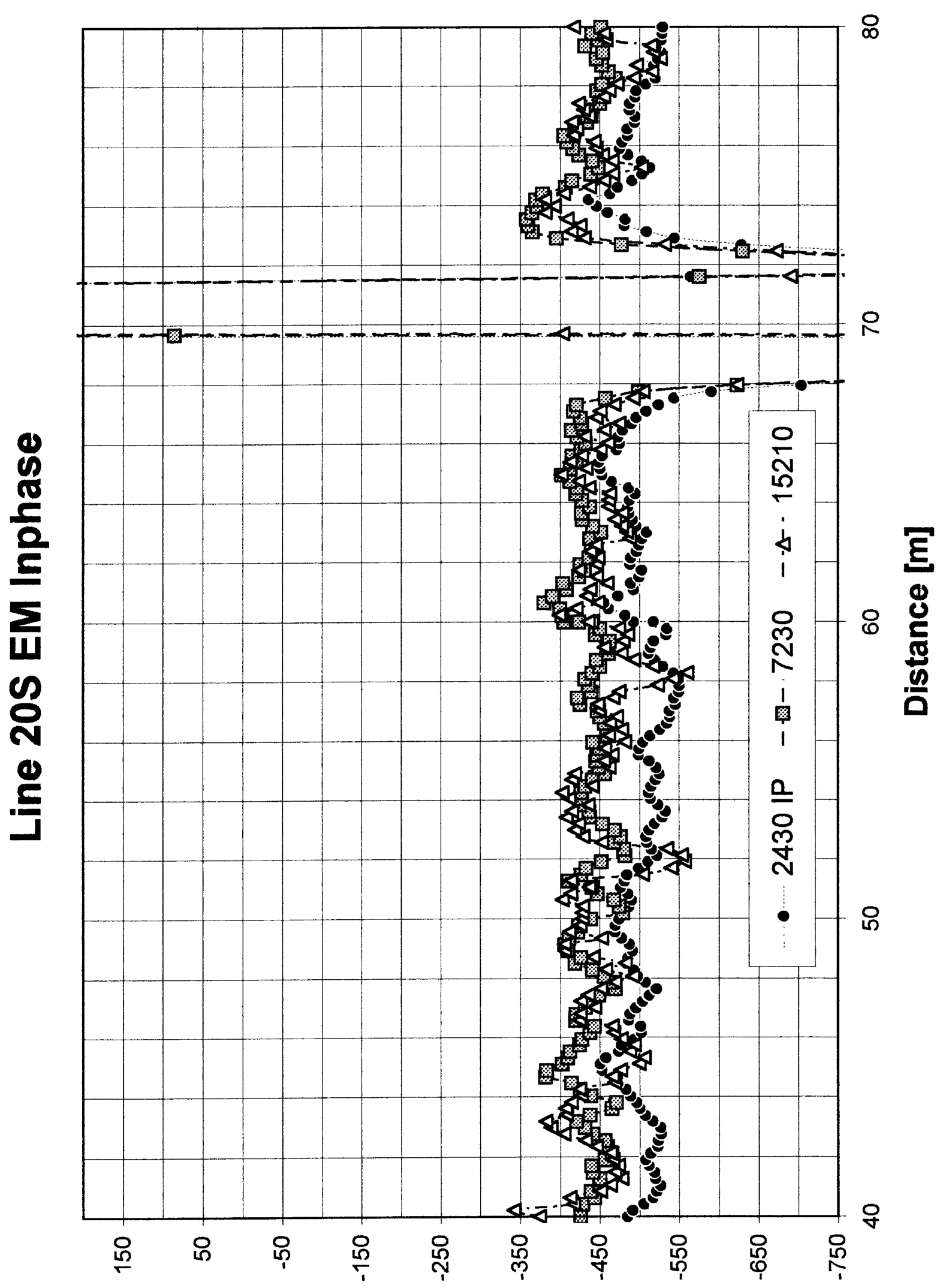




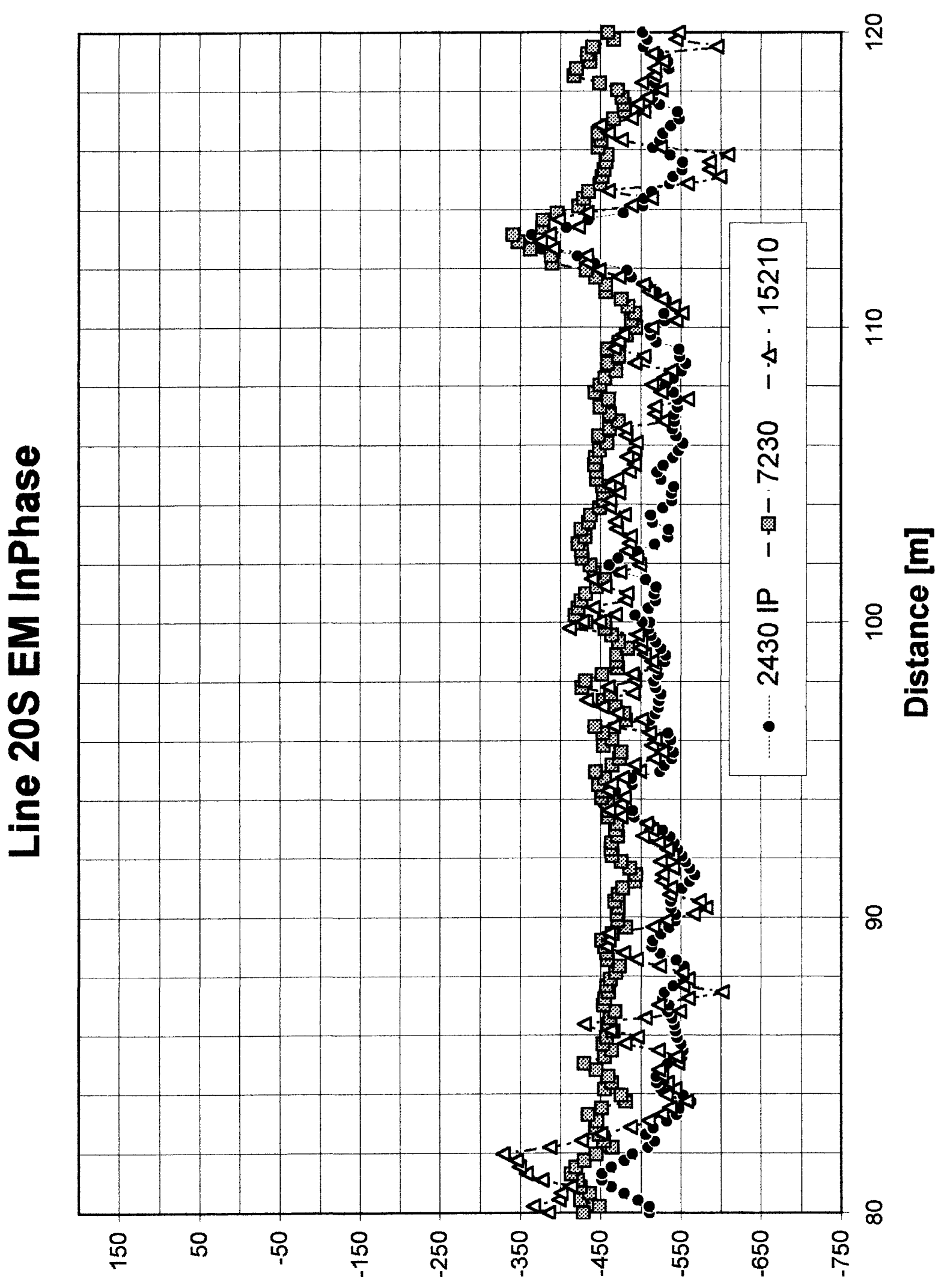




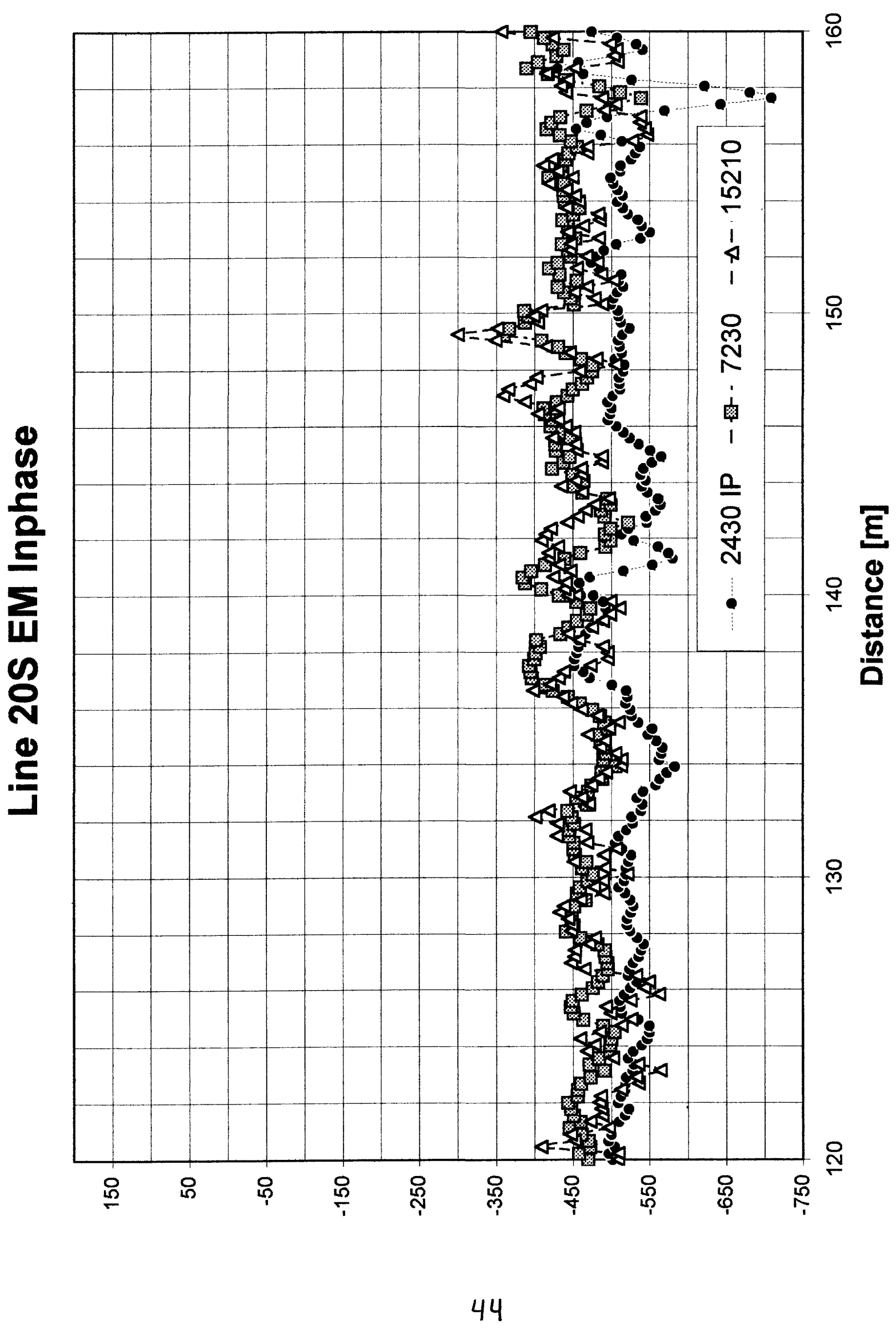




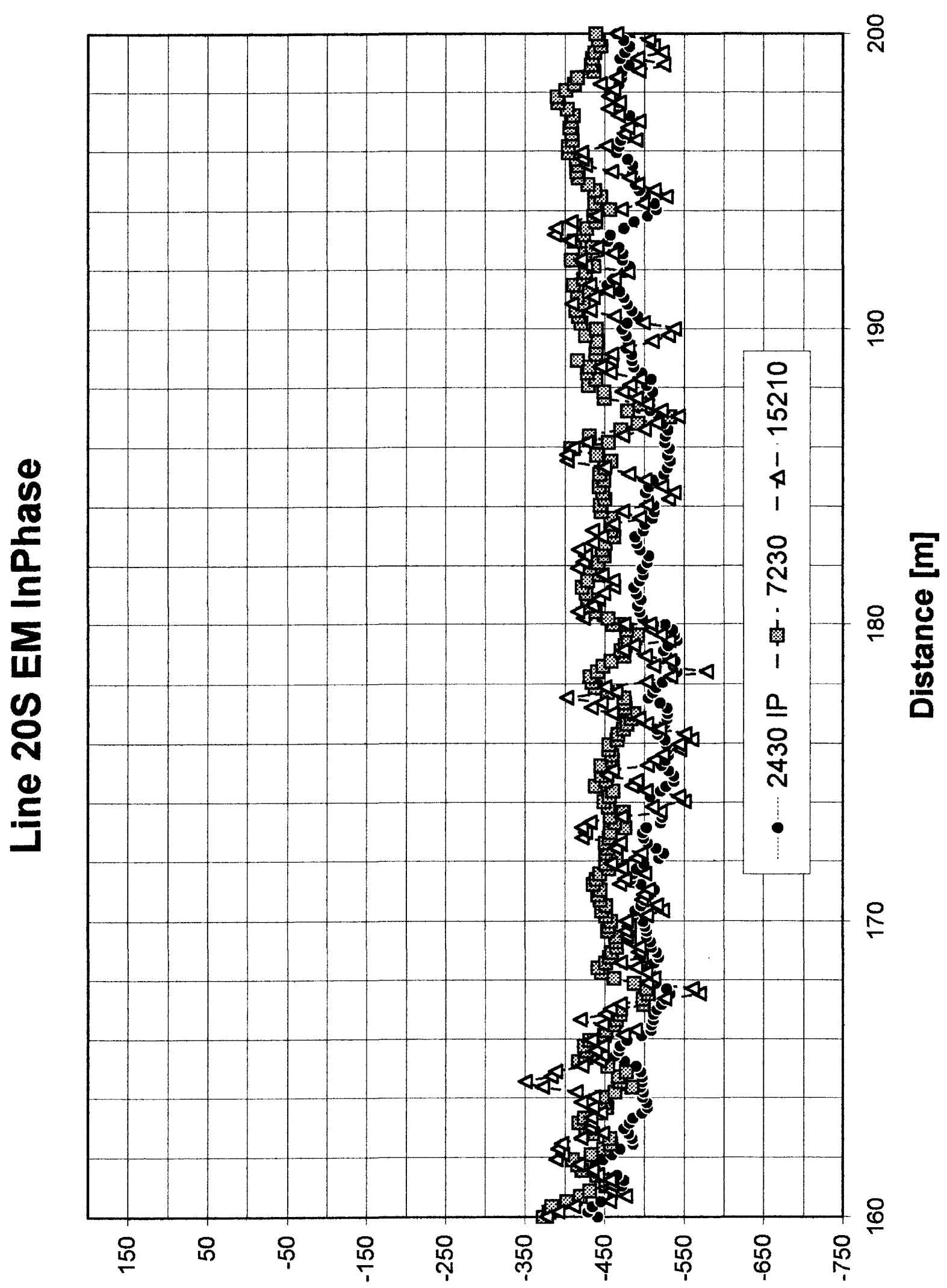




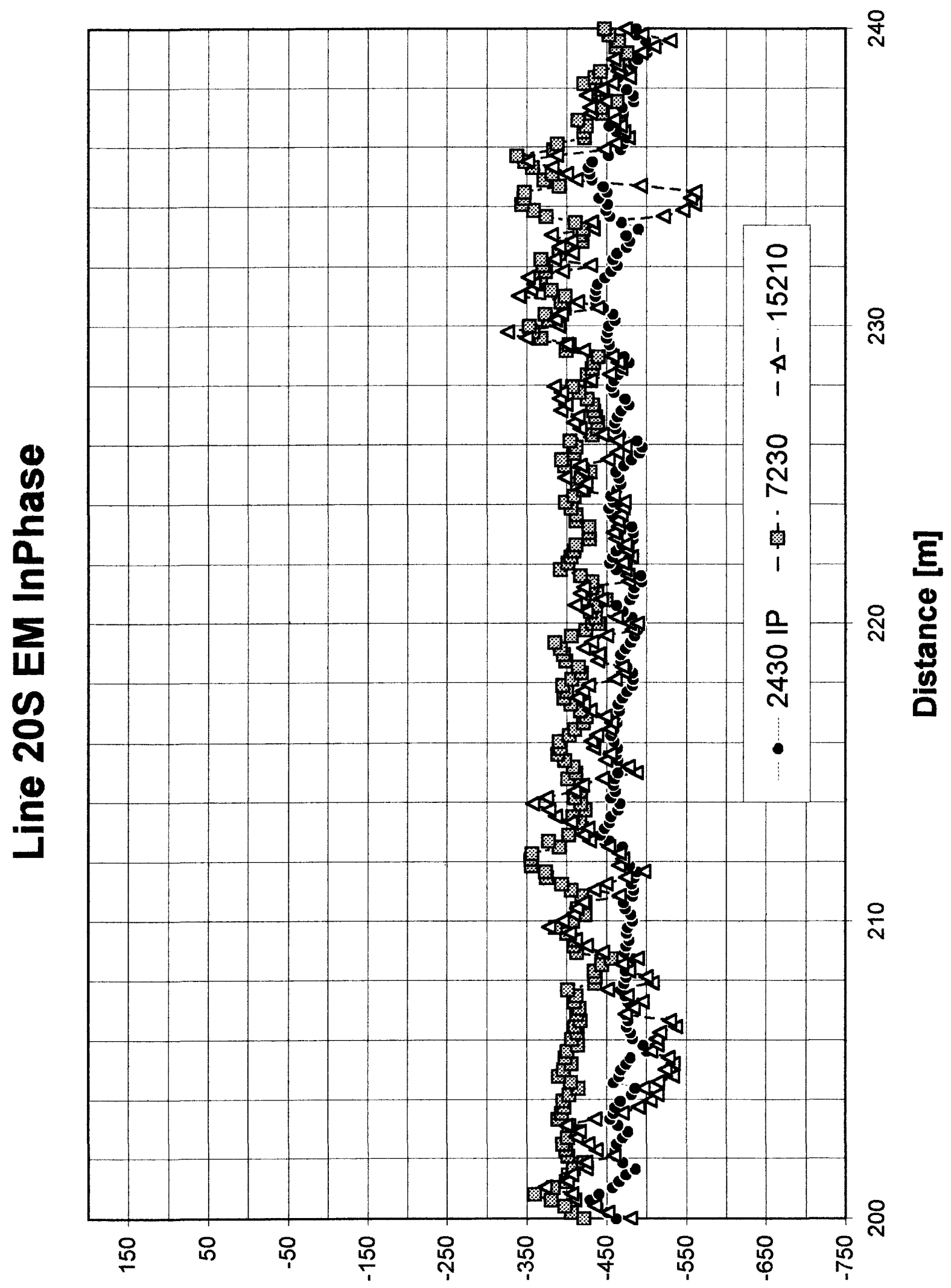




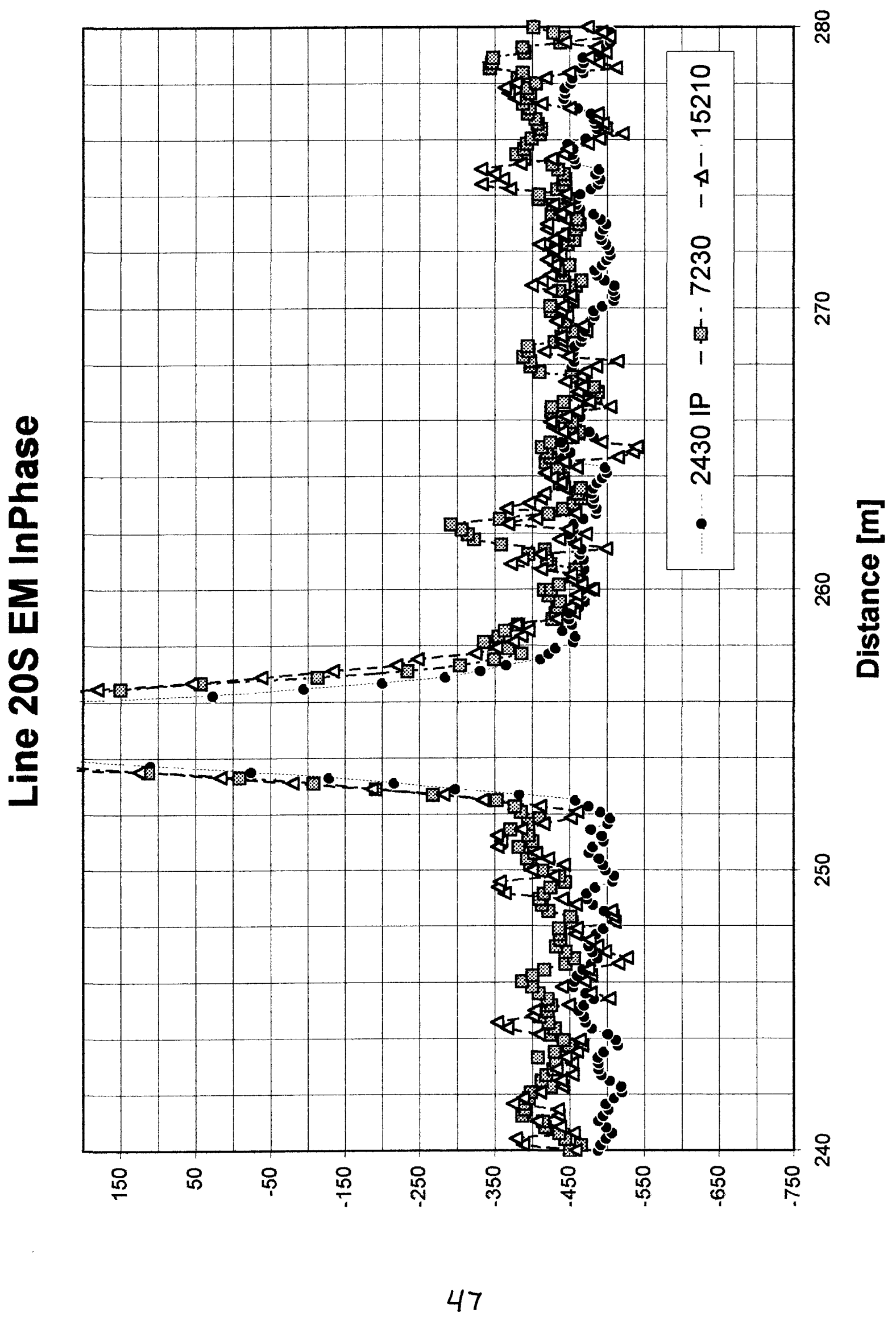




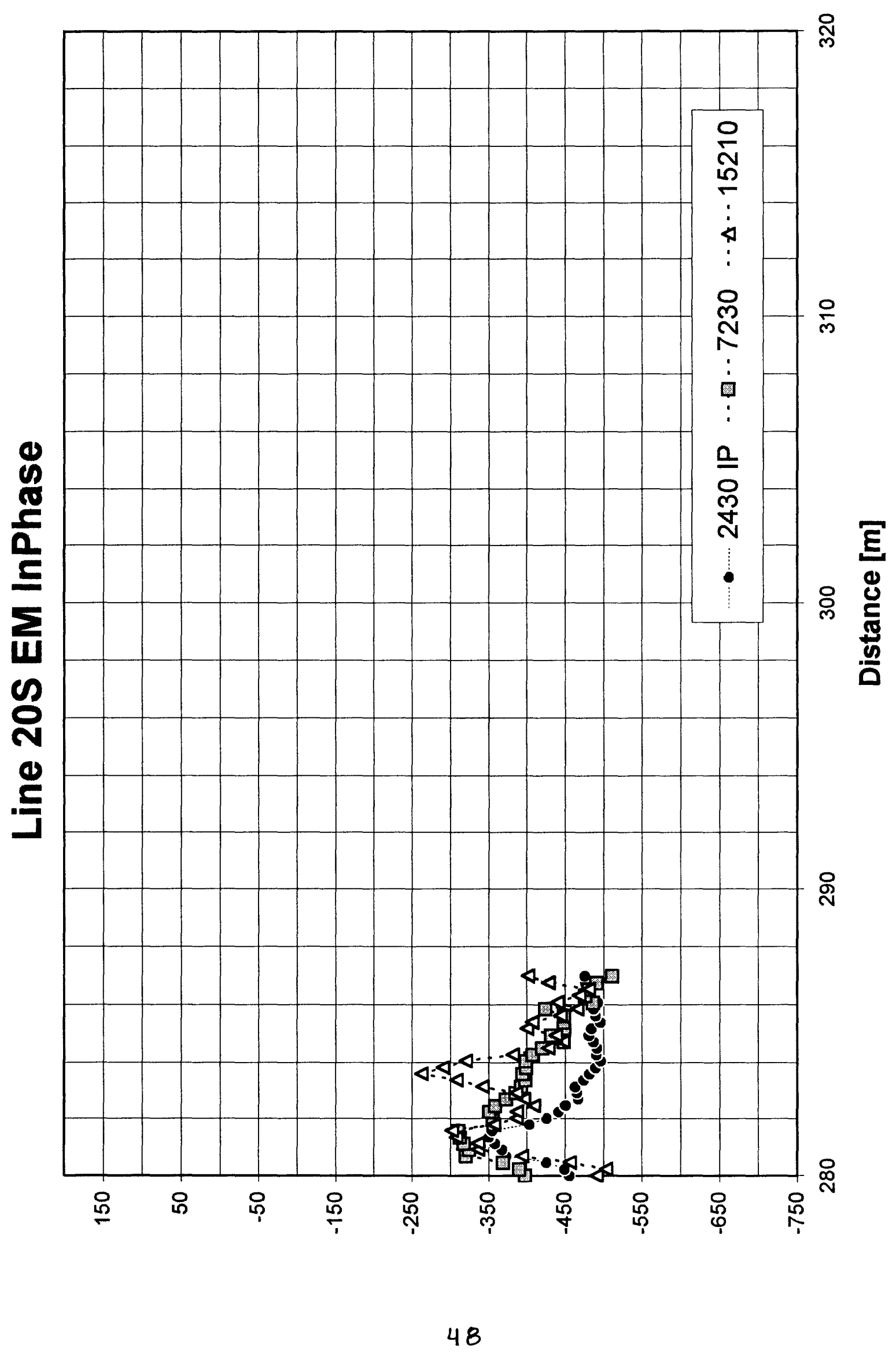




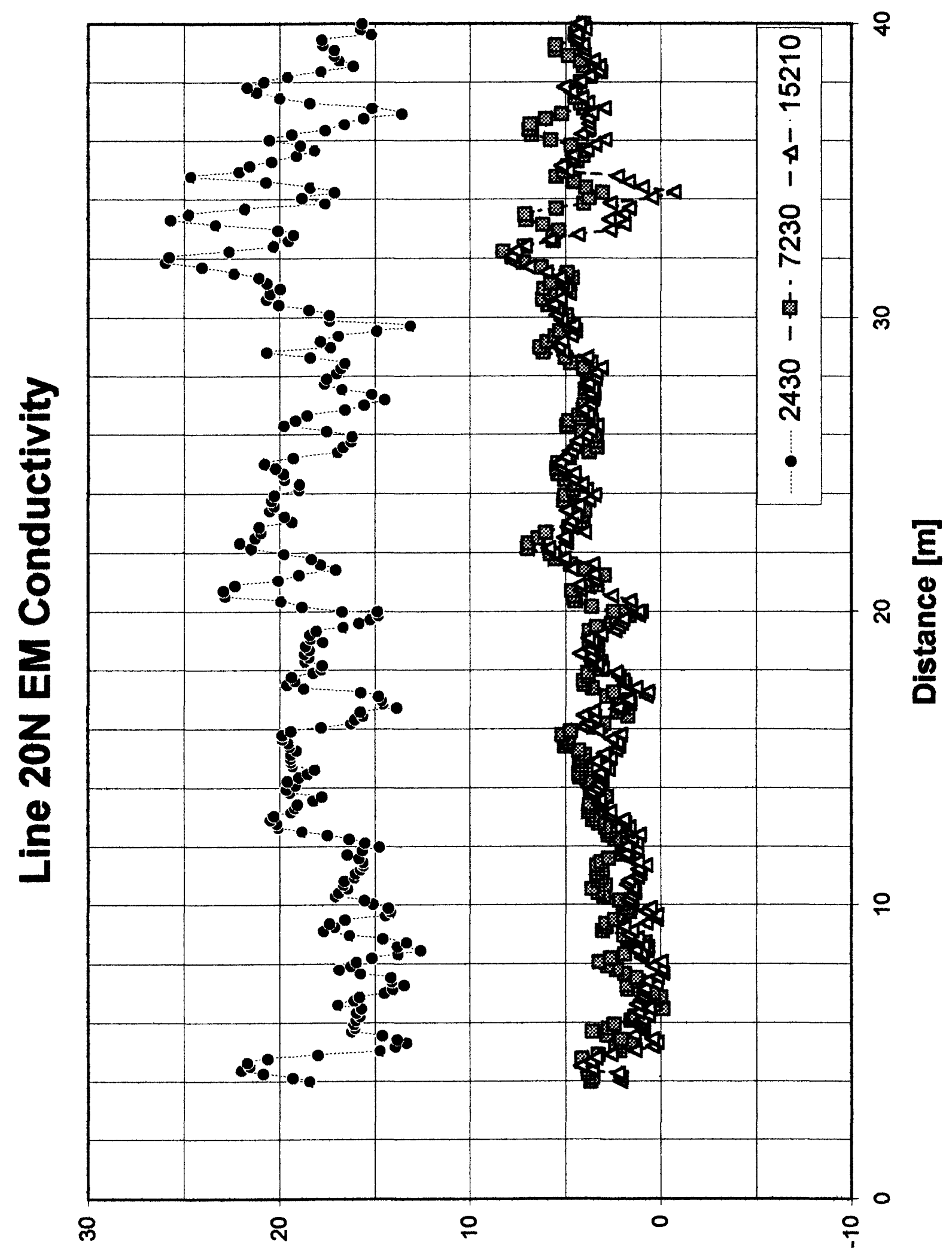




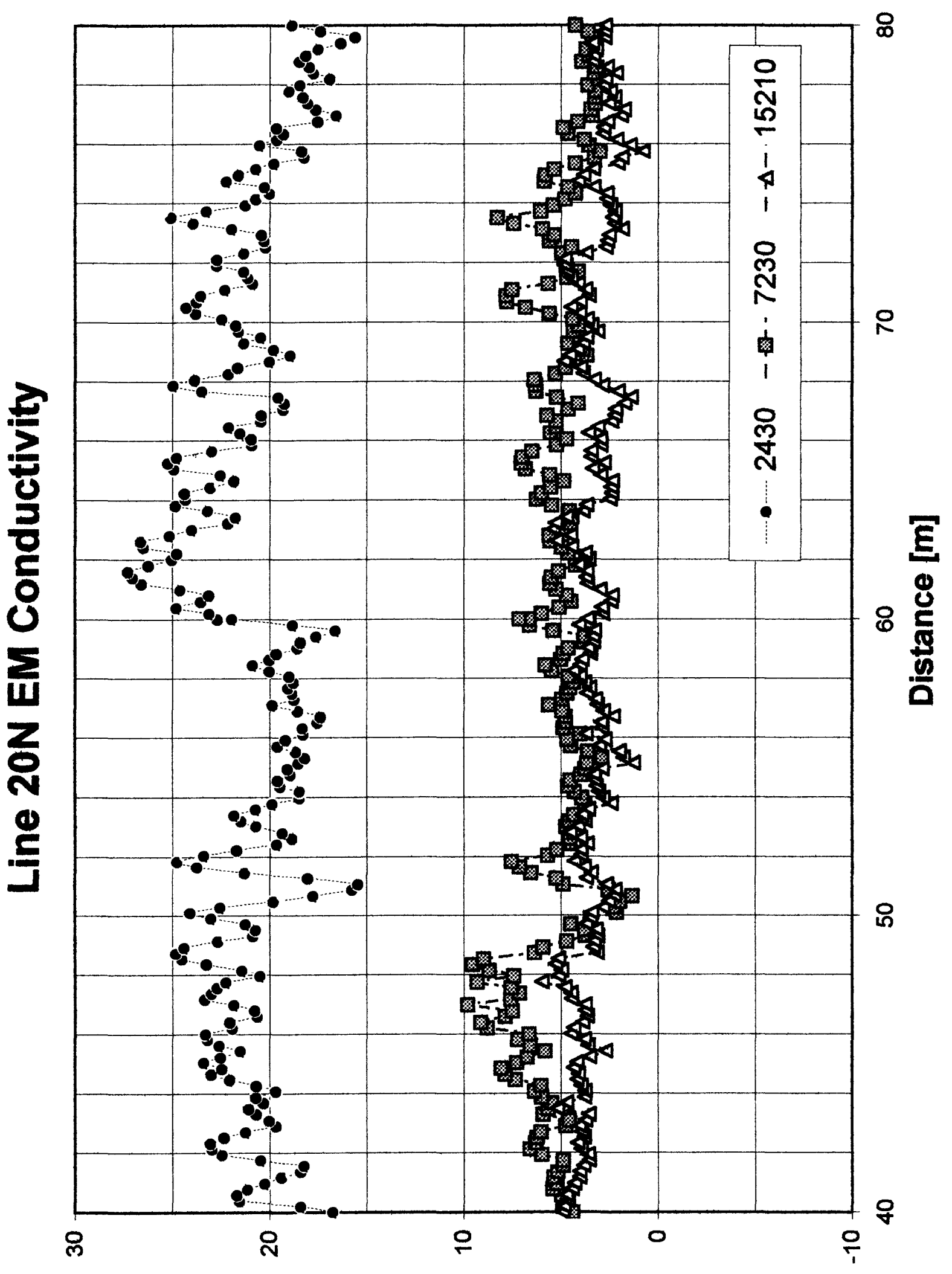




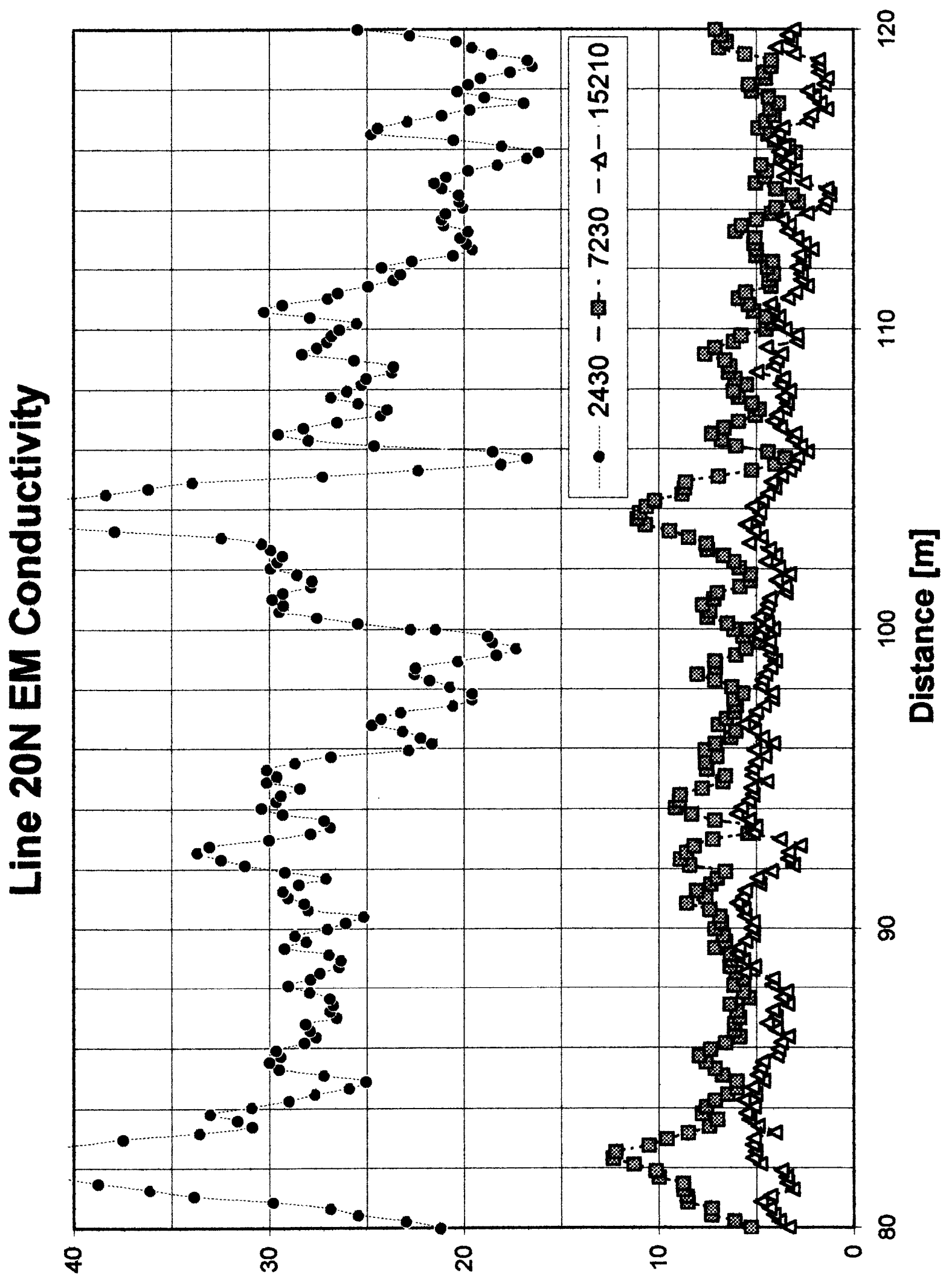




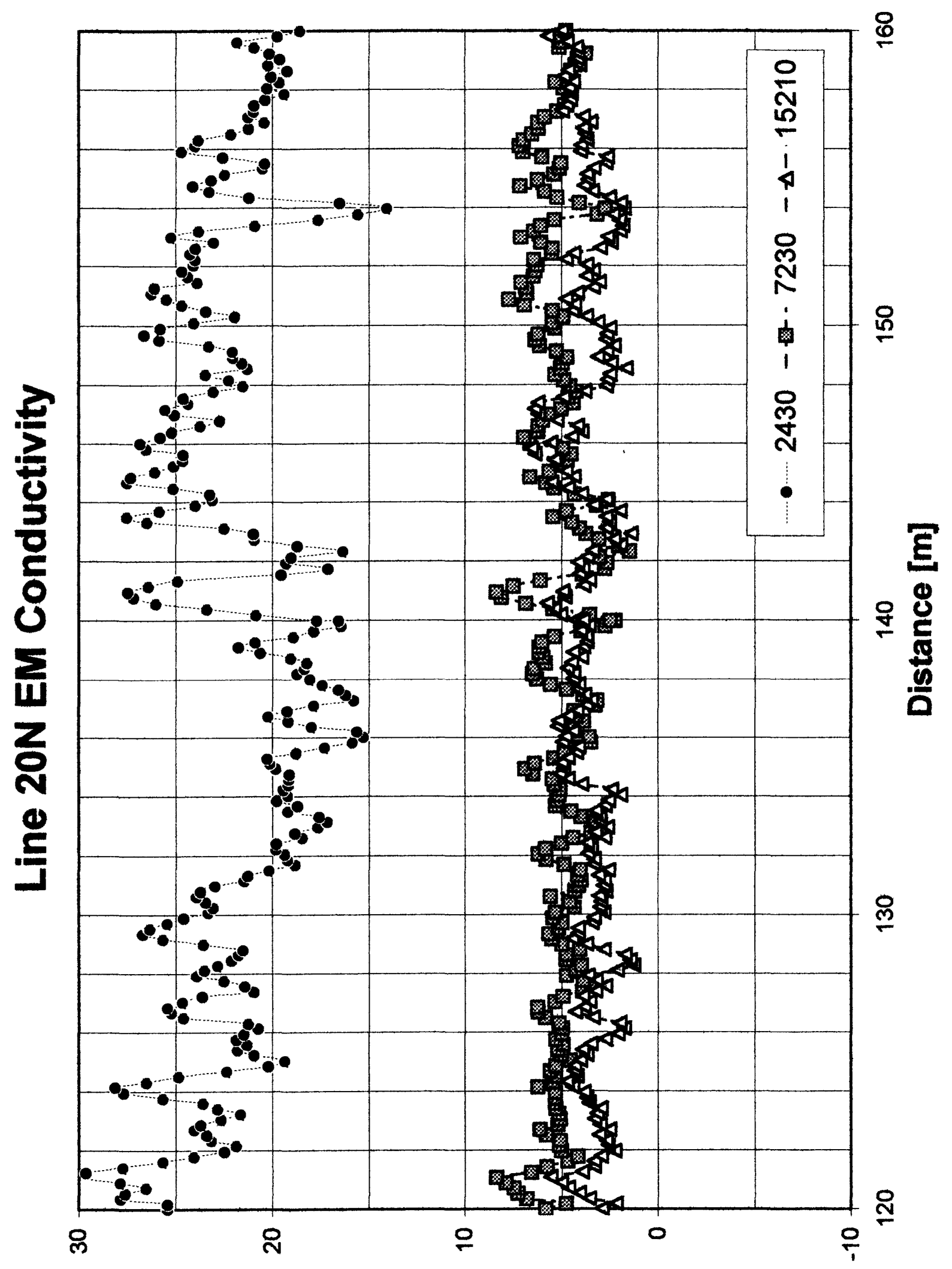




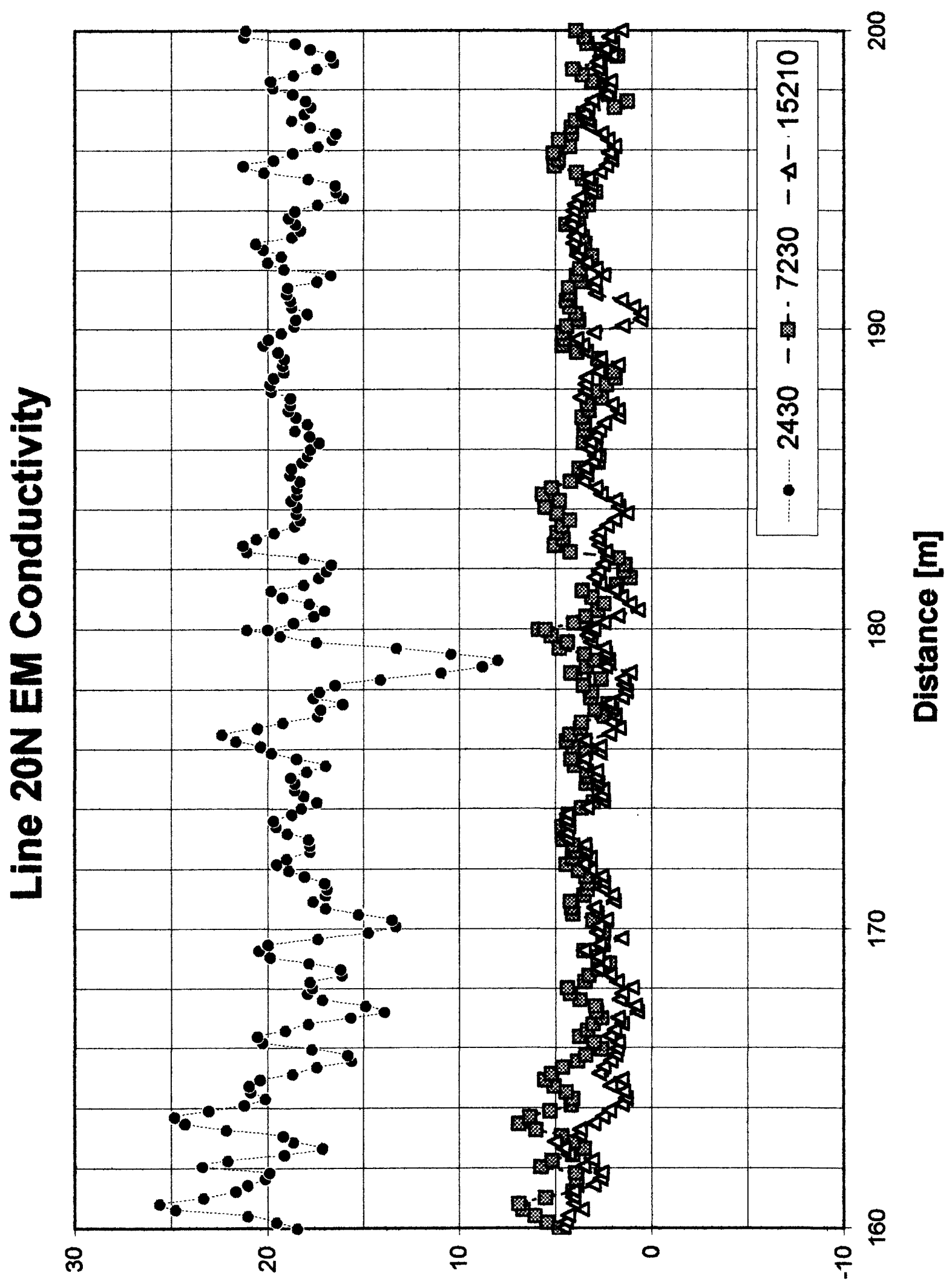




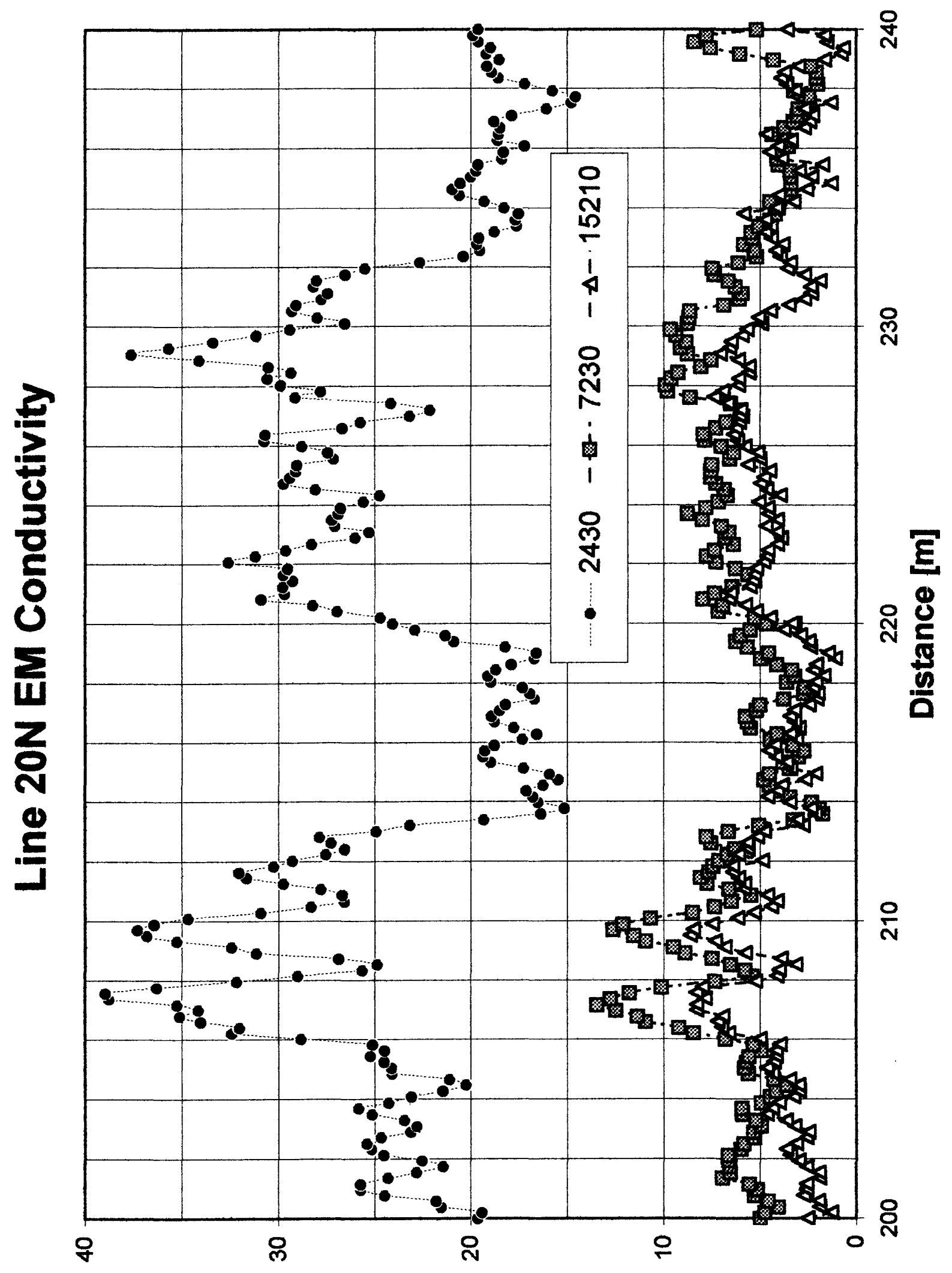




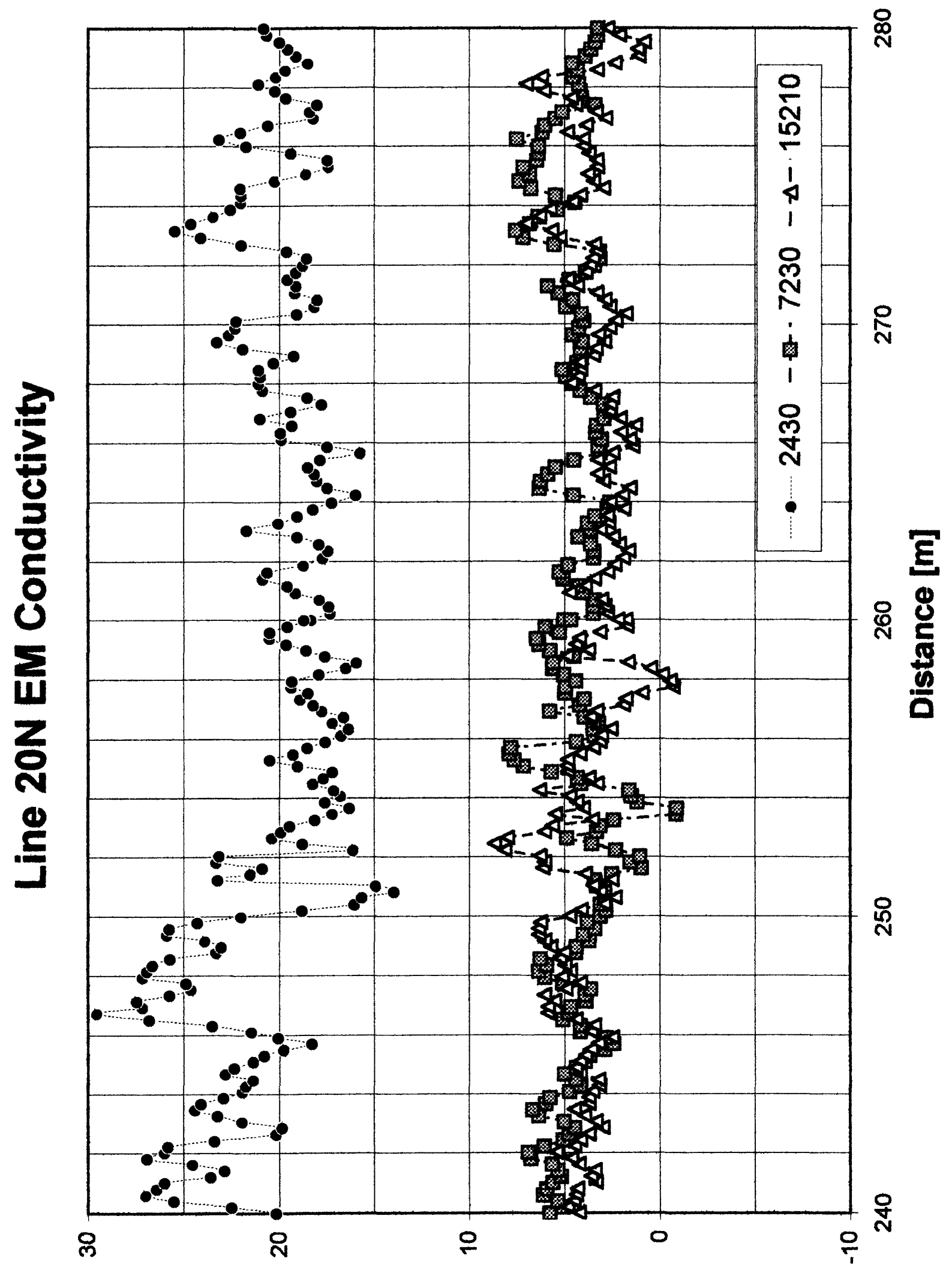




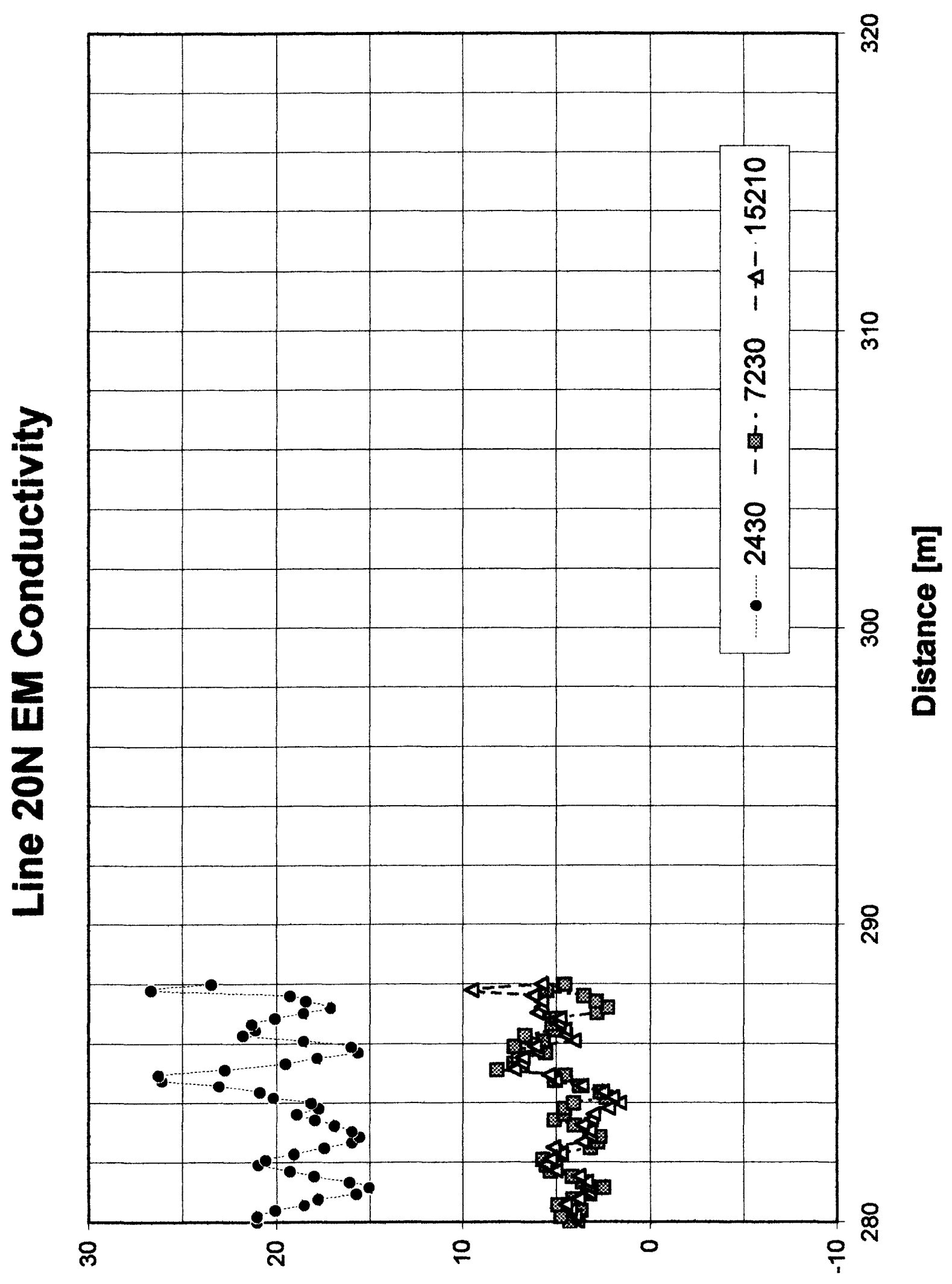




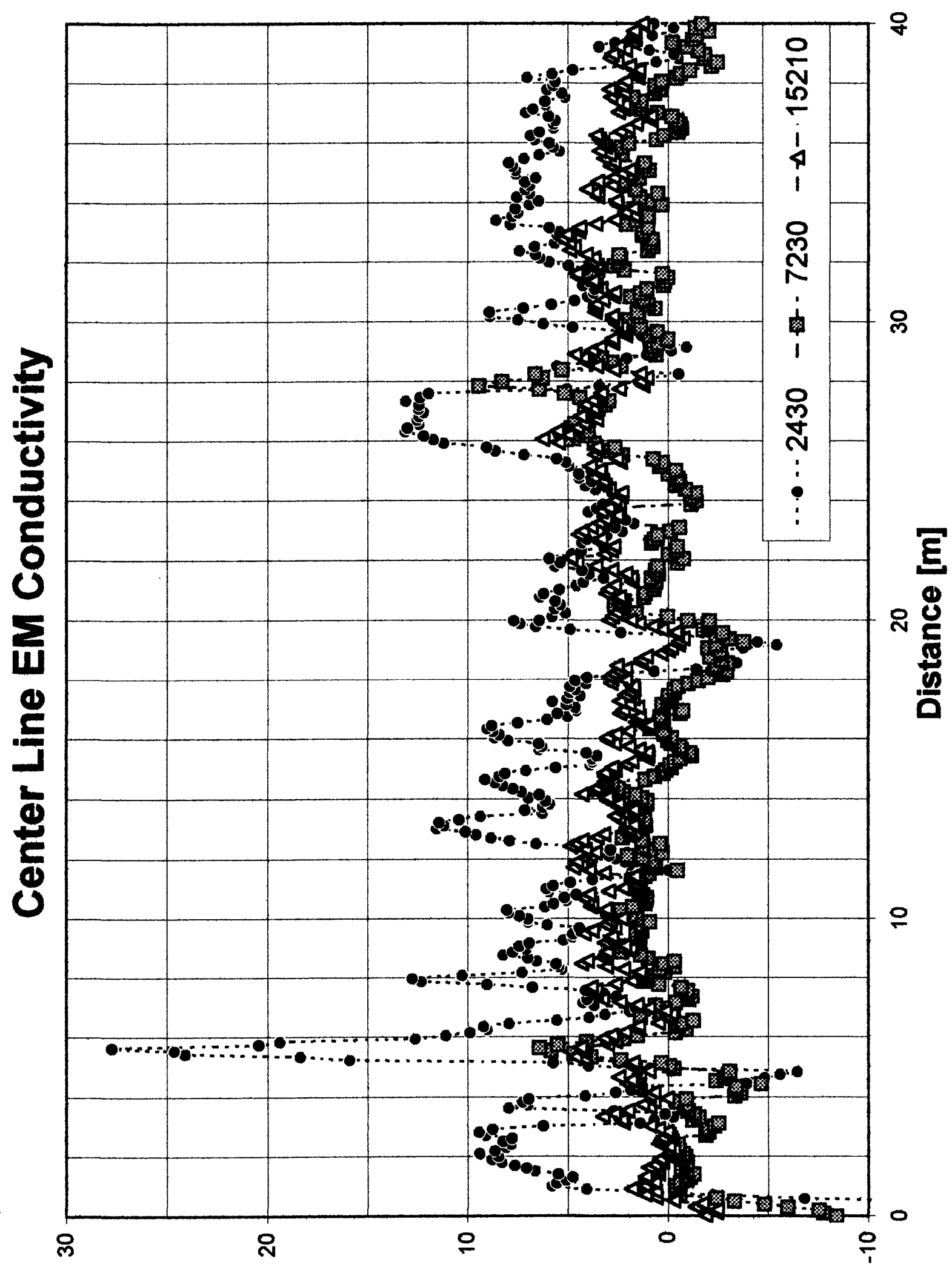




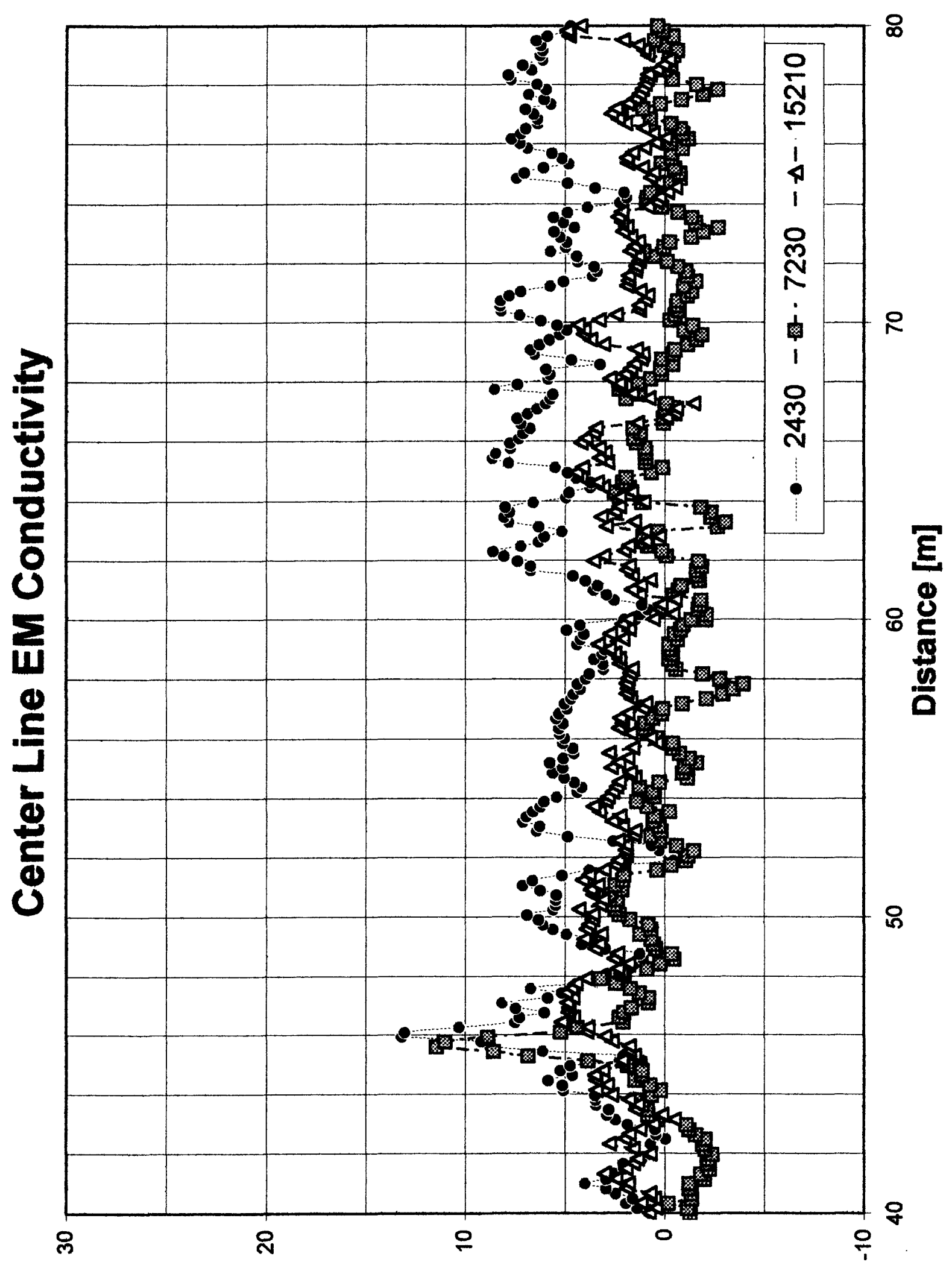




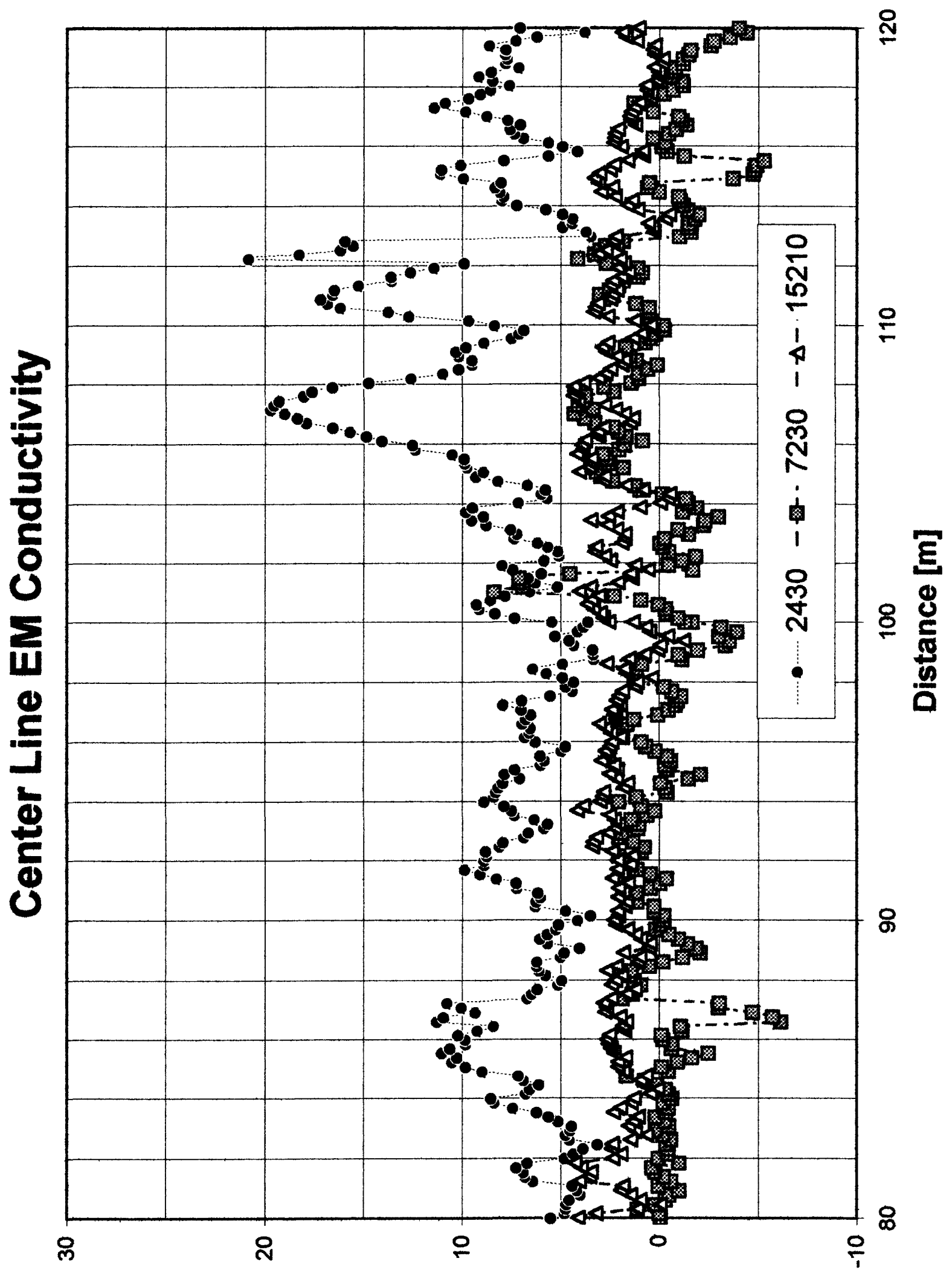




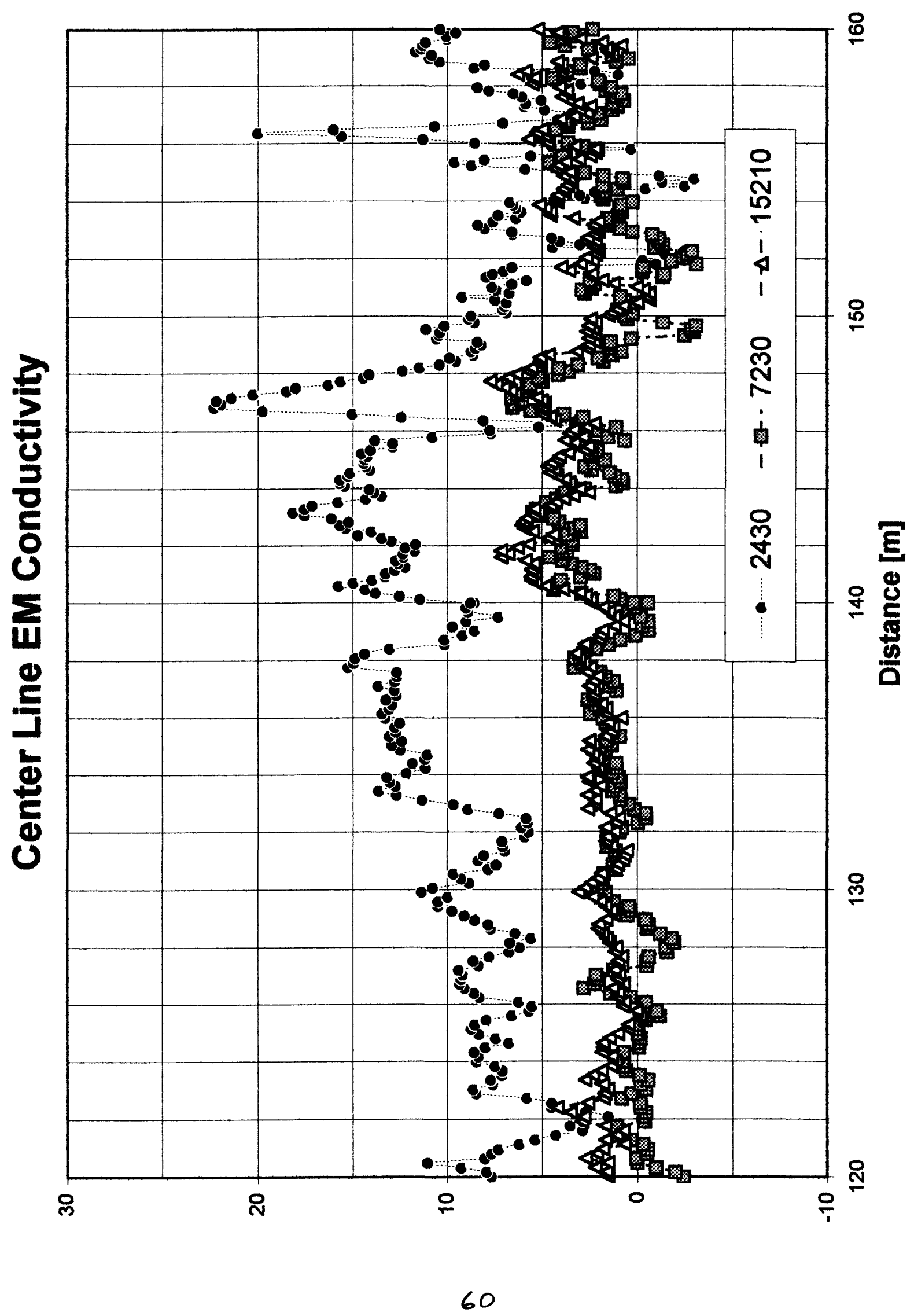




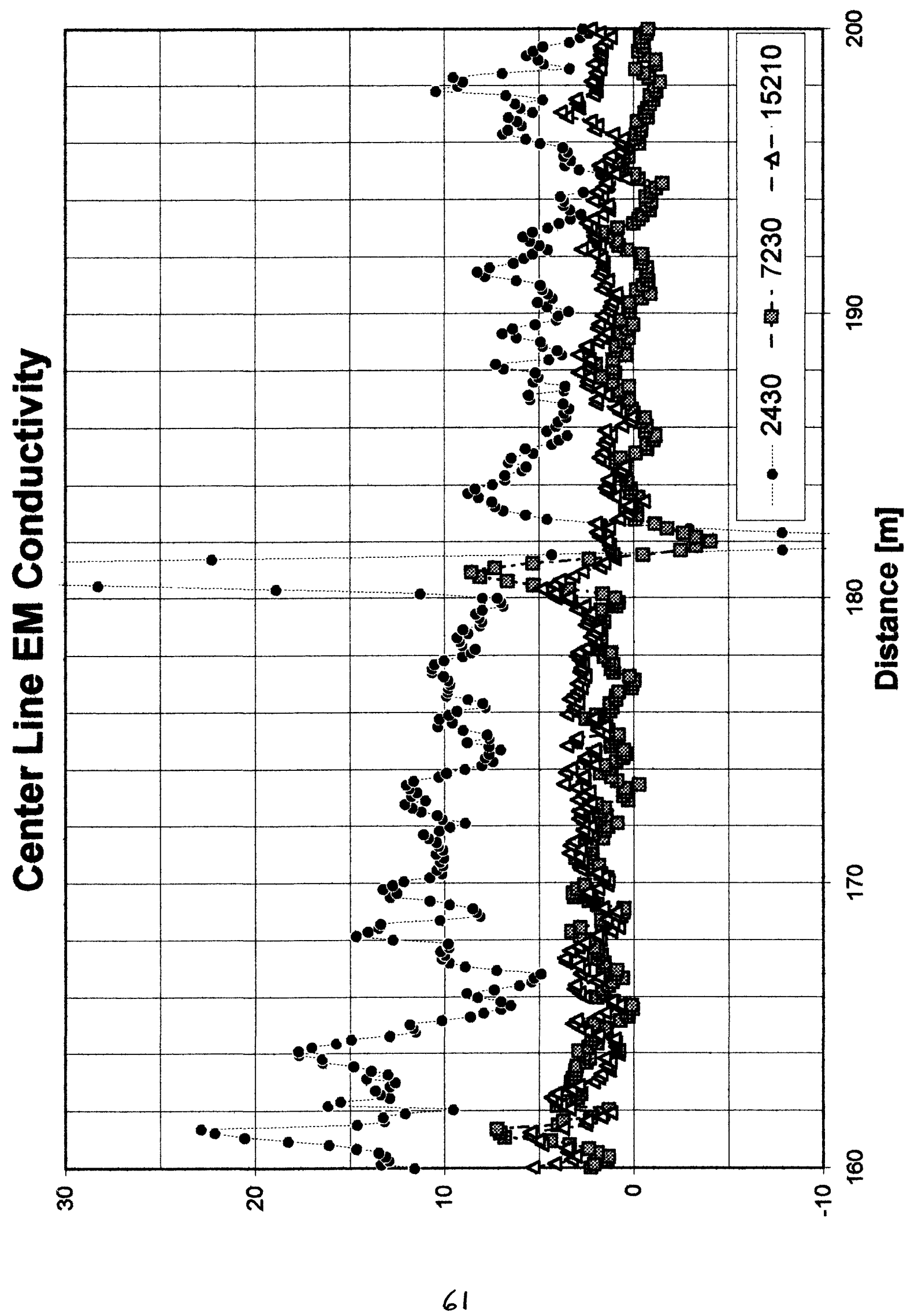




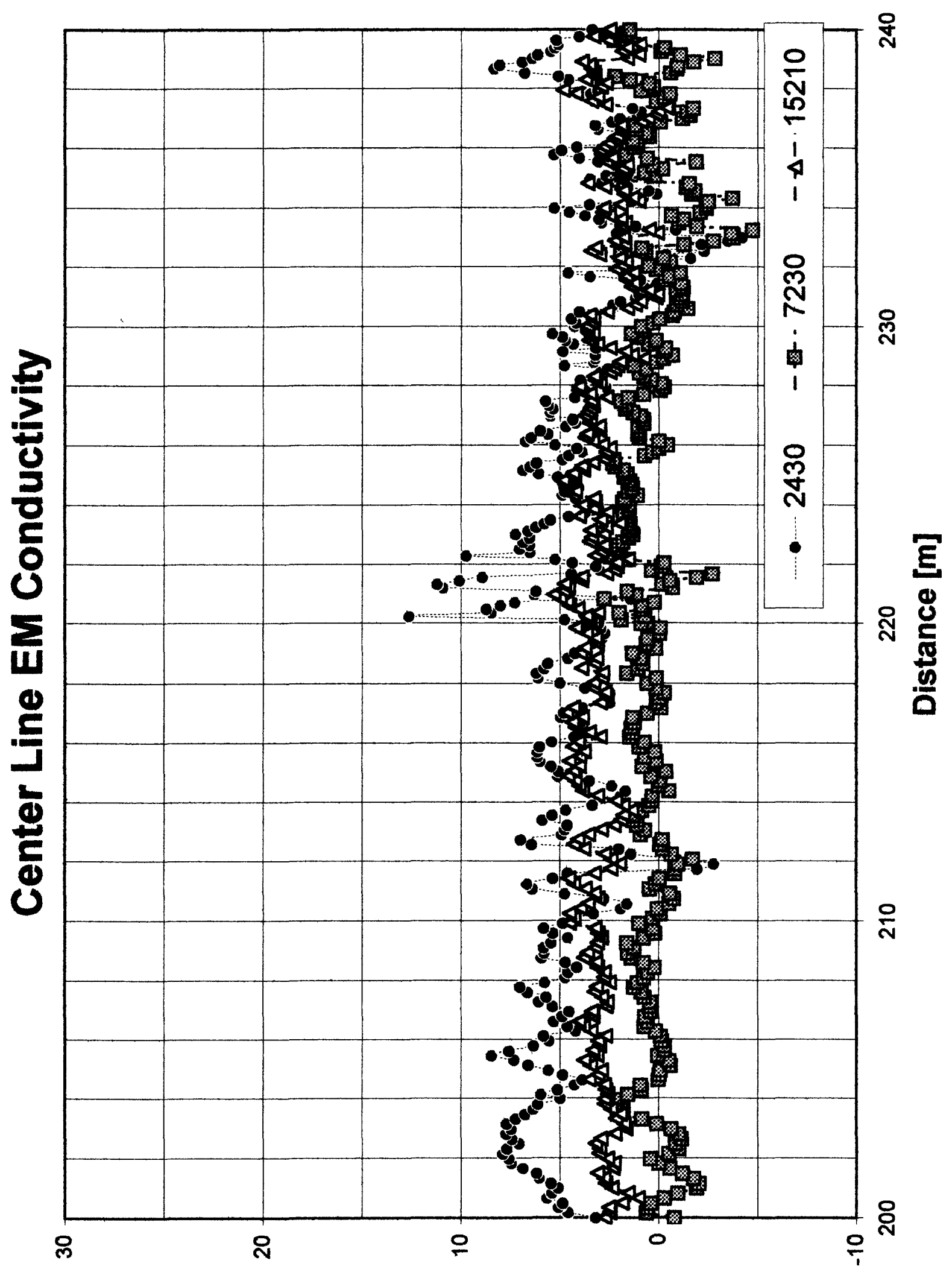




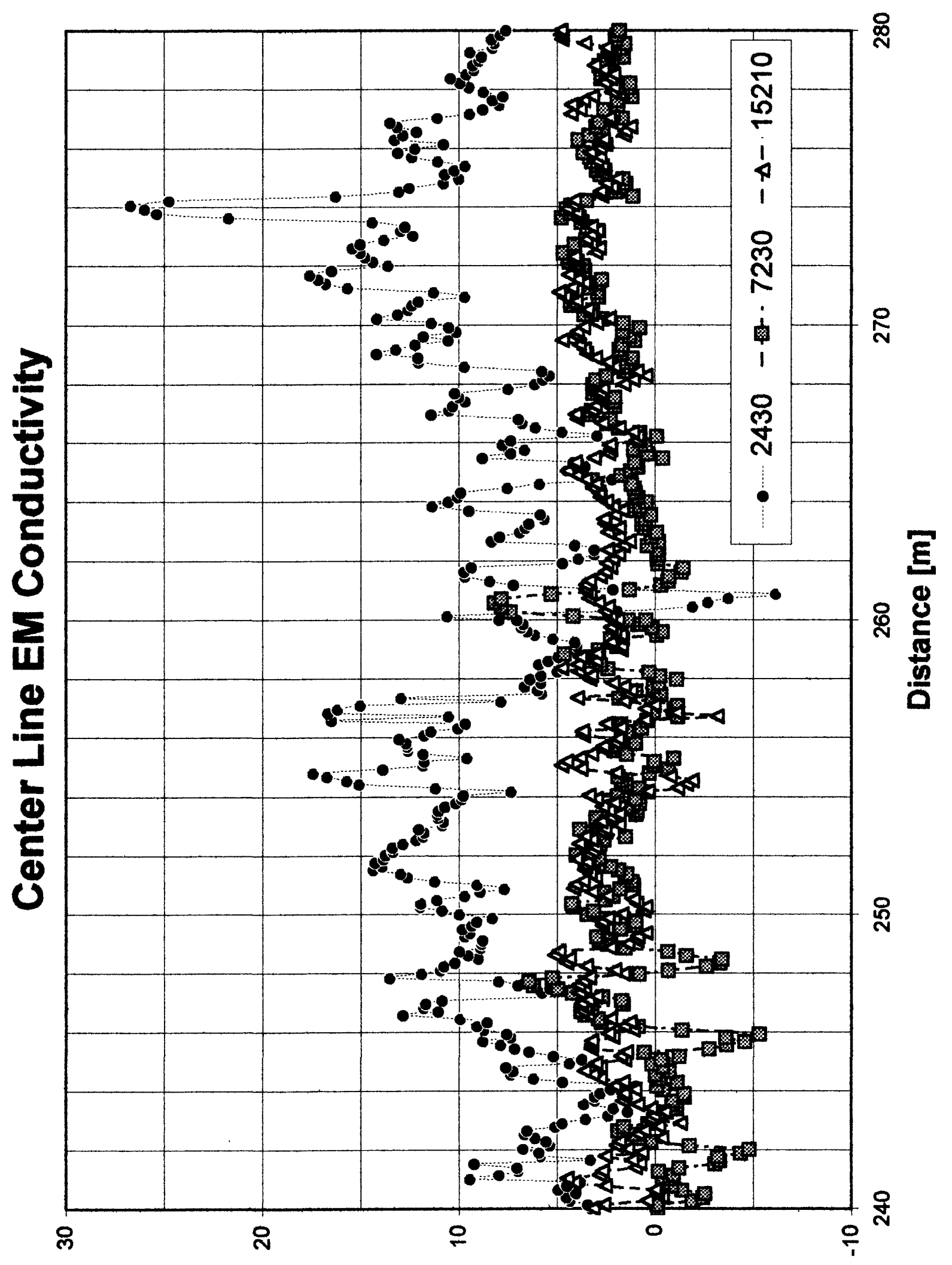




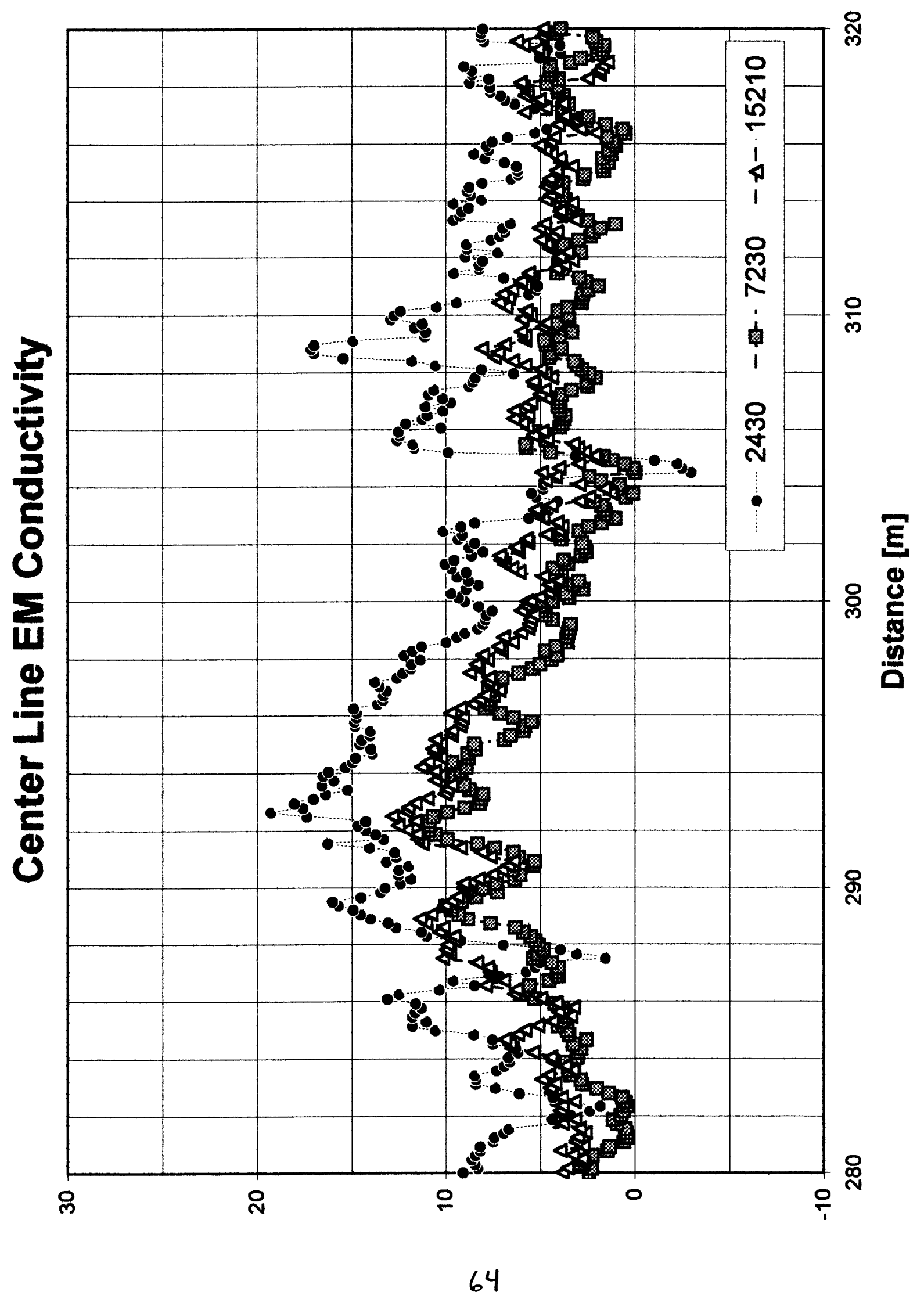




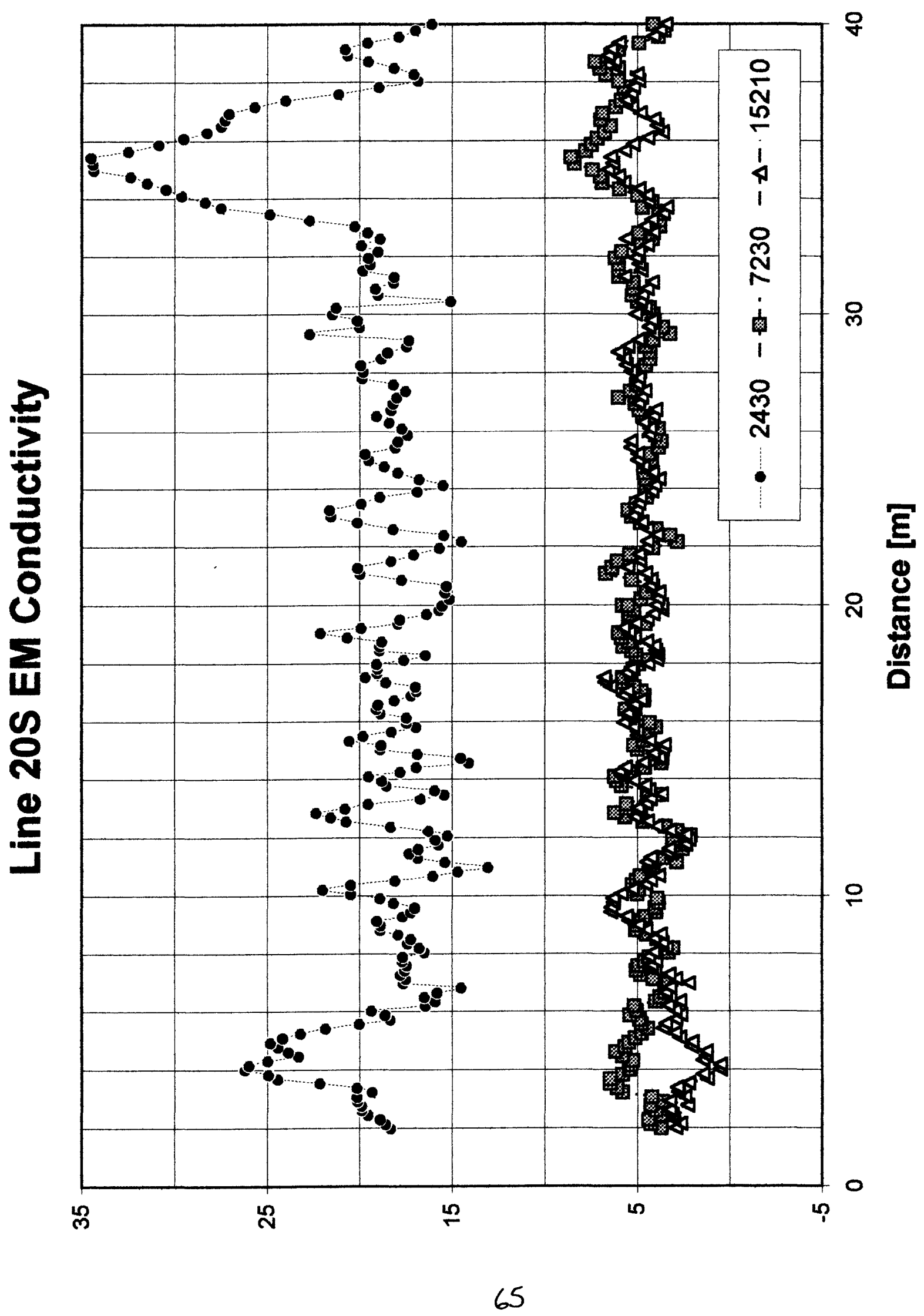




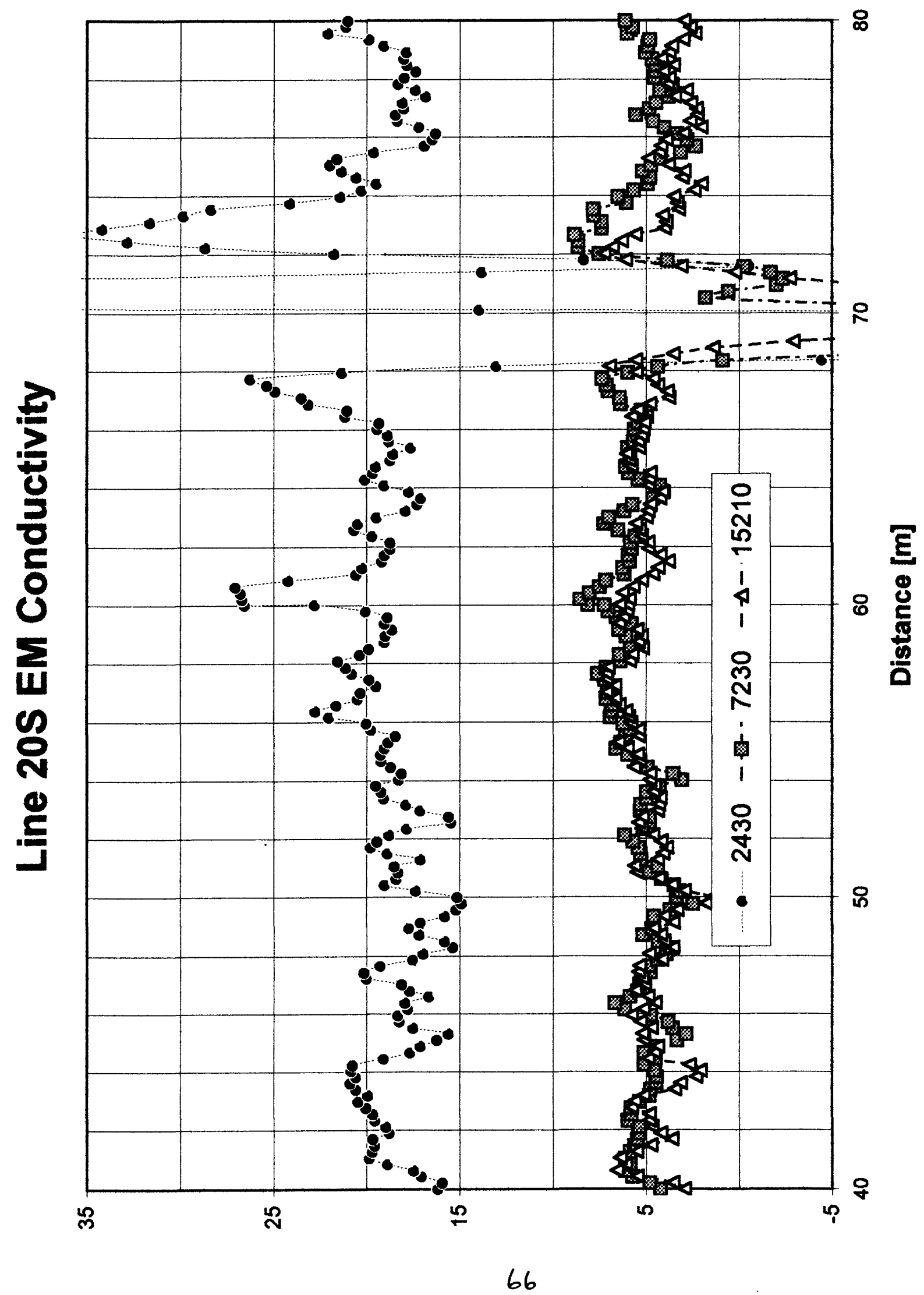




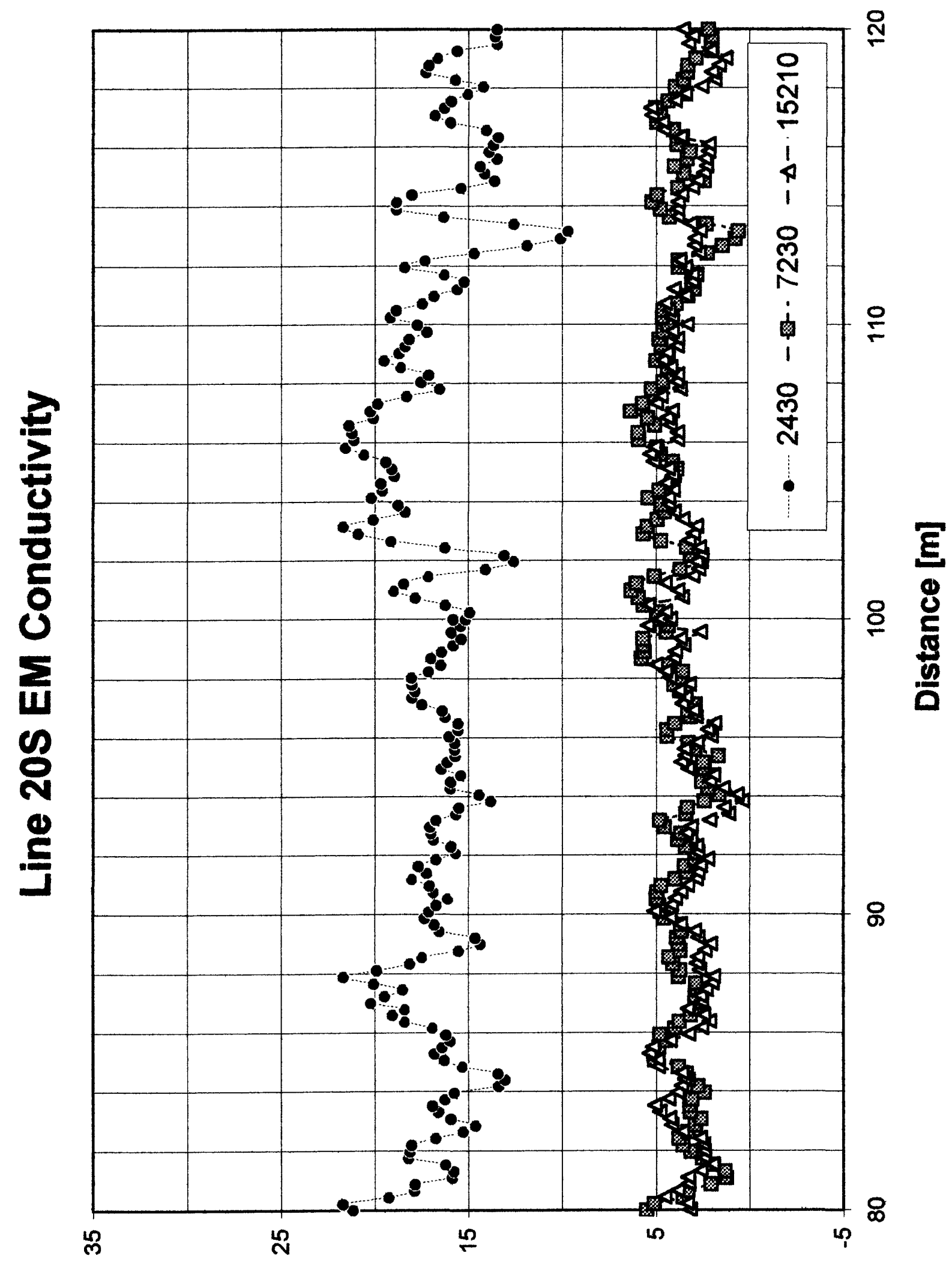




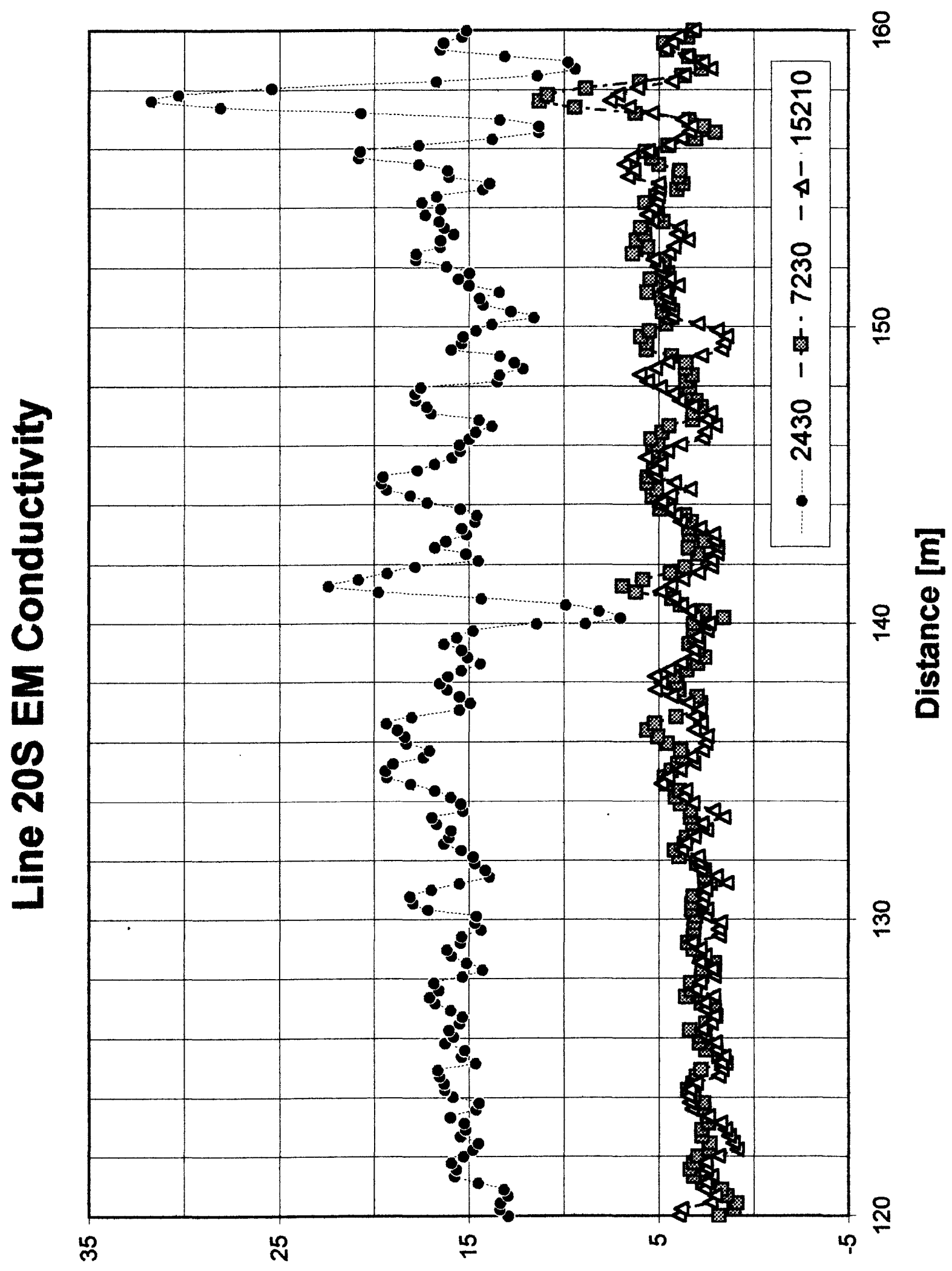




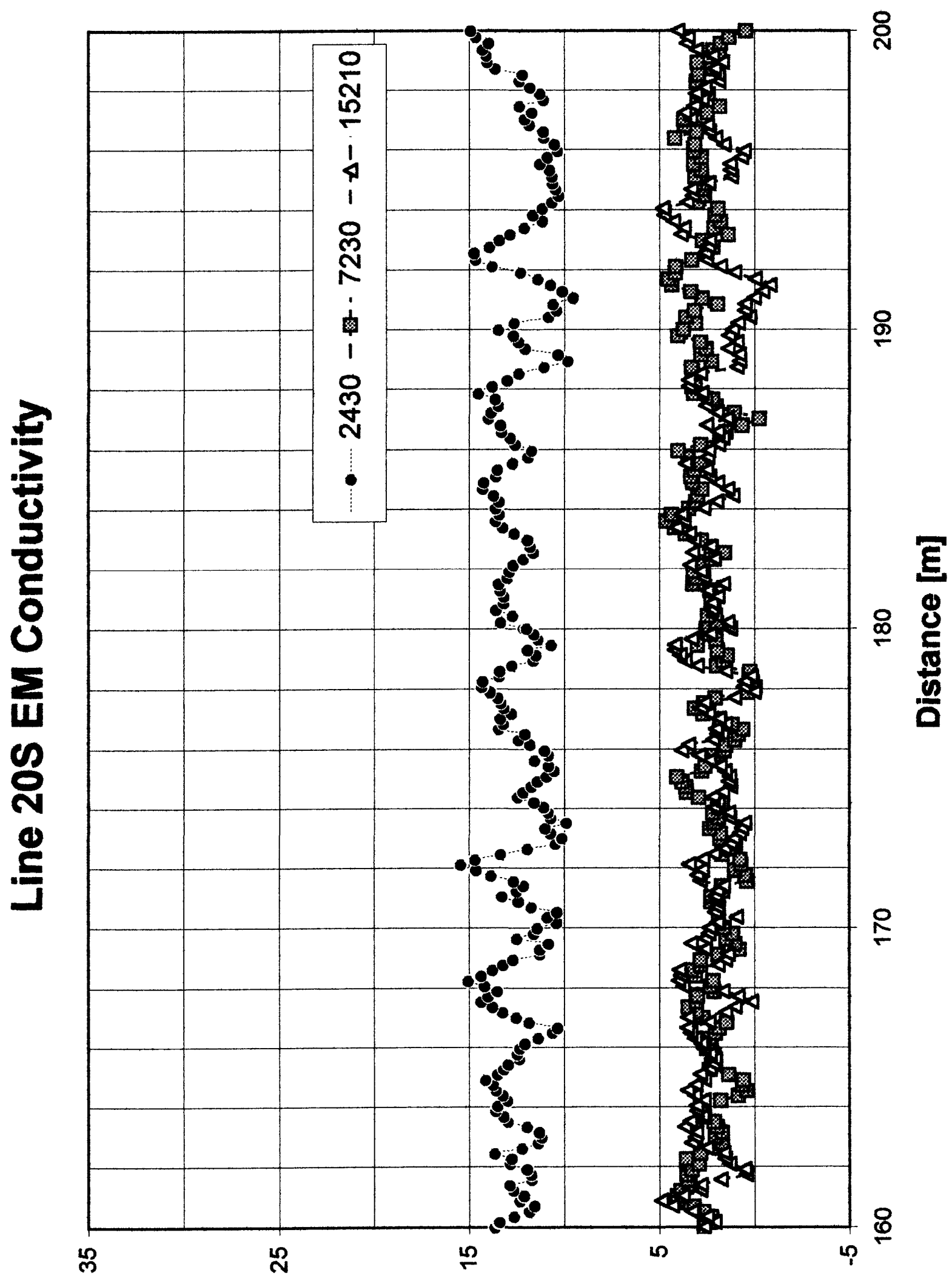




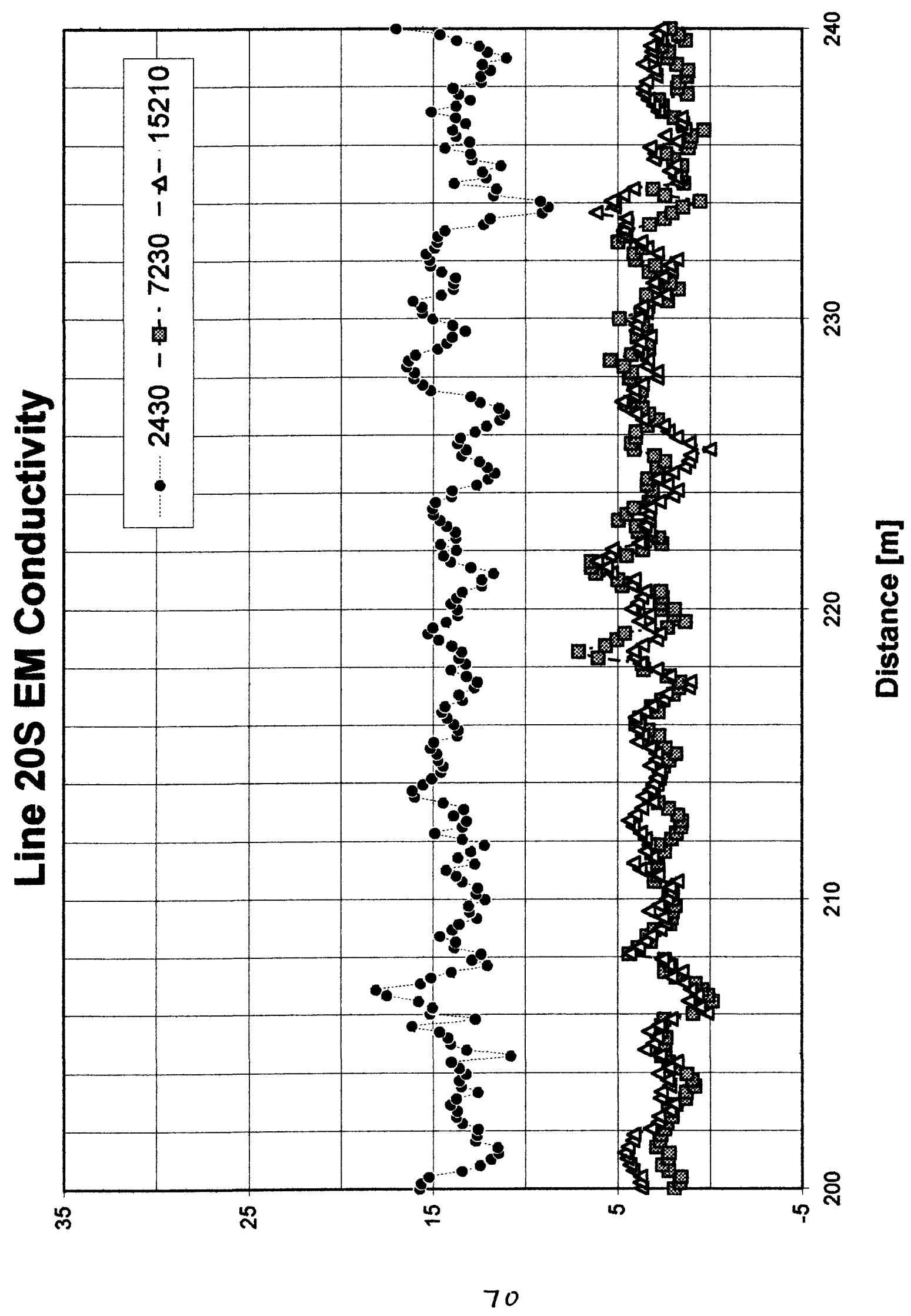




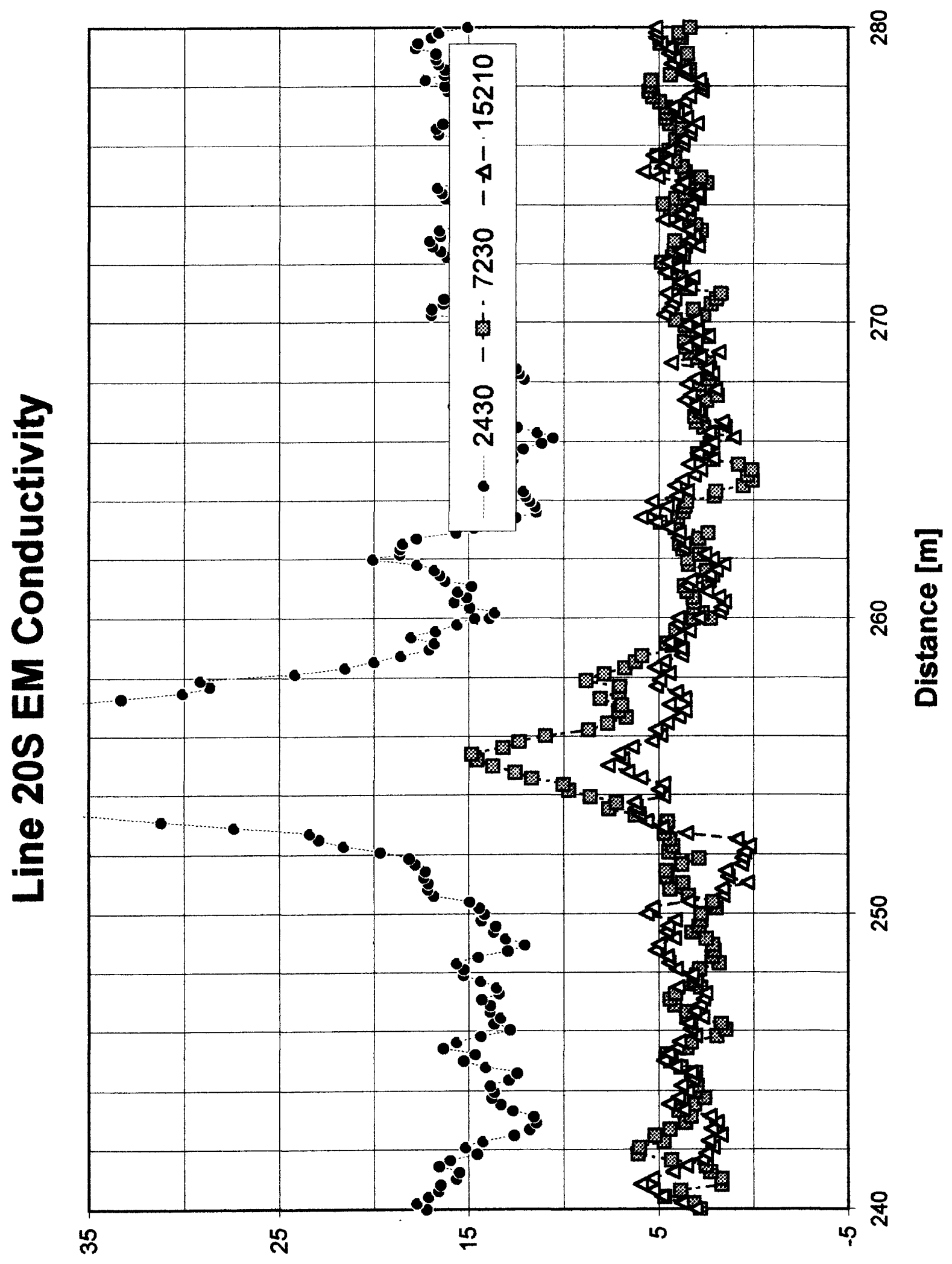




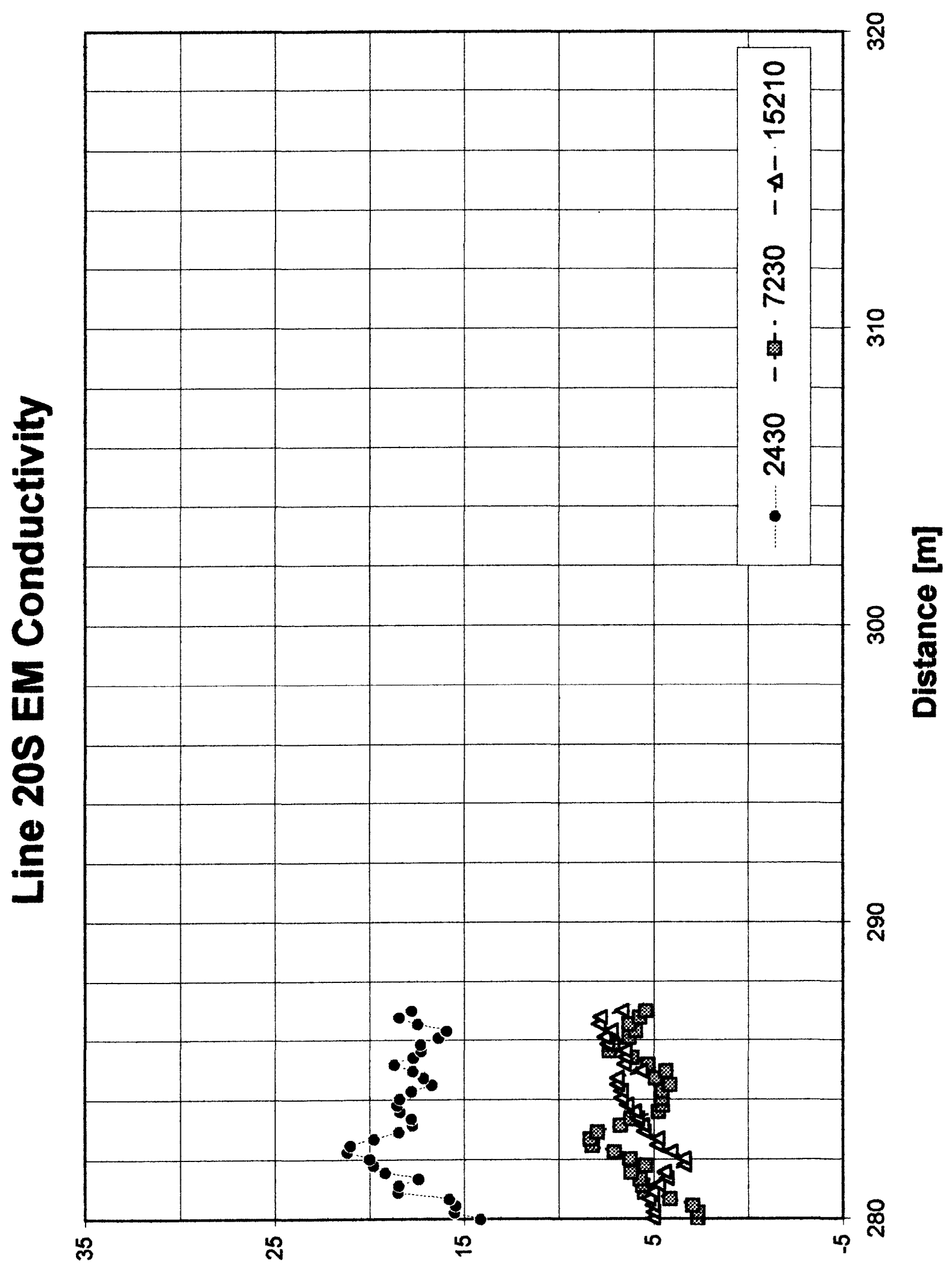




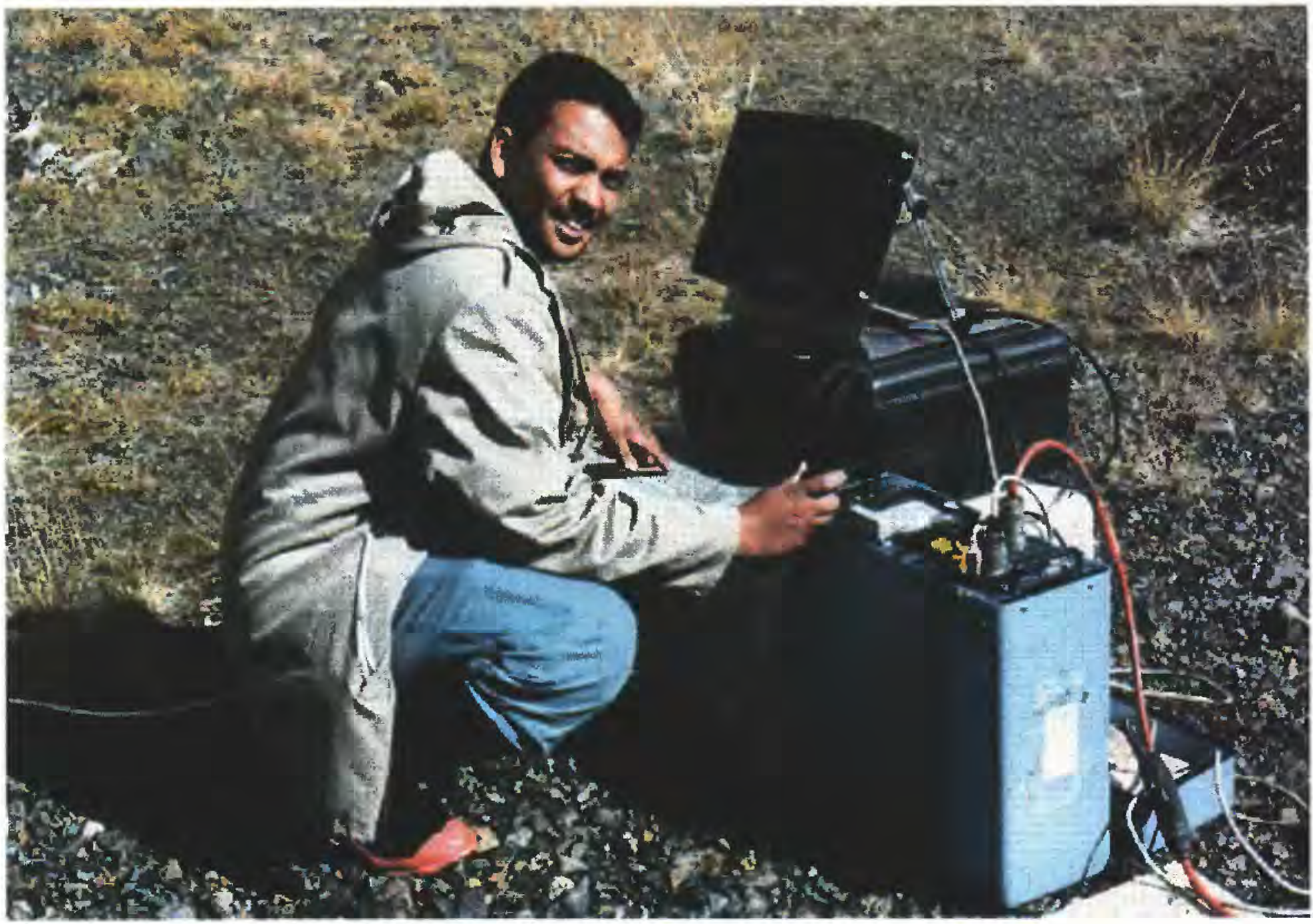

Fig. 4.-- Photograph of GPR console.

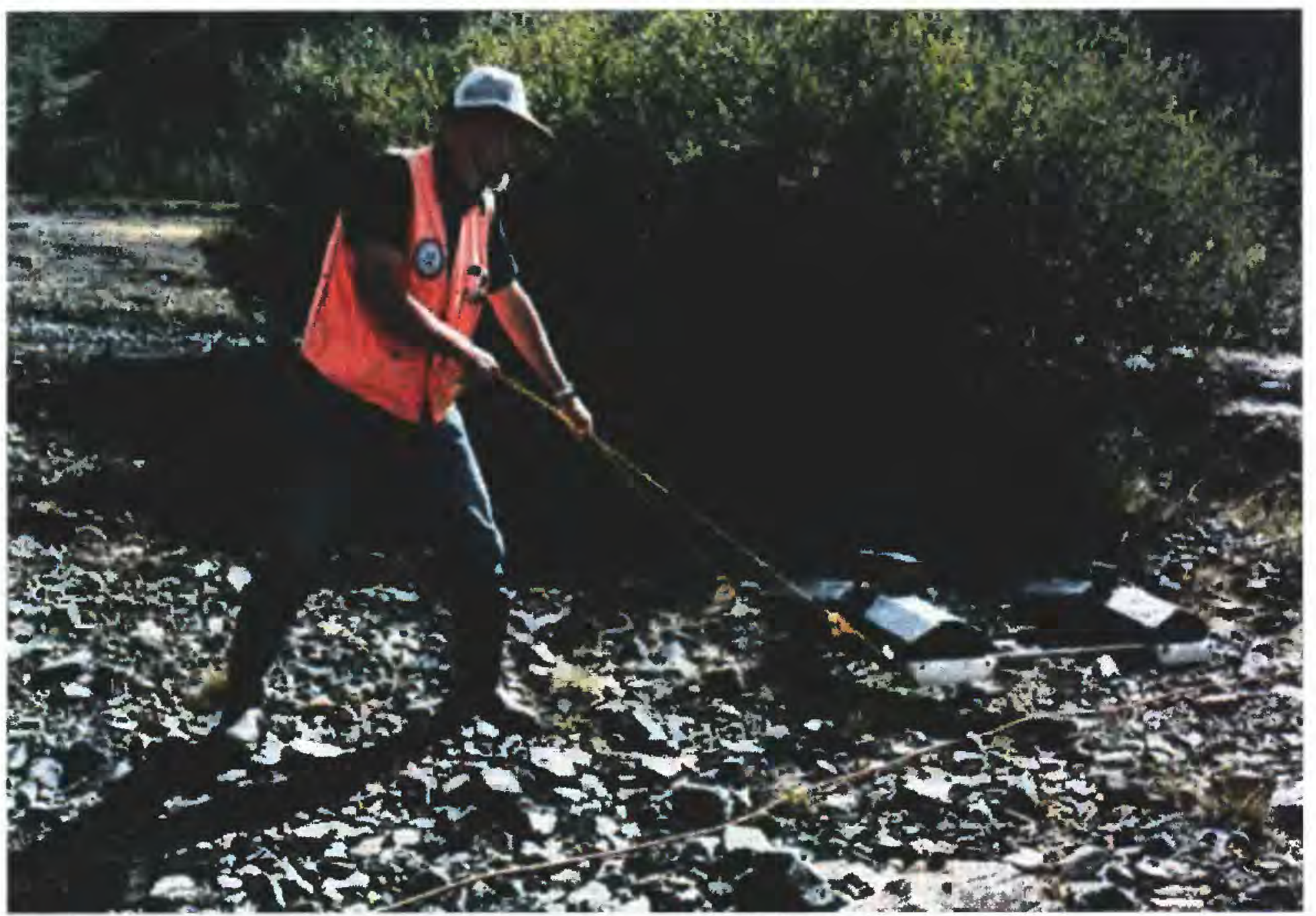

Fig. 5.-- Photograph of GPR antennas being pulled along the trench line. 
Fig. 6.-- GPR time sections at a scale of about 1.25 inches $=2 \mathrm{~m}$. This scale matches the trench stratigraphy sections of Vincent and Elliott (work in progress.).

This figure consists of 29 pages, which directly follow this page. Each page covers $10 \mathrm{~m}$ of line, except for pages covering $220-225 \mathrm{~m}$ and $225-230 \mathrm{~m}$. The break at $225 \mathrm{~m}$ is because original line segments joined at that coordinate. 


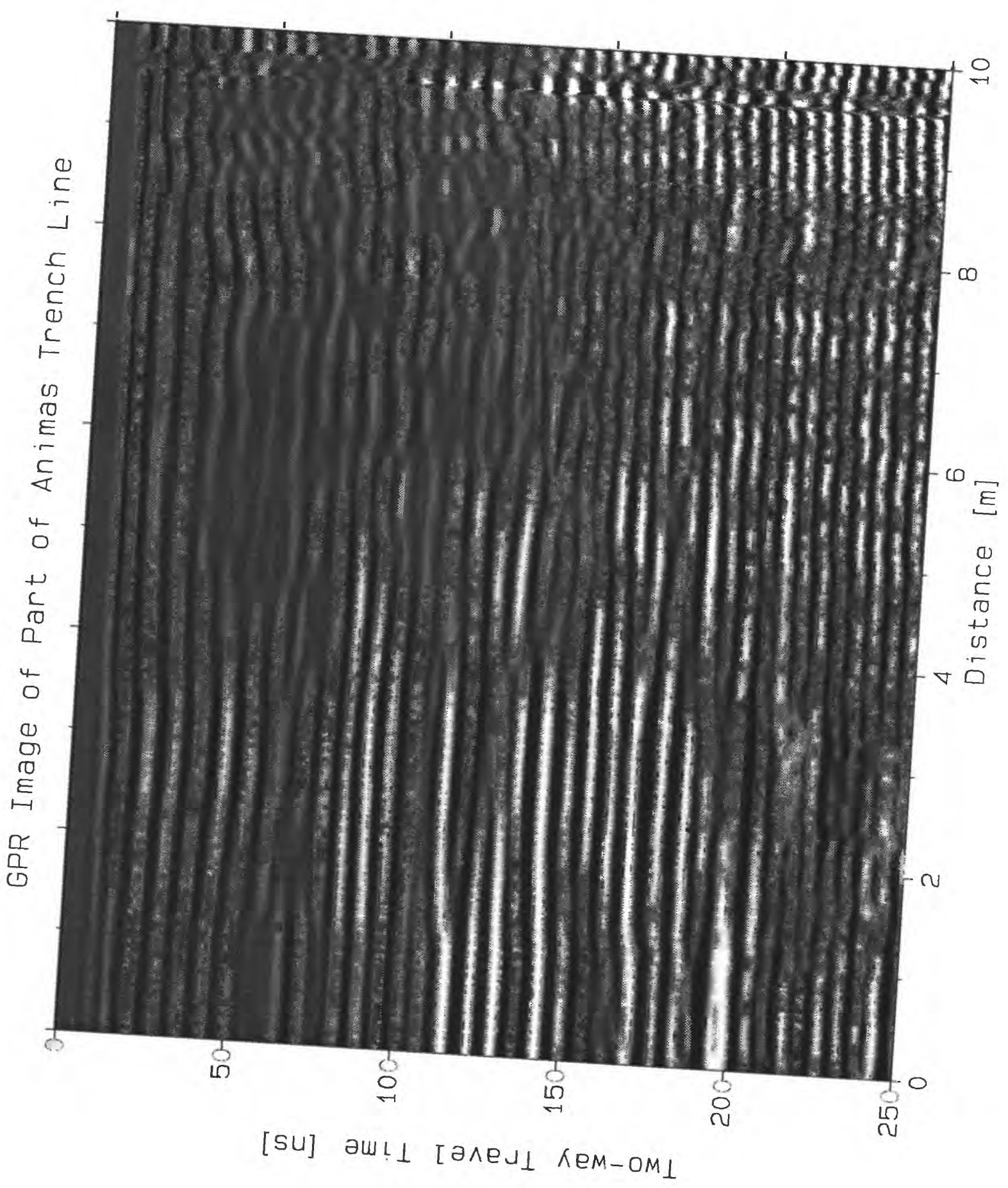




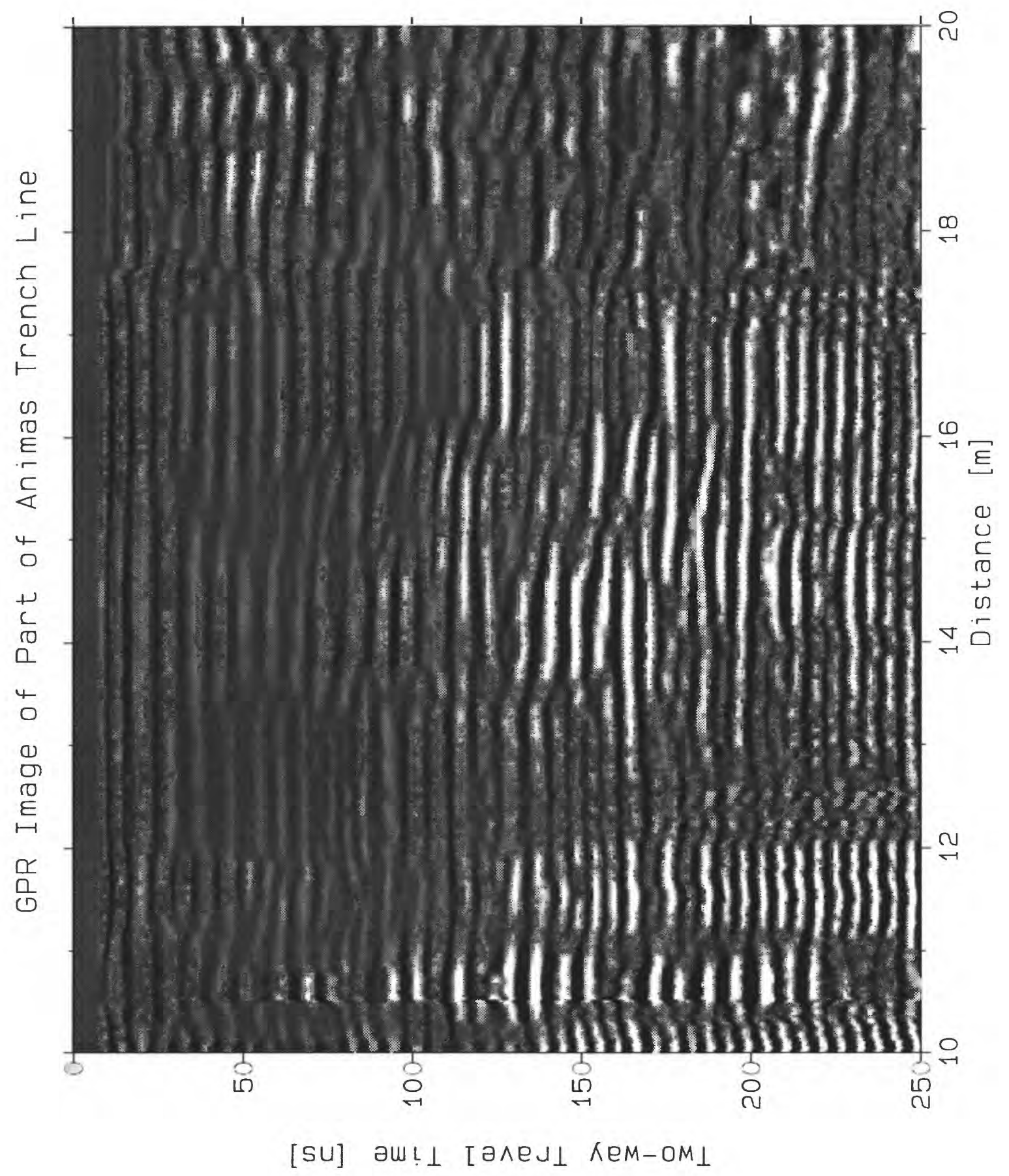




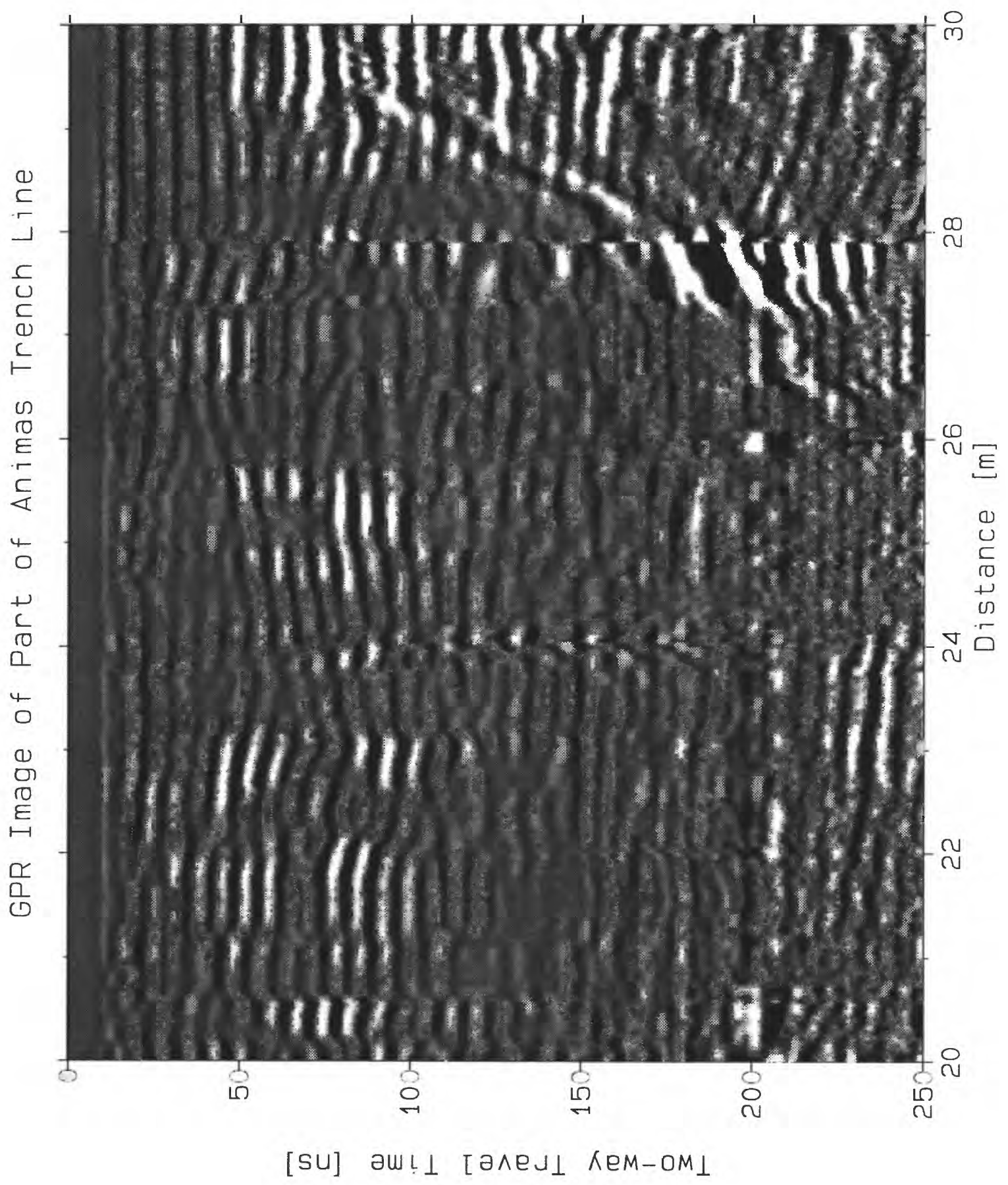




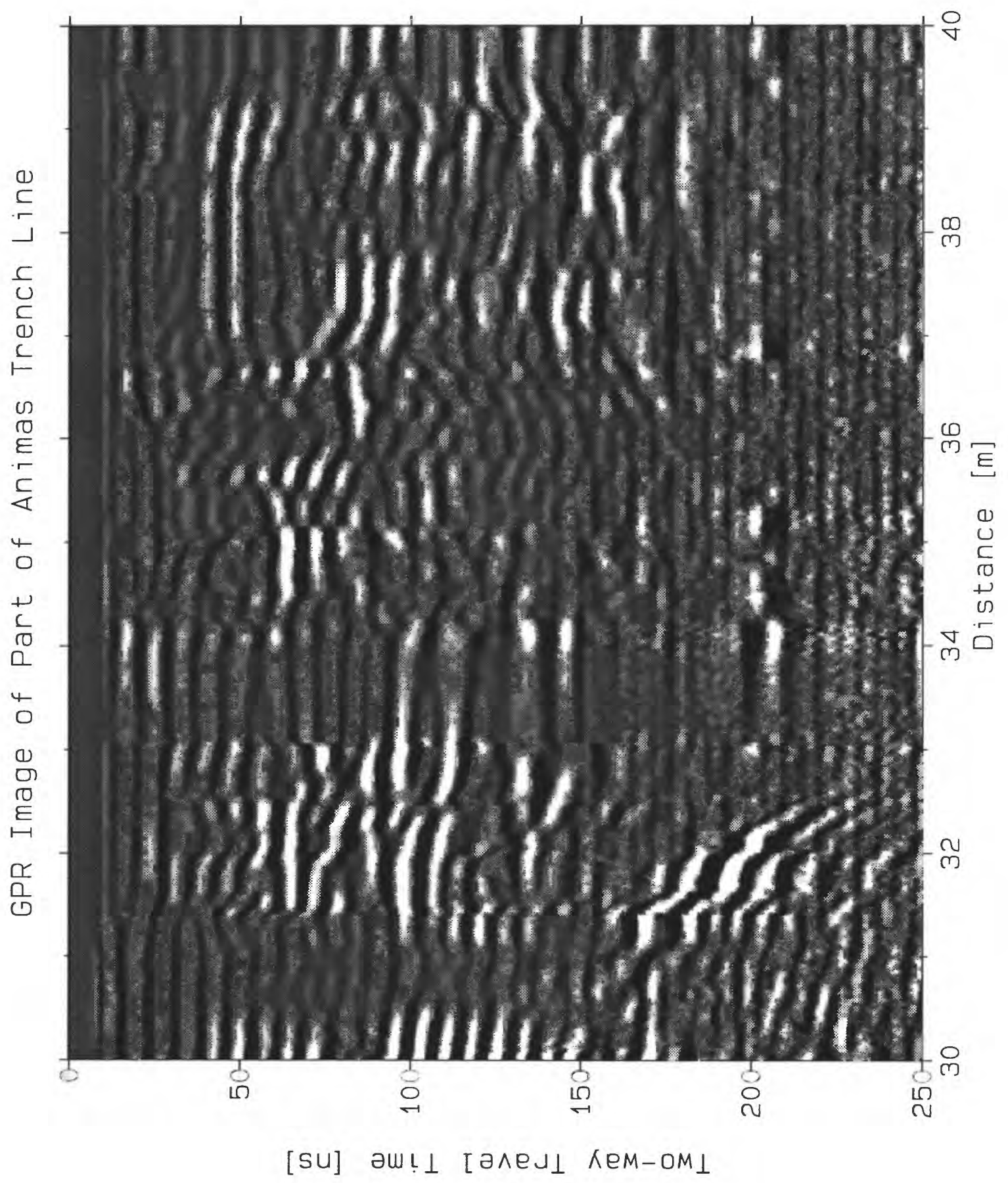




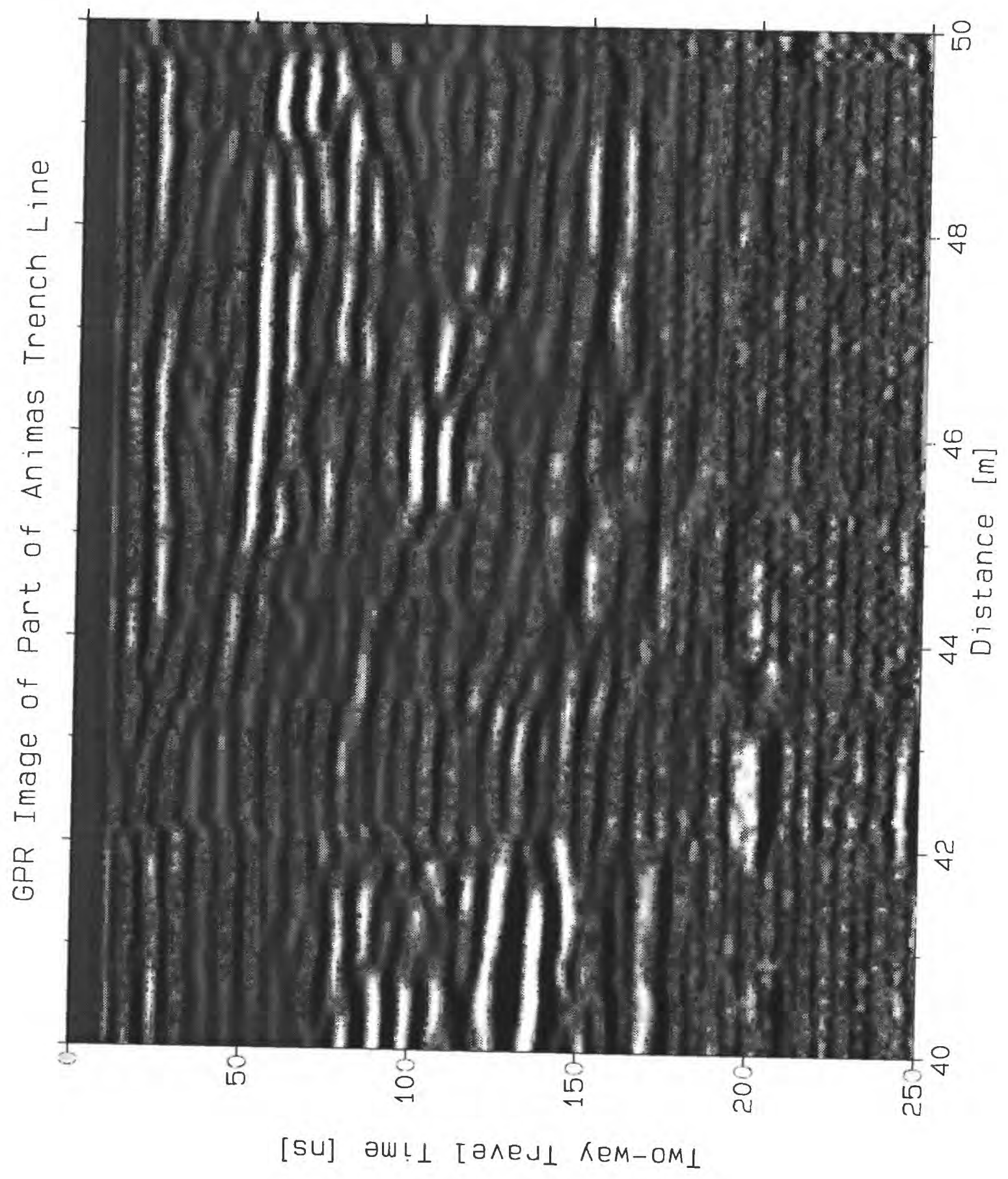




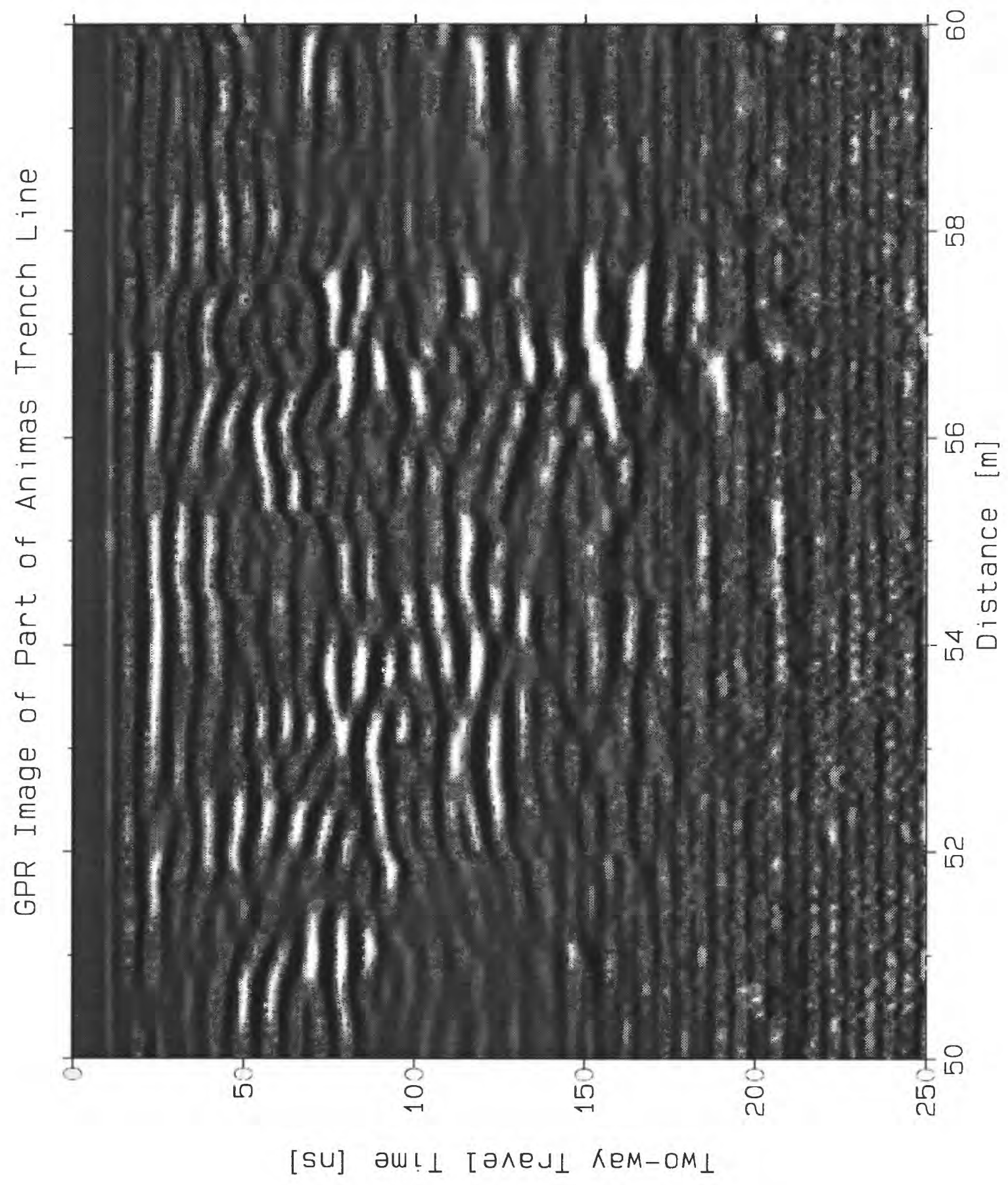




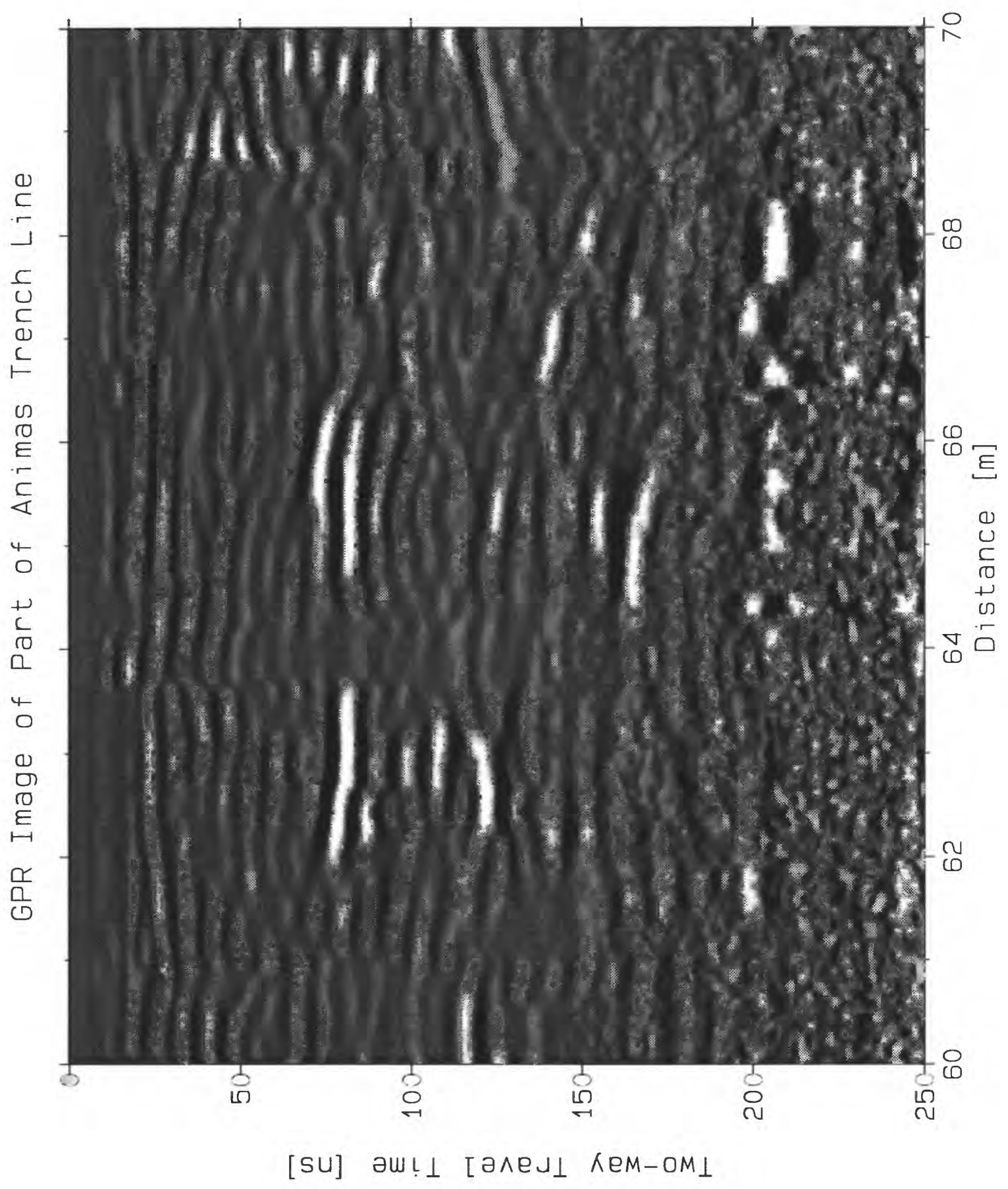




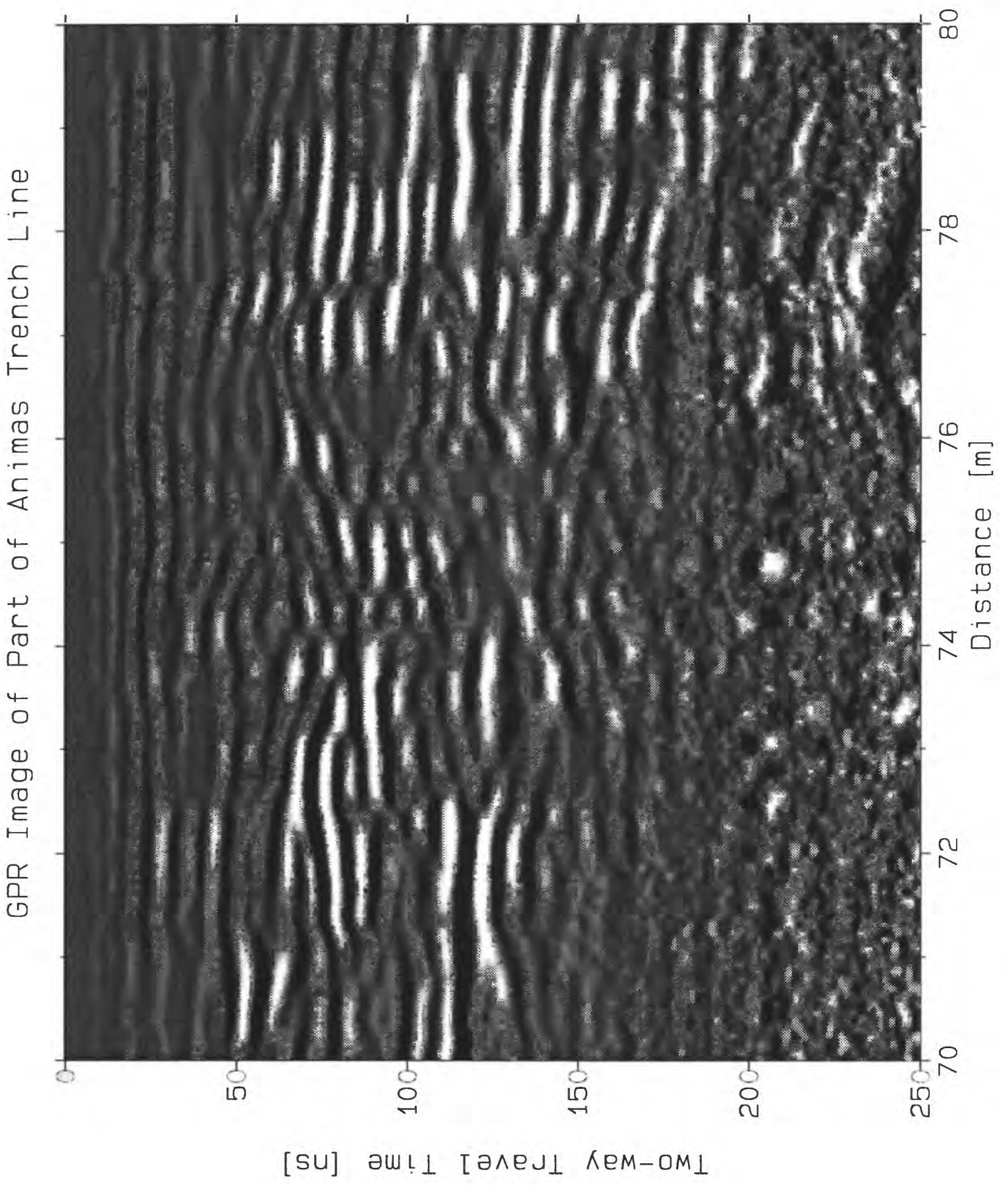




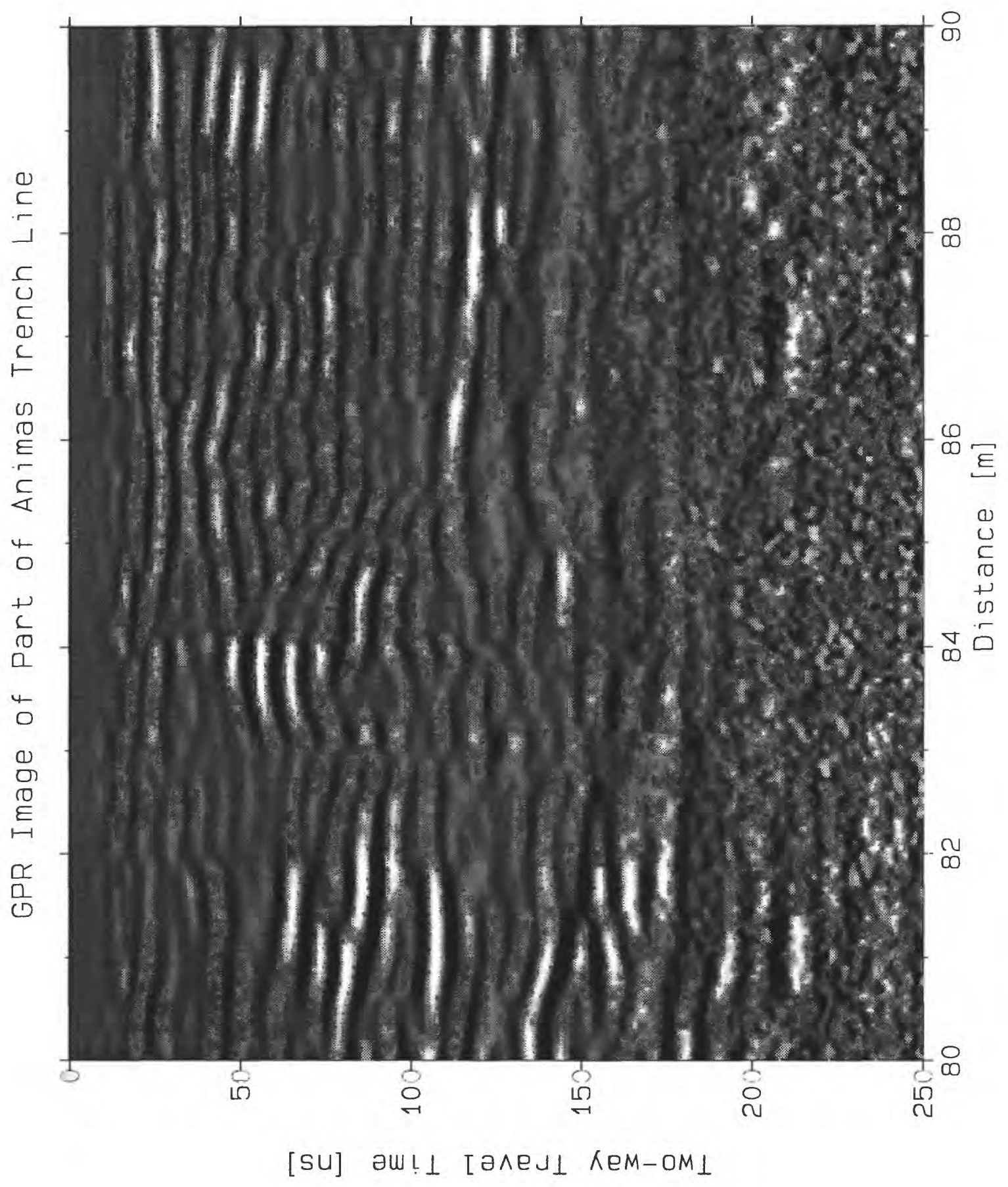




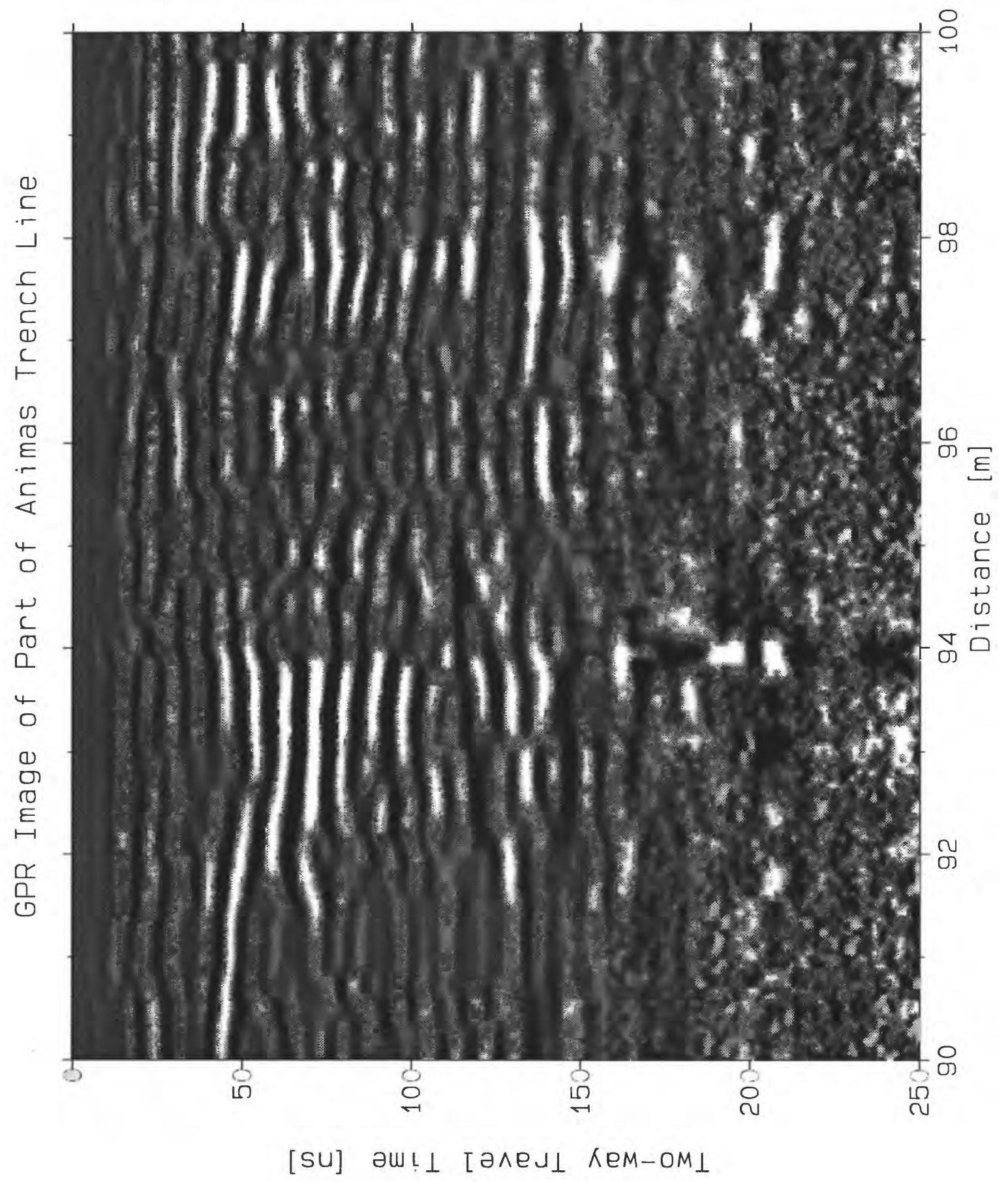




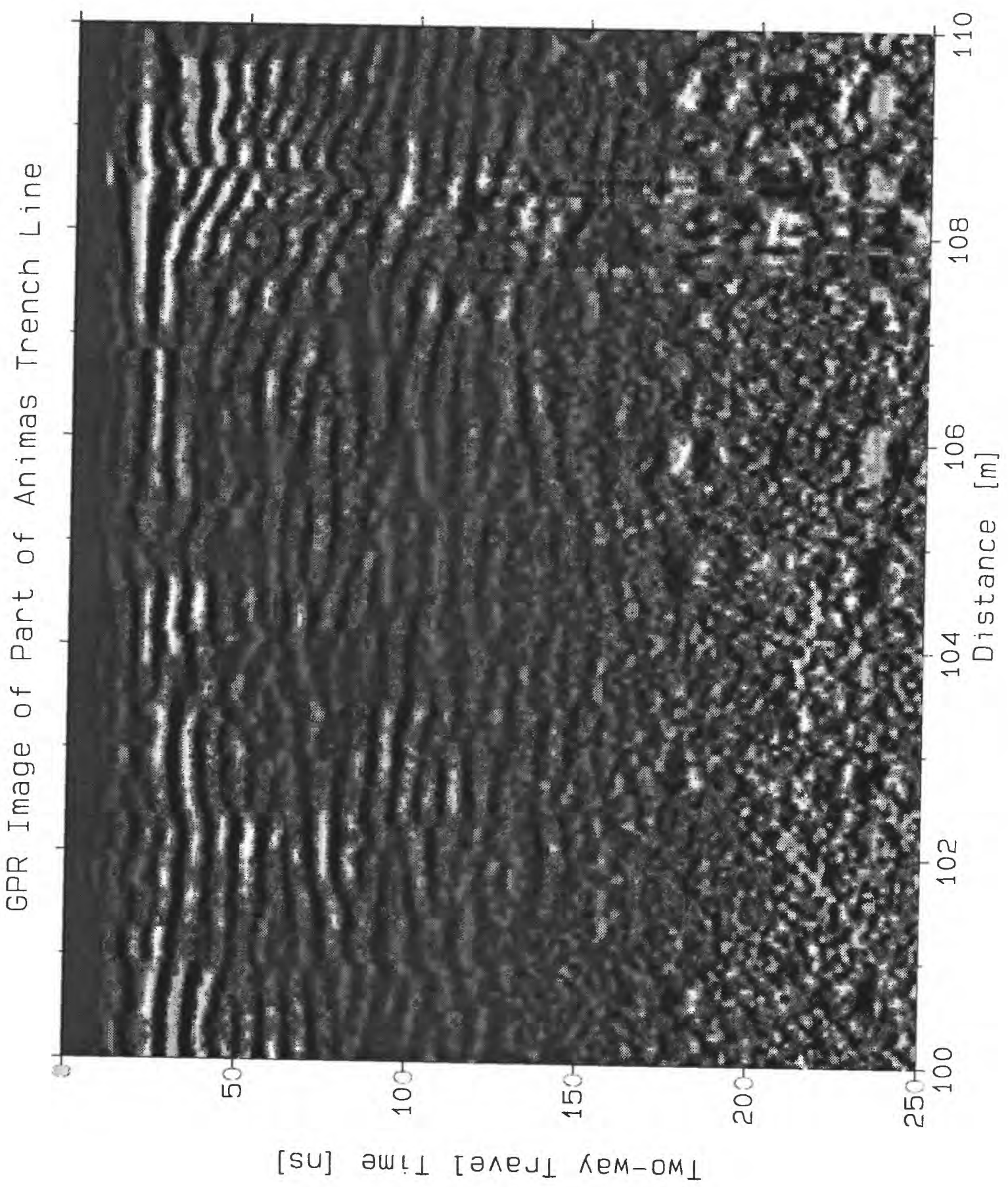




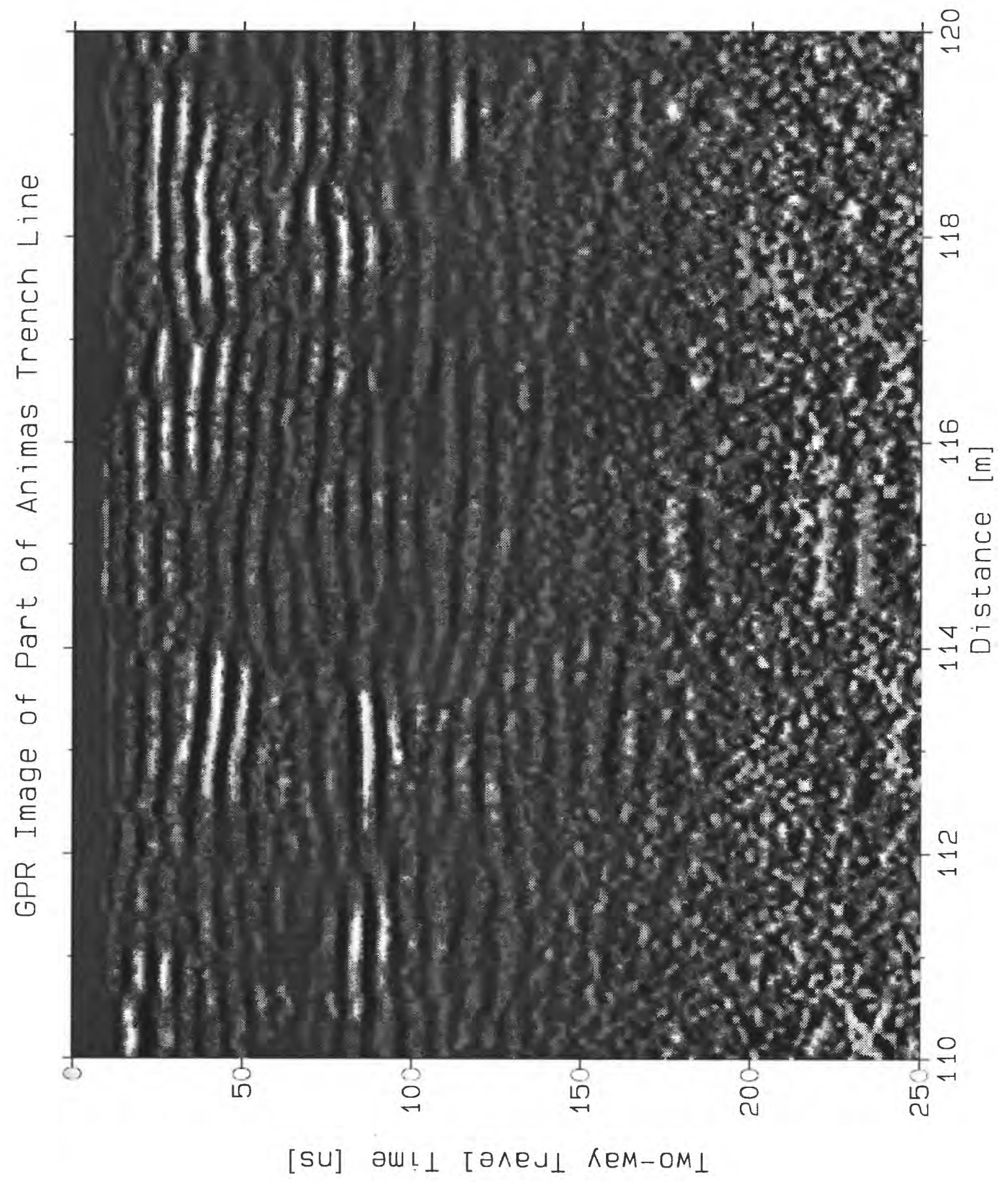




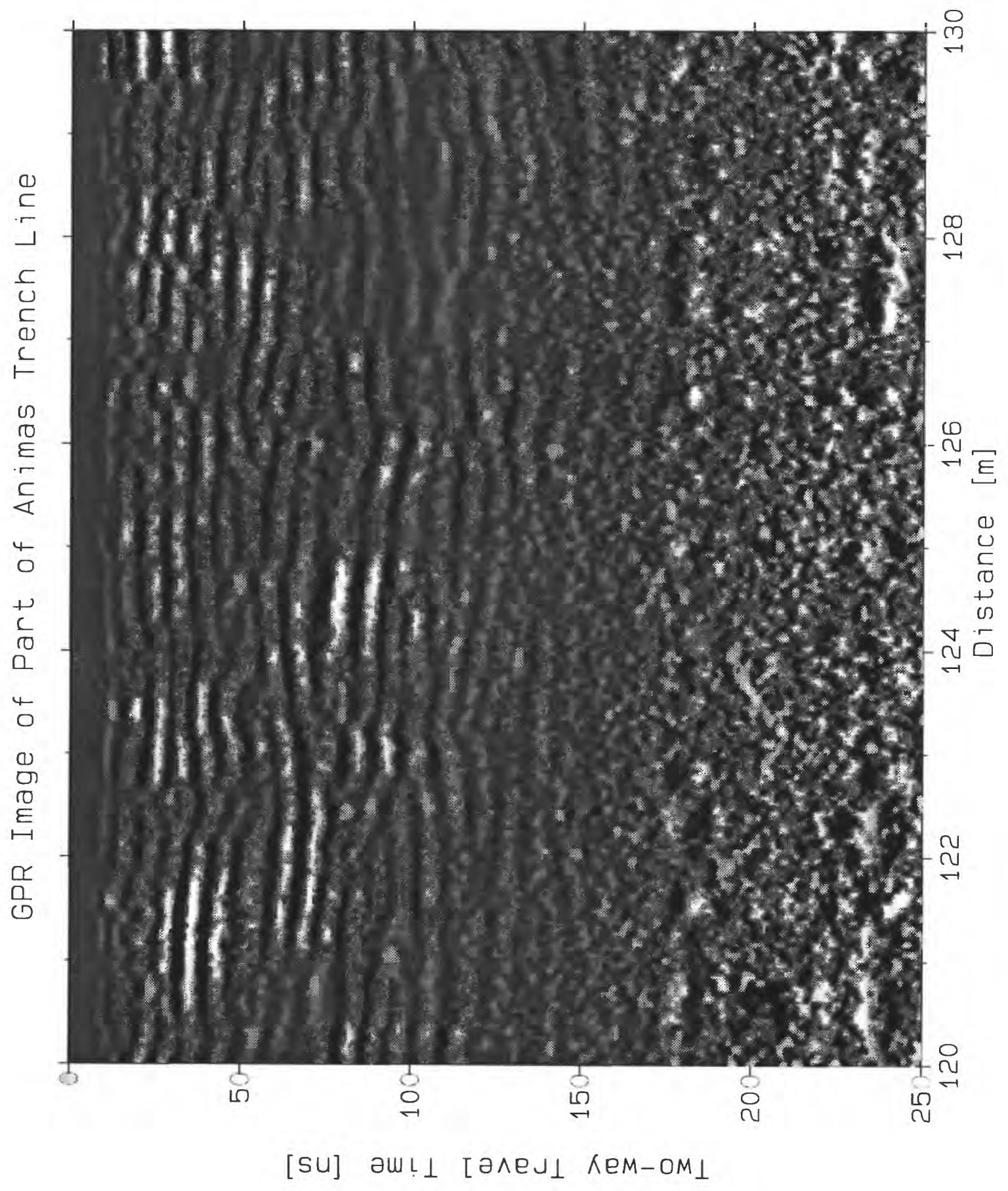




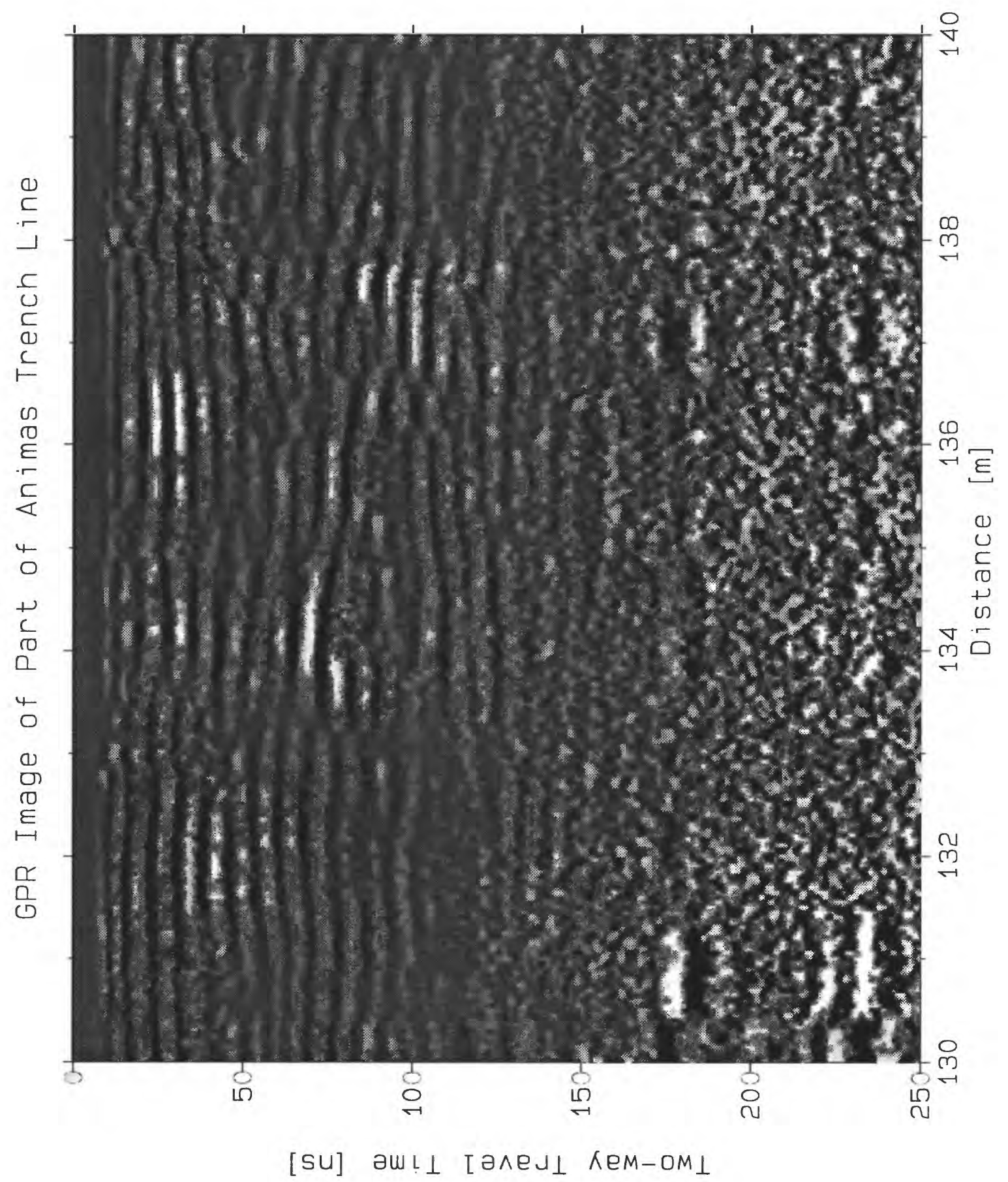




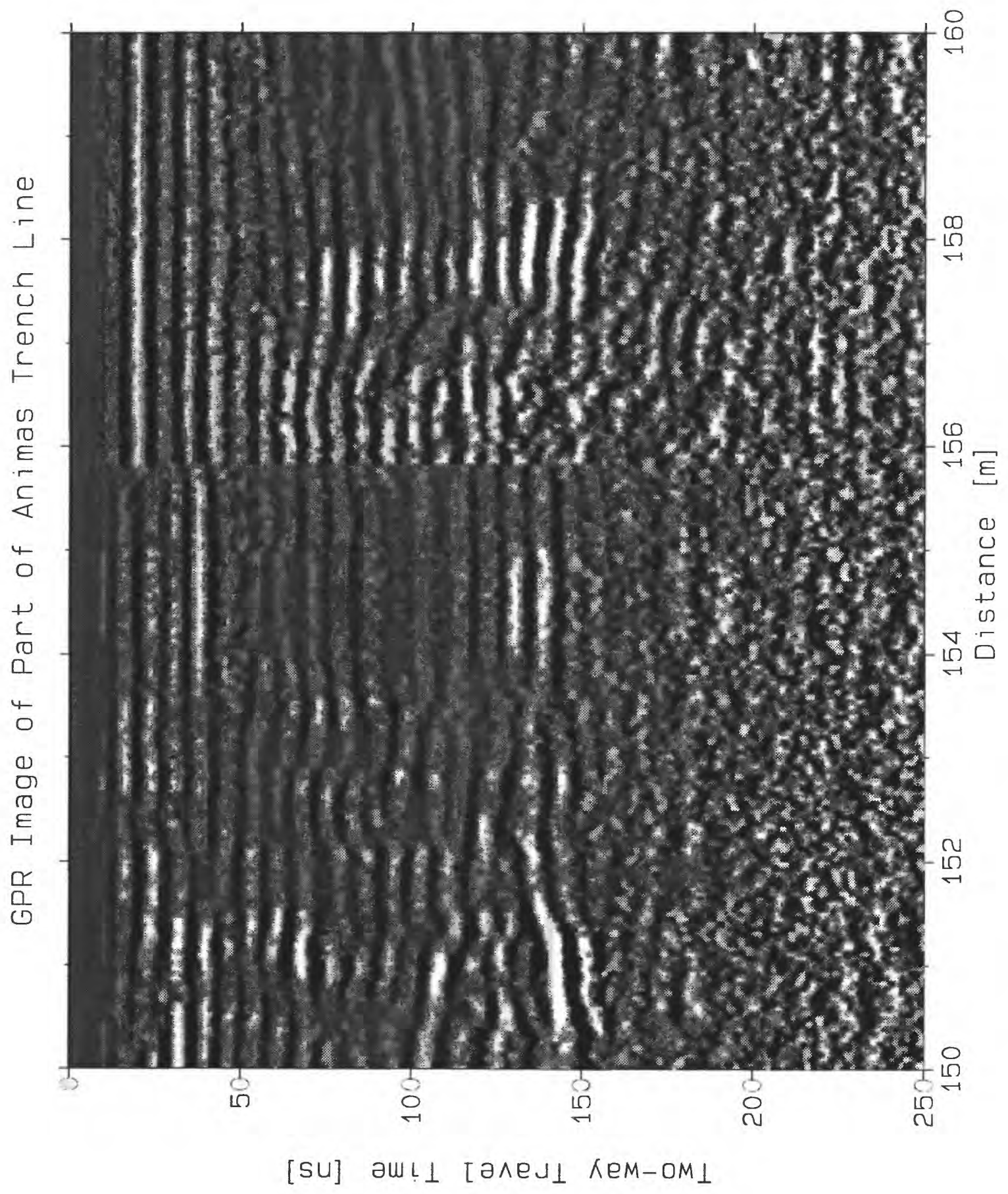




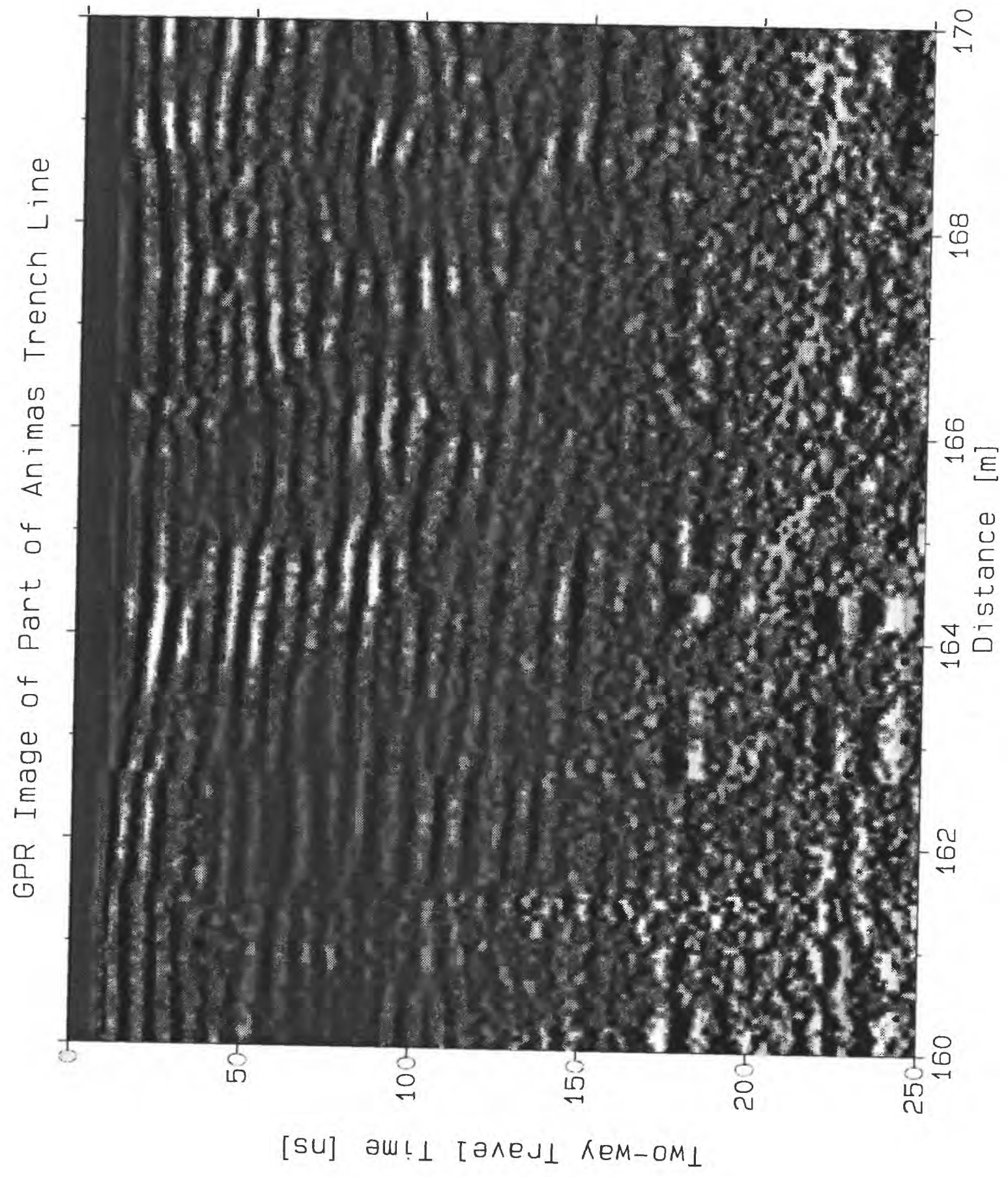




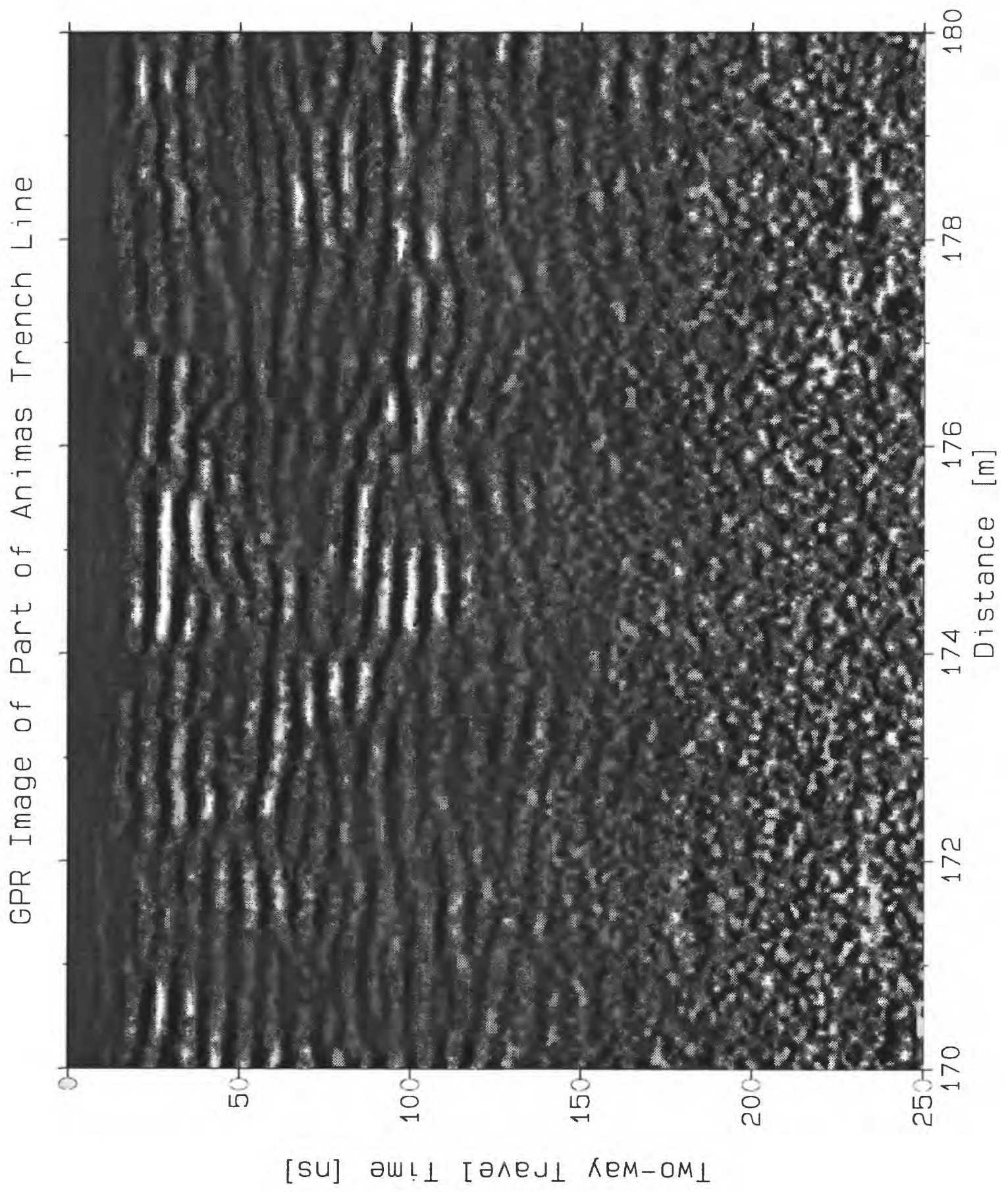




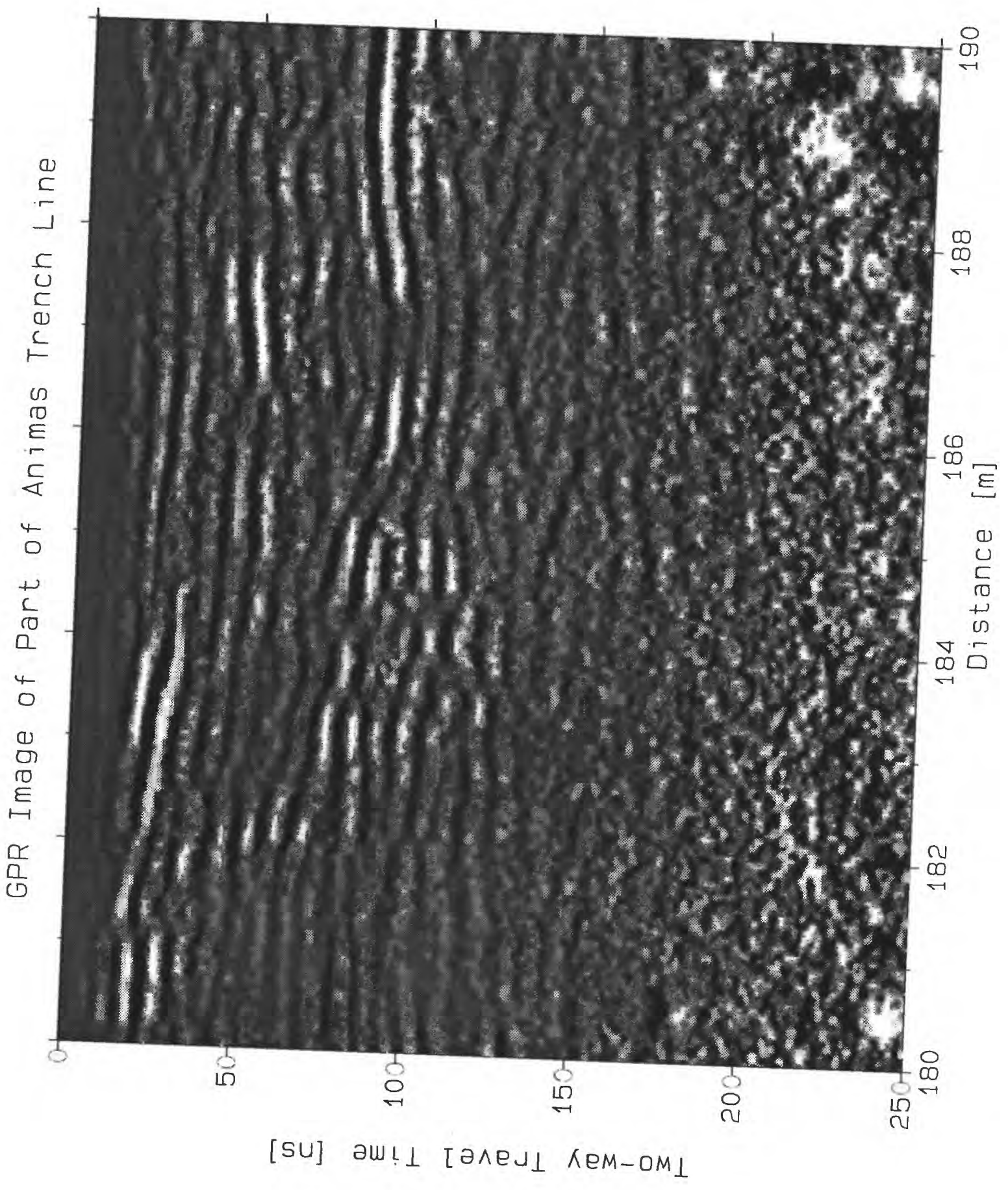




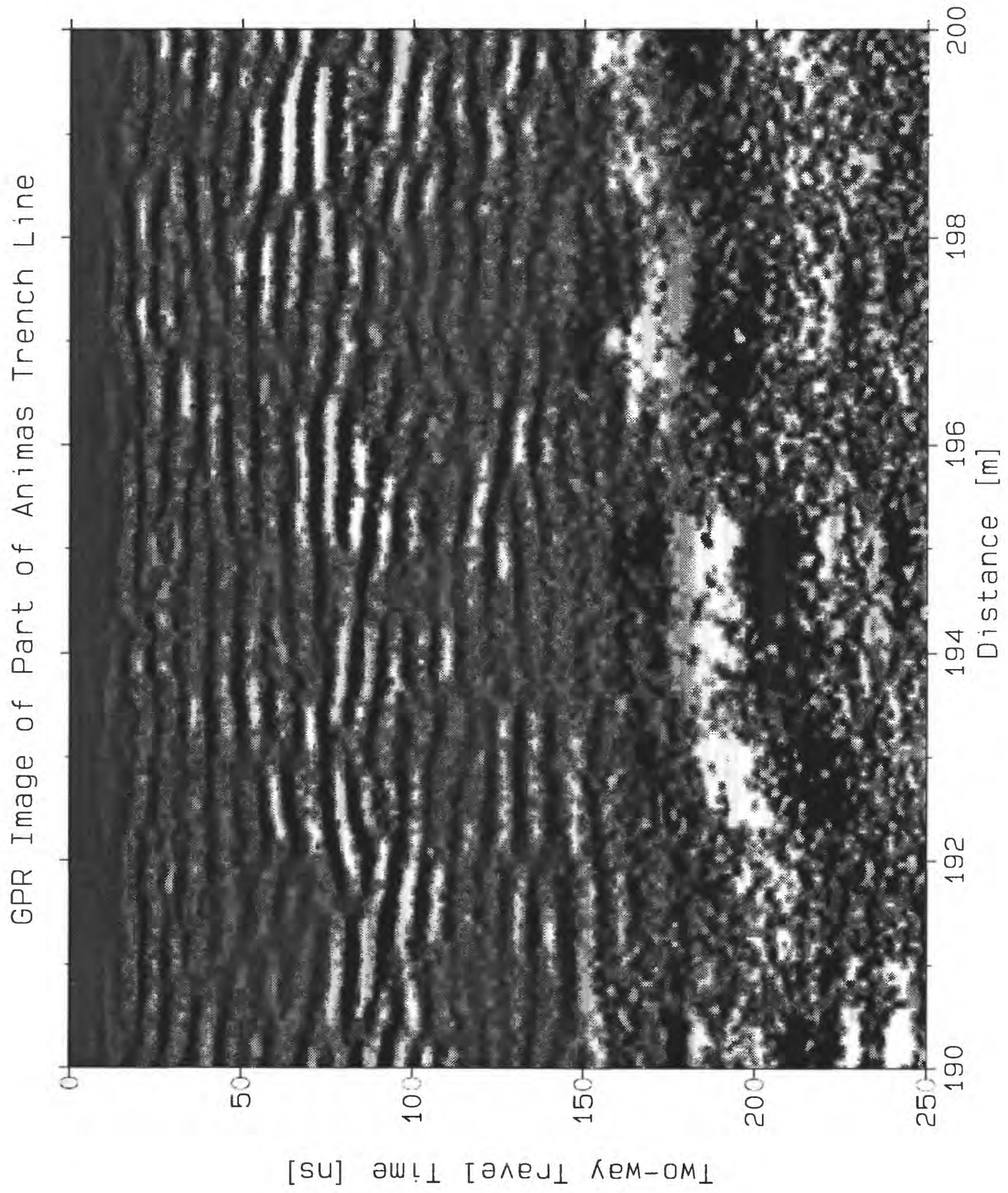




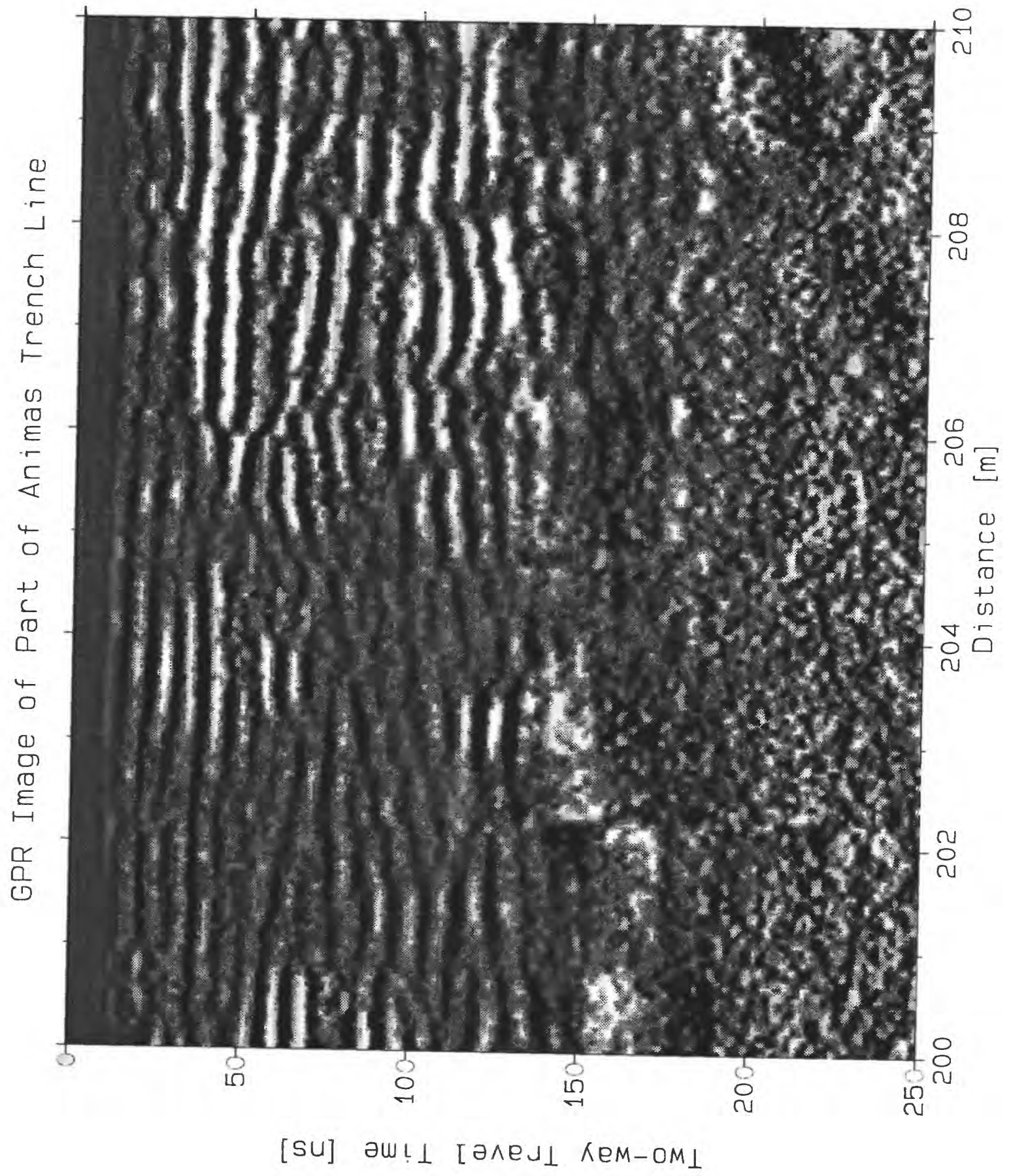




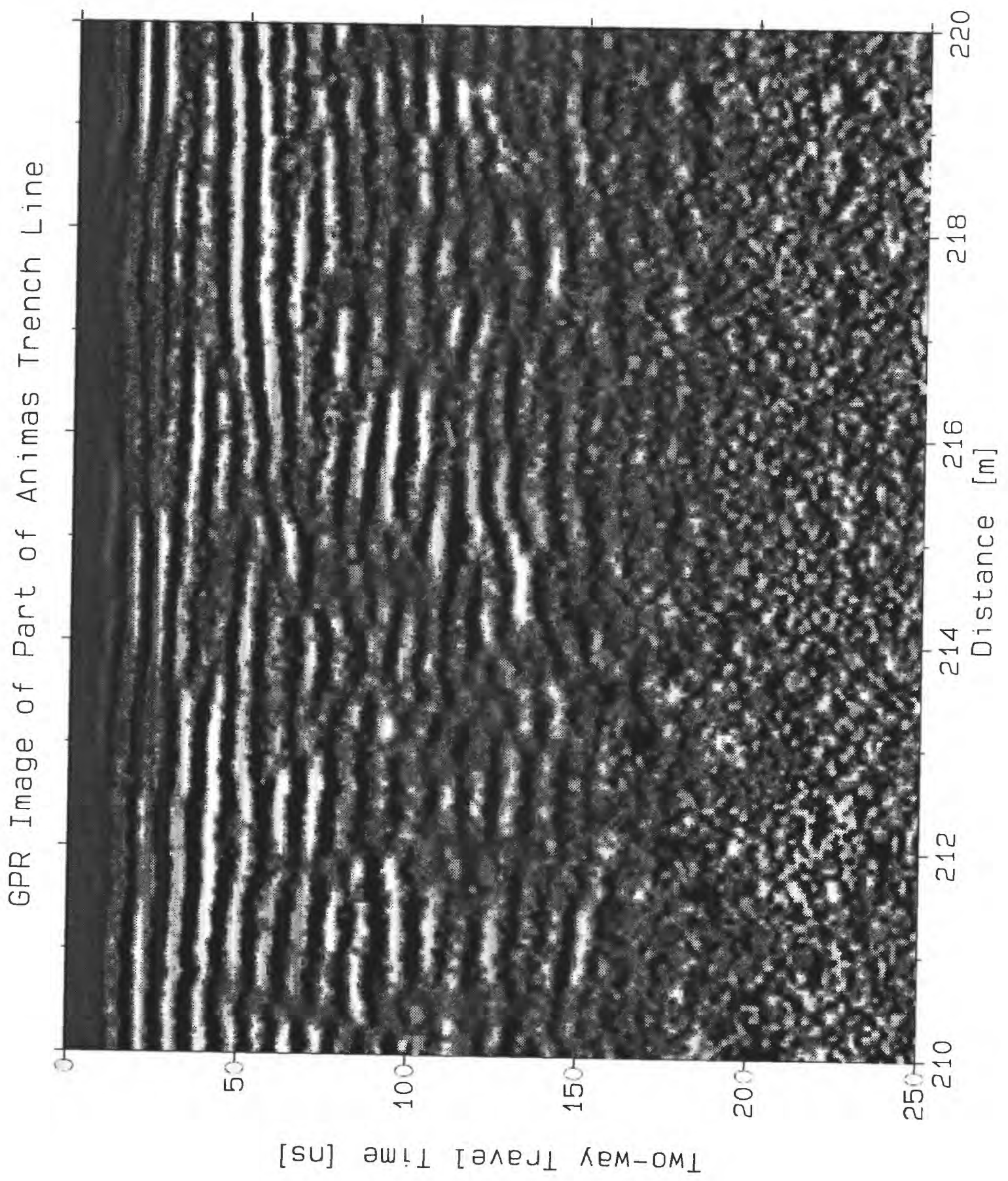




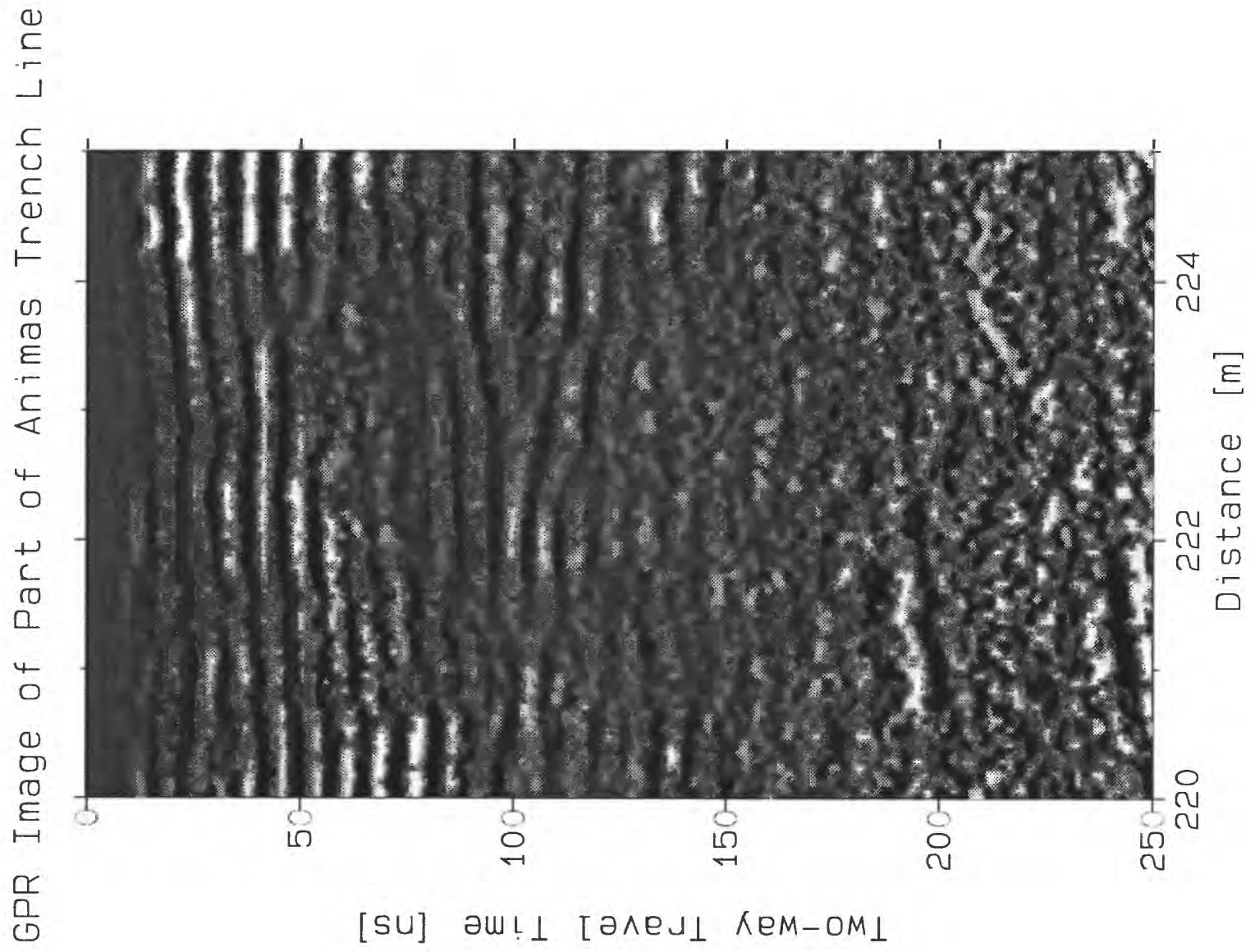




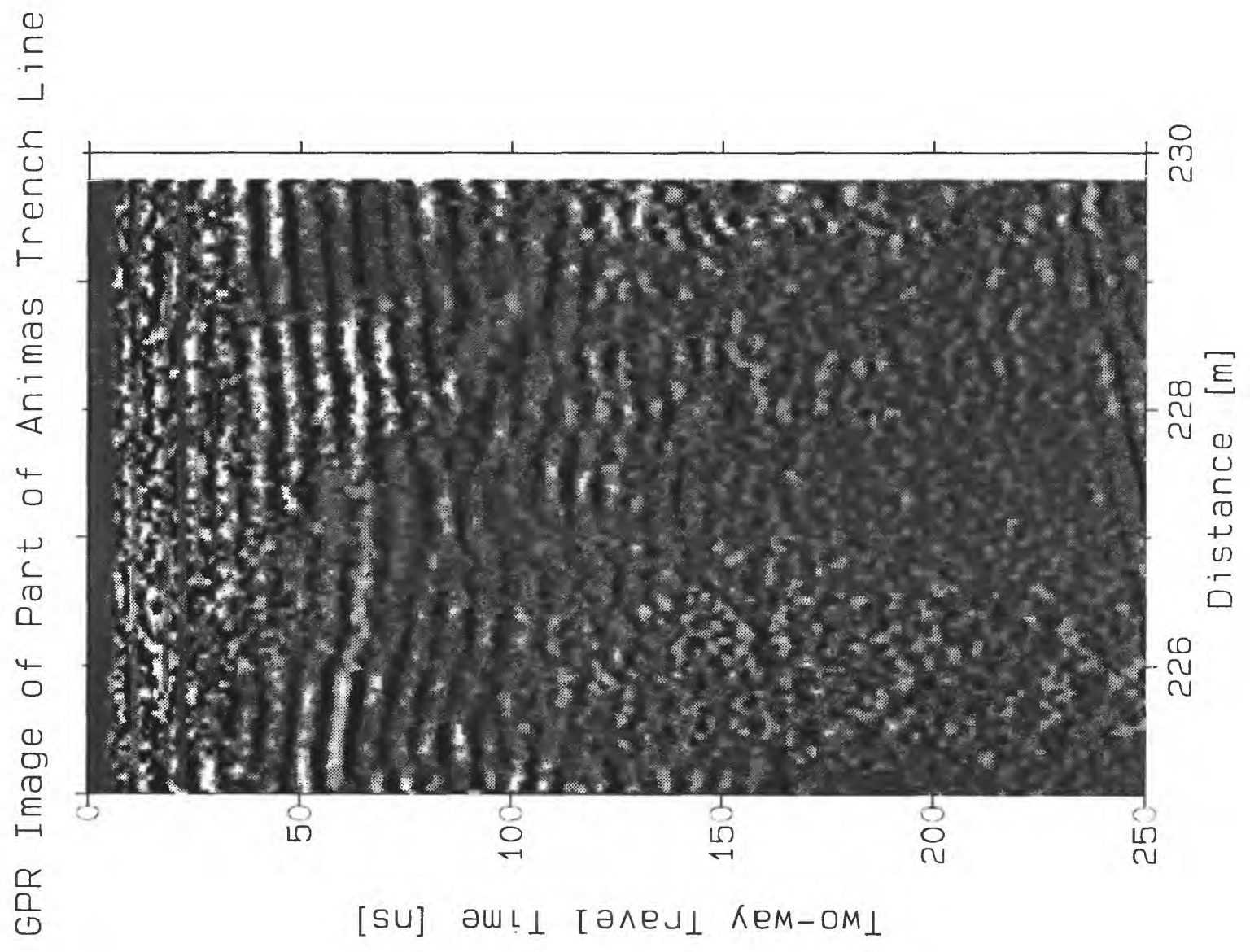




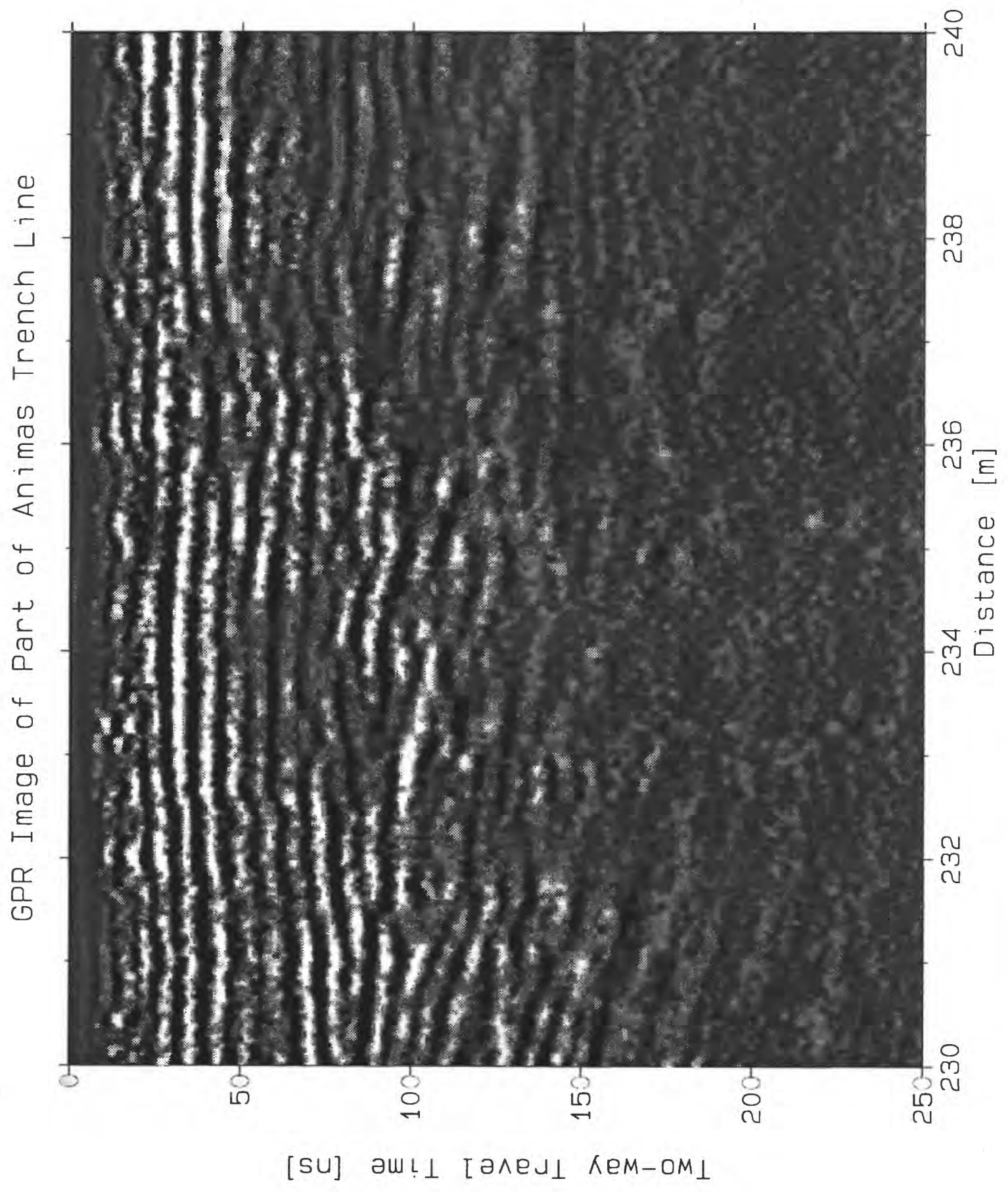




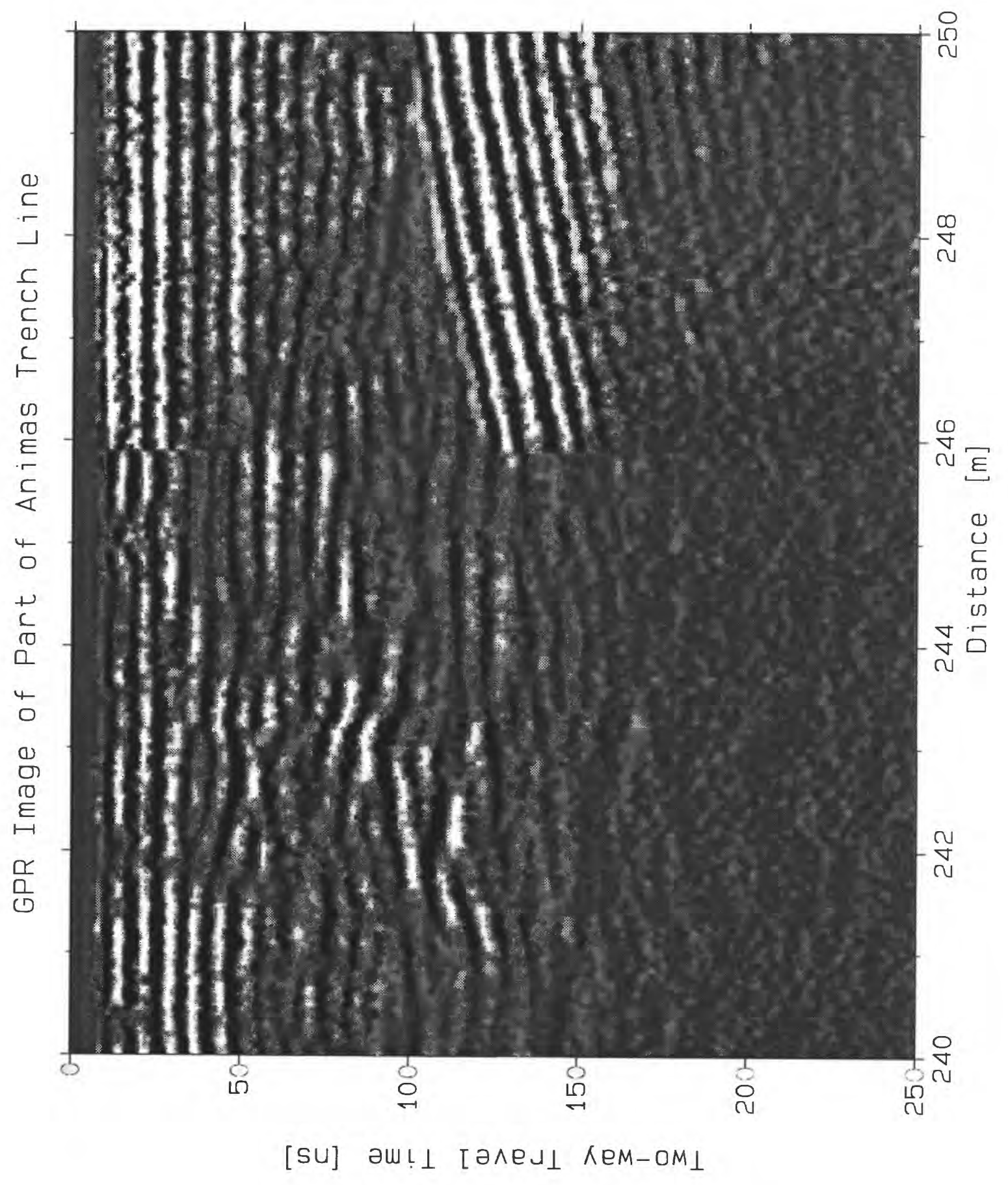




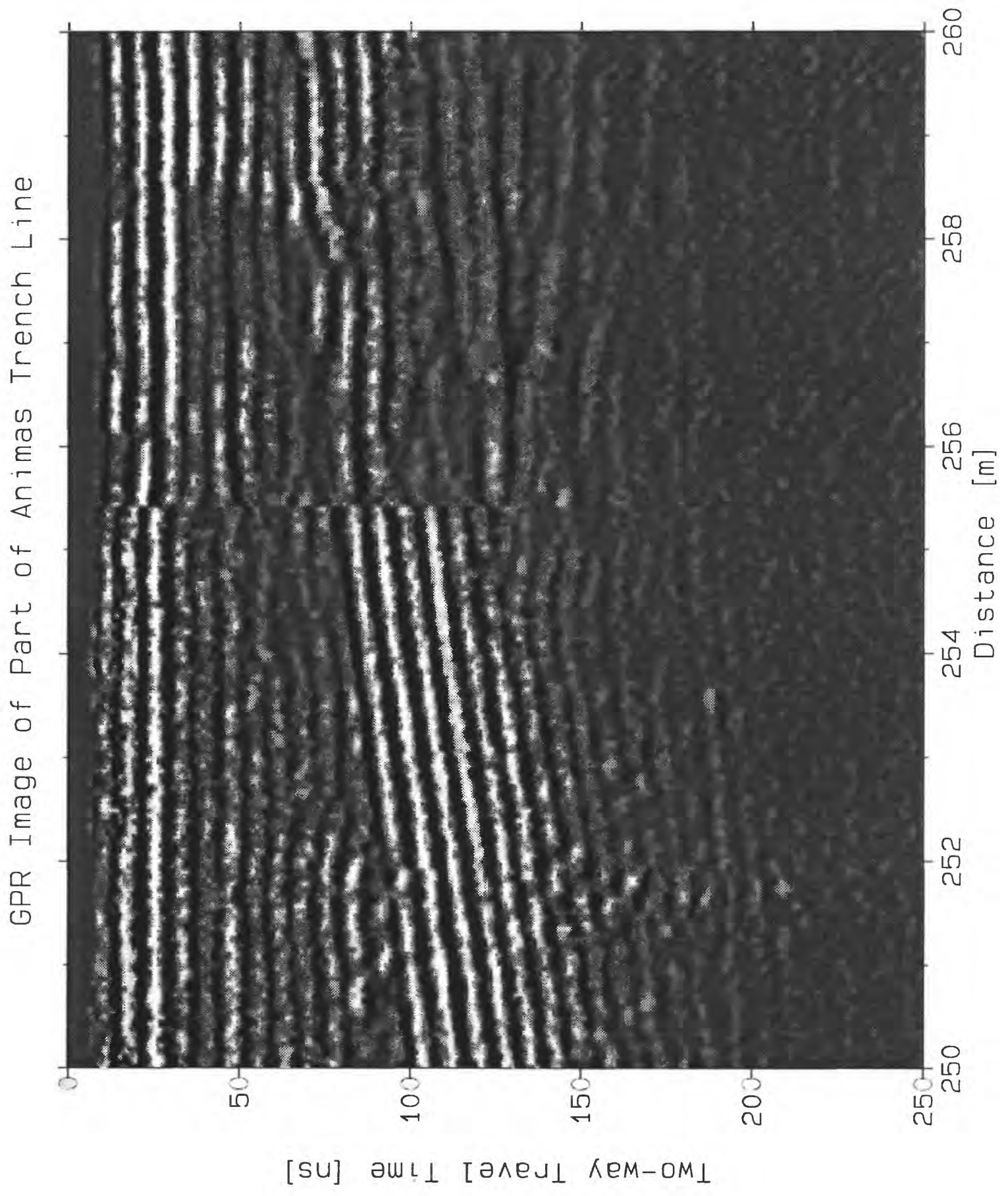




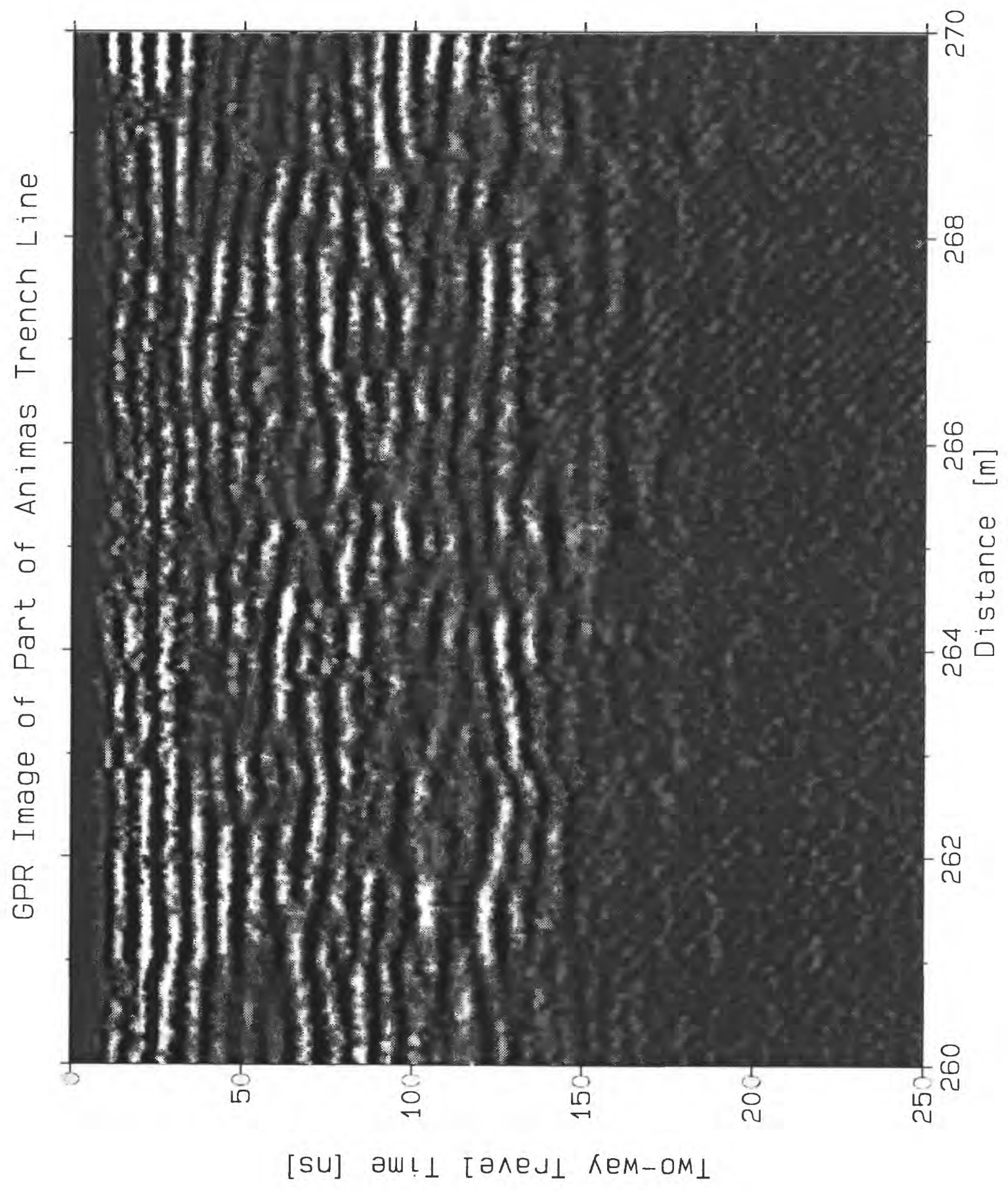




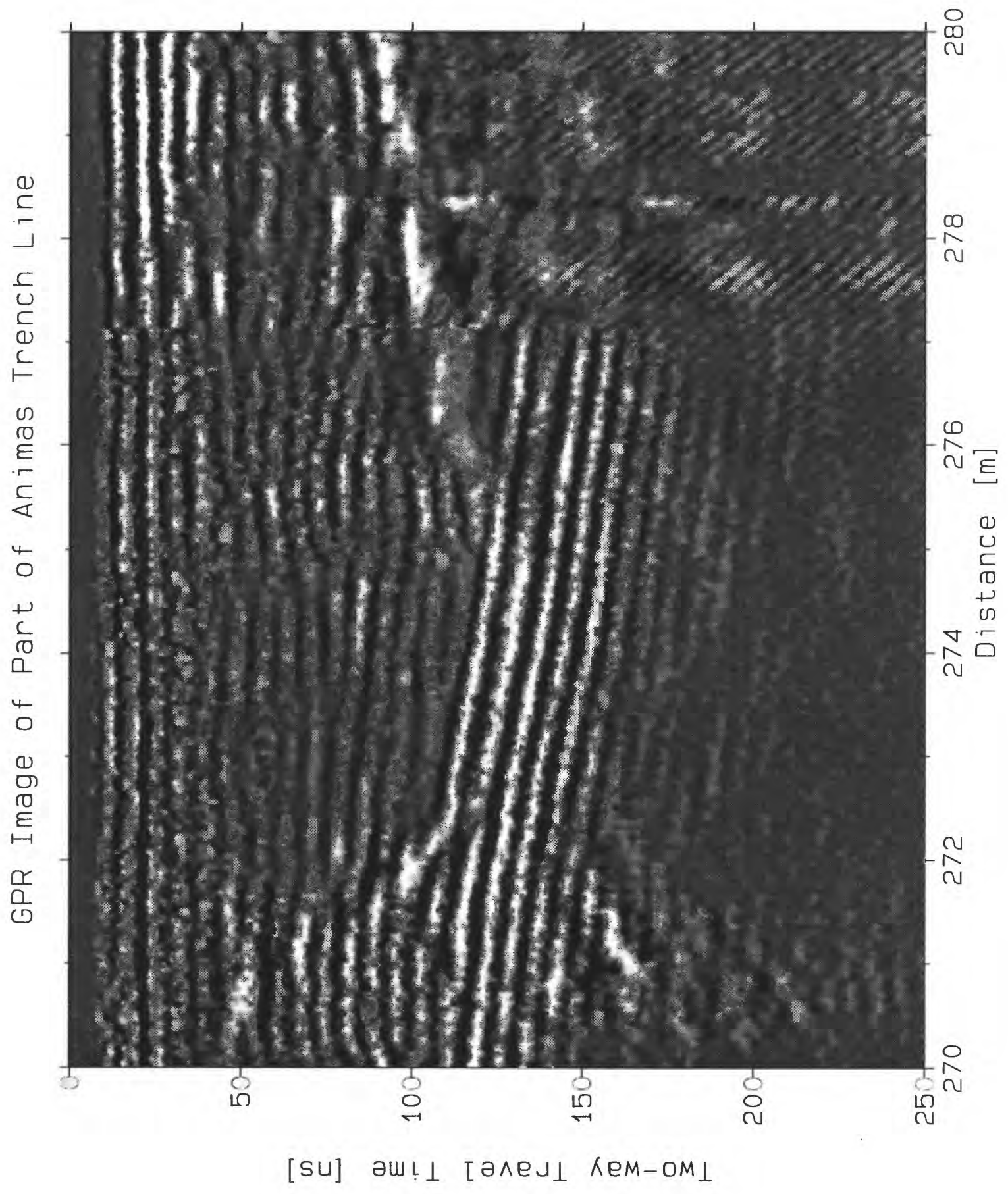




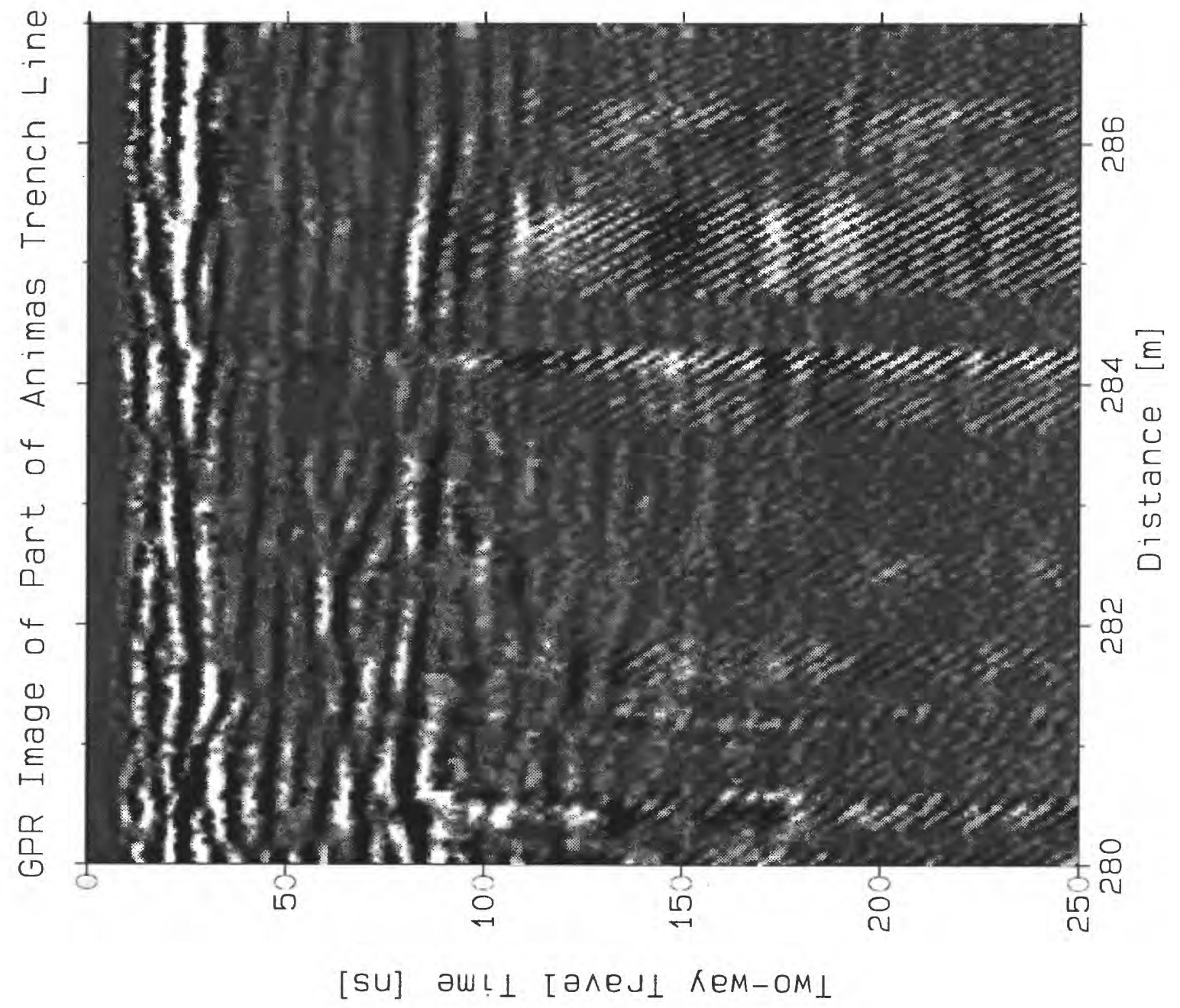


Fig. 7.-- GPR detail, showing hyperbolic arrival due to air wave reflection from GPR console. Heavy horizontal bars at the top of the figure indicate locations of streams, across which the GPR antennas were carried, just clearing the water surface.

\section{GPR Image Showing an Air-Wave Reflection}

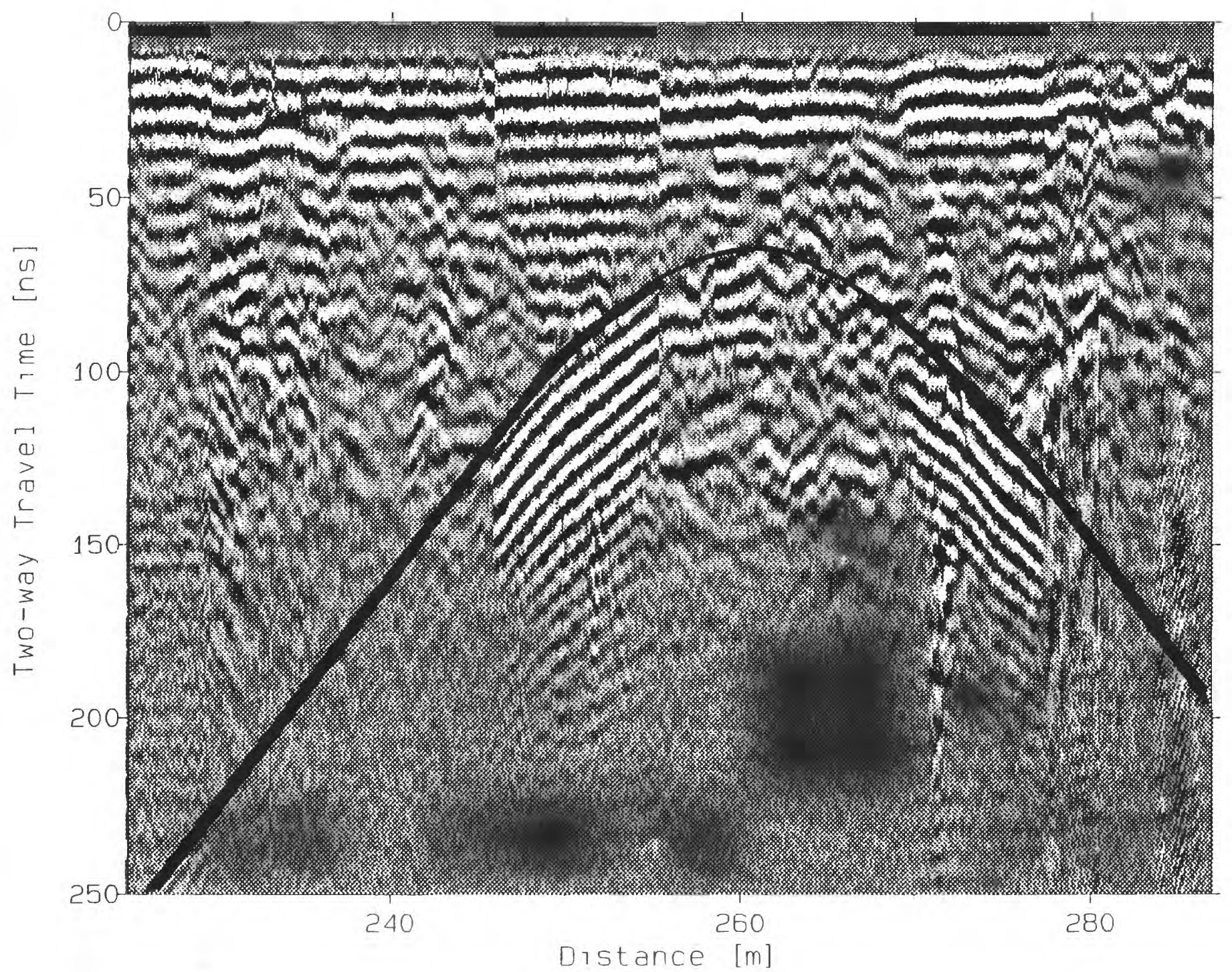


Fig. 8.-- GPR approximate depth sections at a scale of 1:2000 $(10 \mathrm{~cm}=20 \mathrm{~m})$.

This figure consists of 5 separate pages which directly follow this page. Though this figure is on separate pages for Open-File reproduction, it is intended that the pages be pasted together end to end so as to easily compare with Plate 1. 

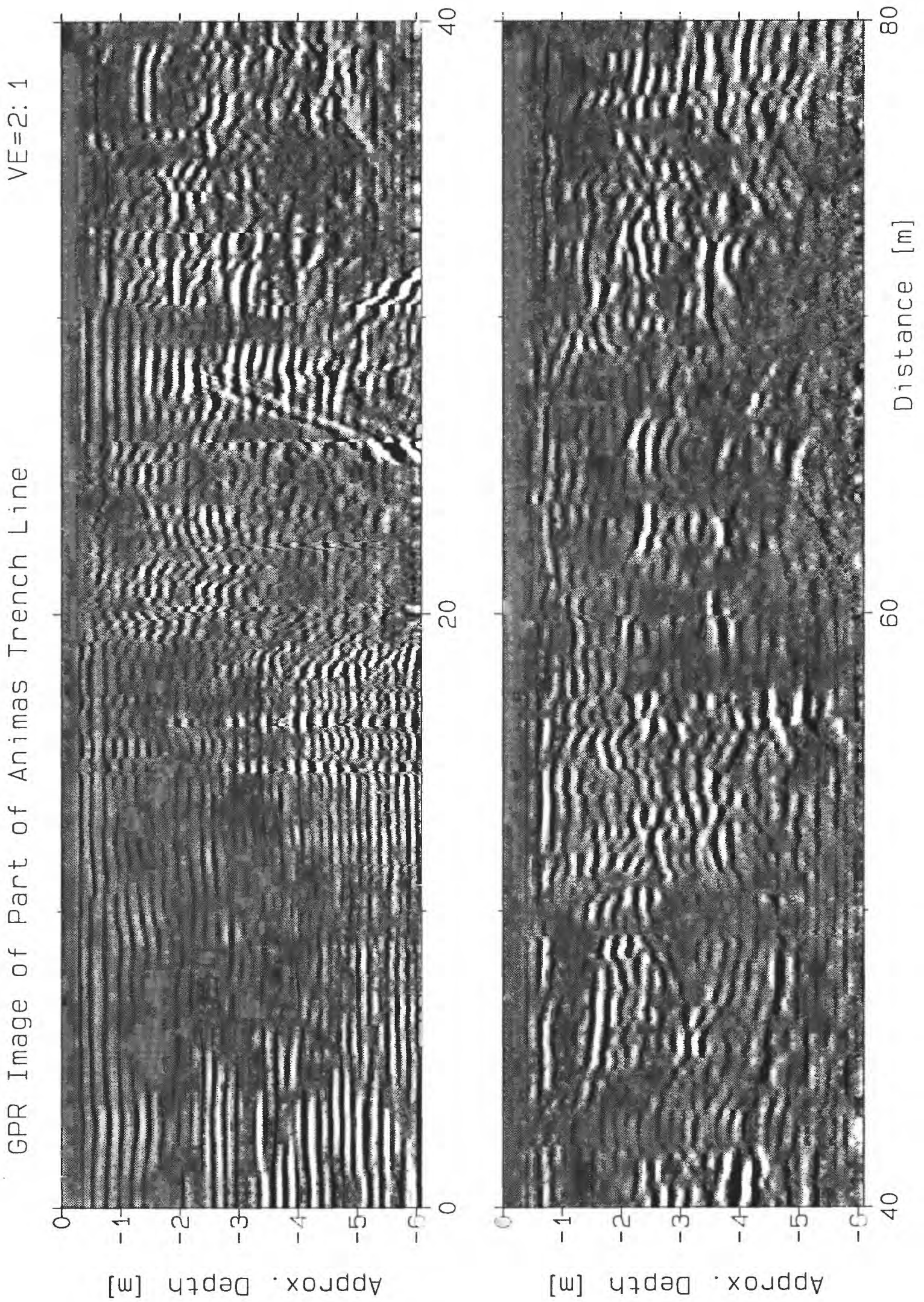

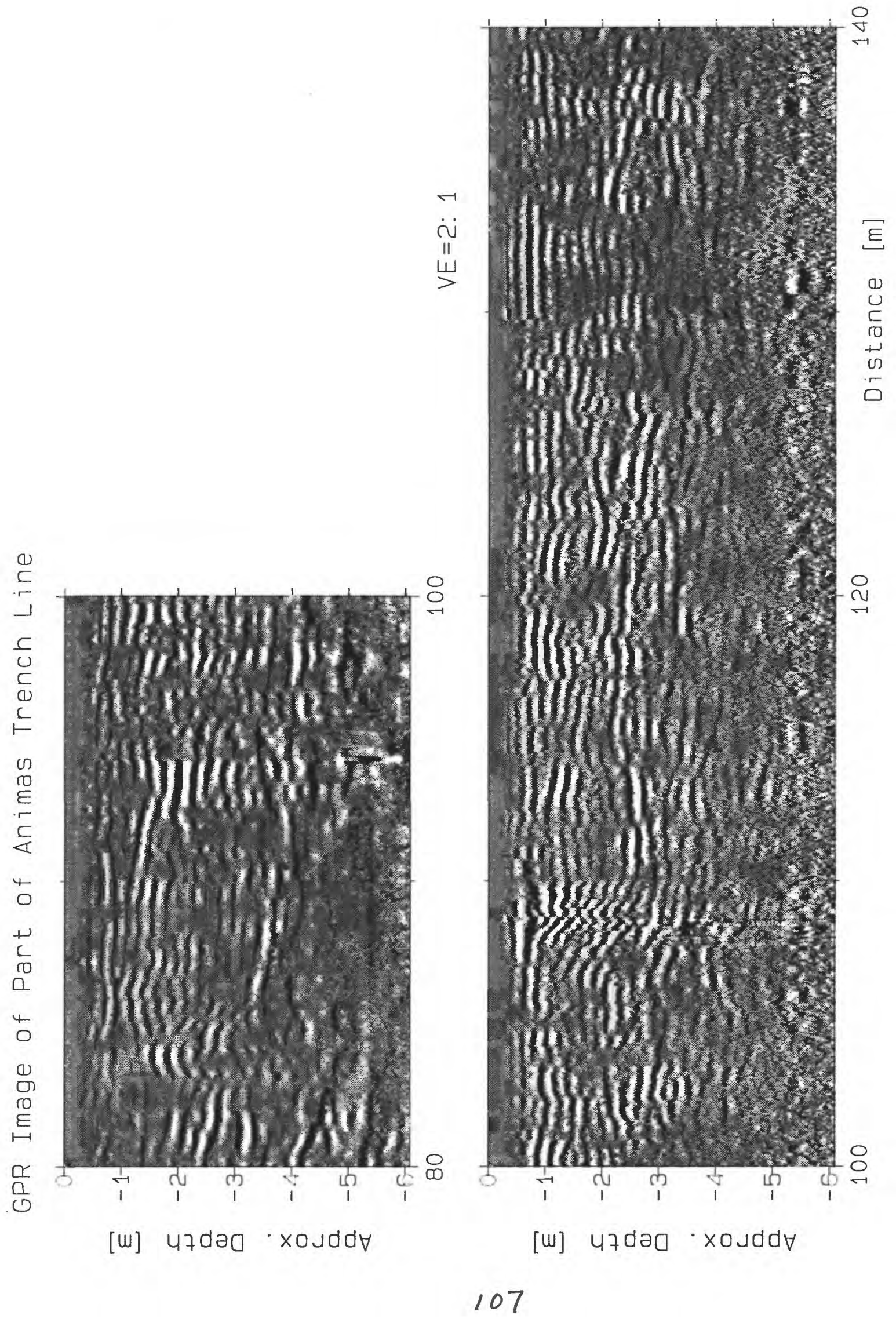


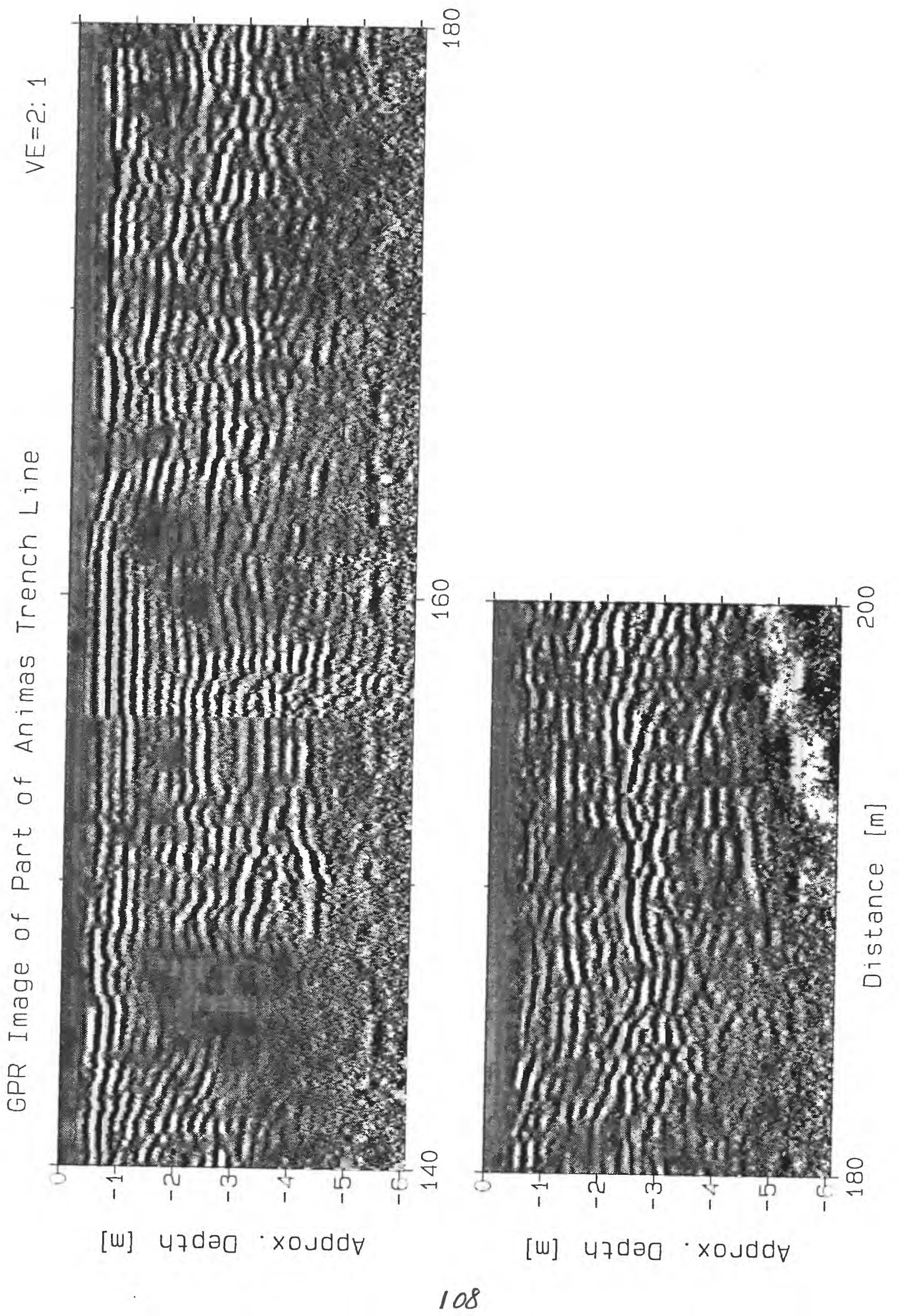



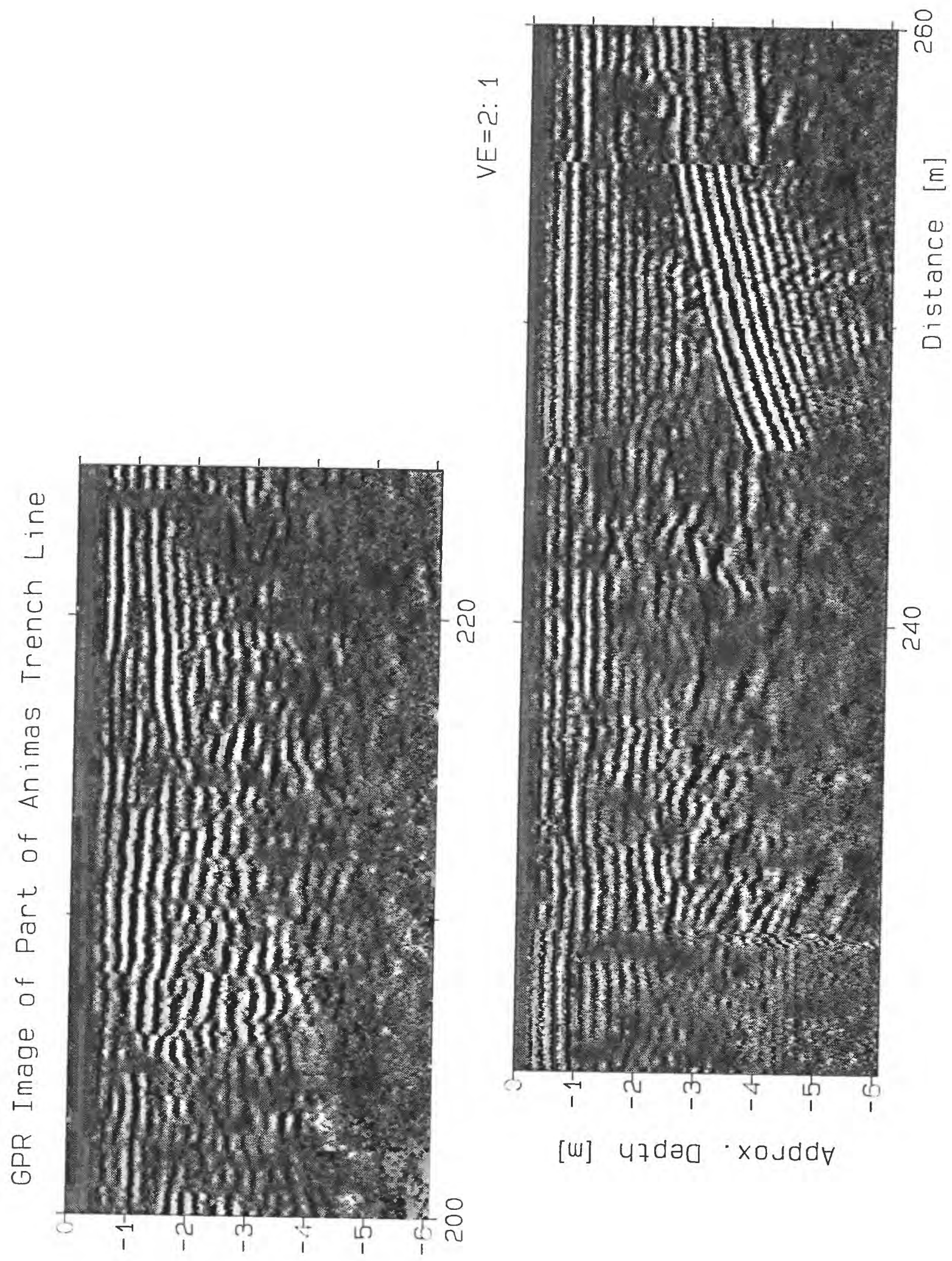

[w] 47da0 xoudd 


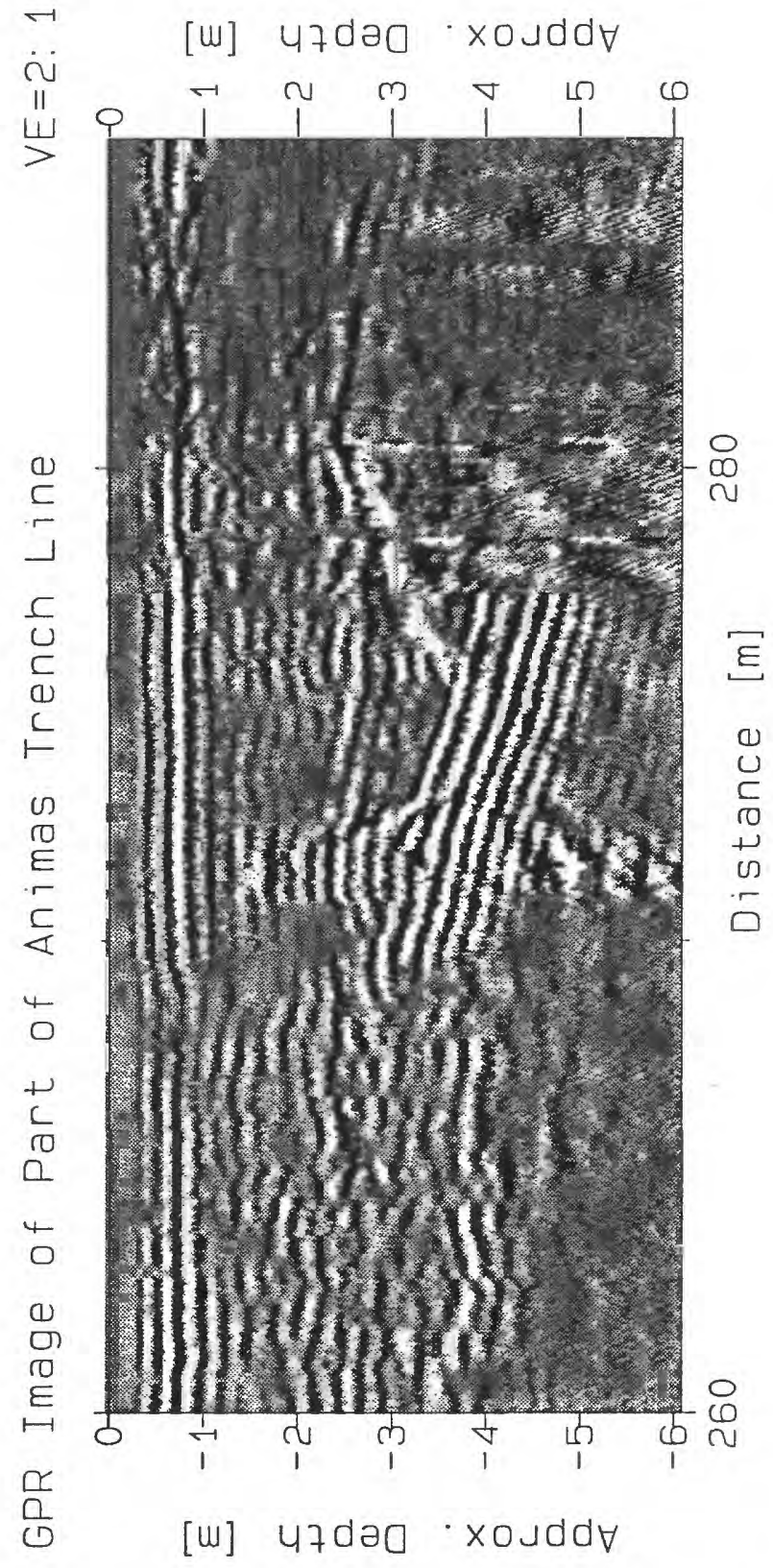




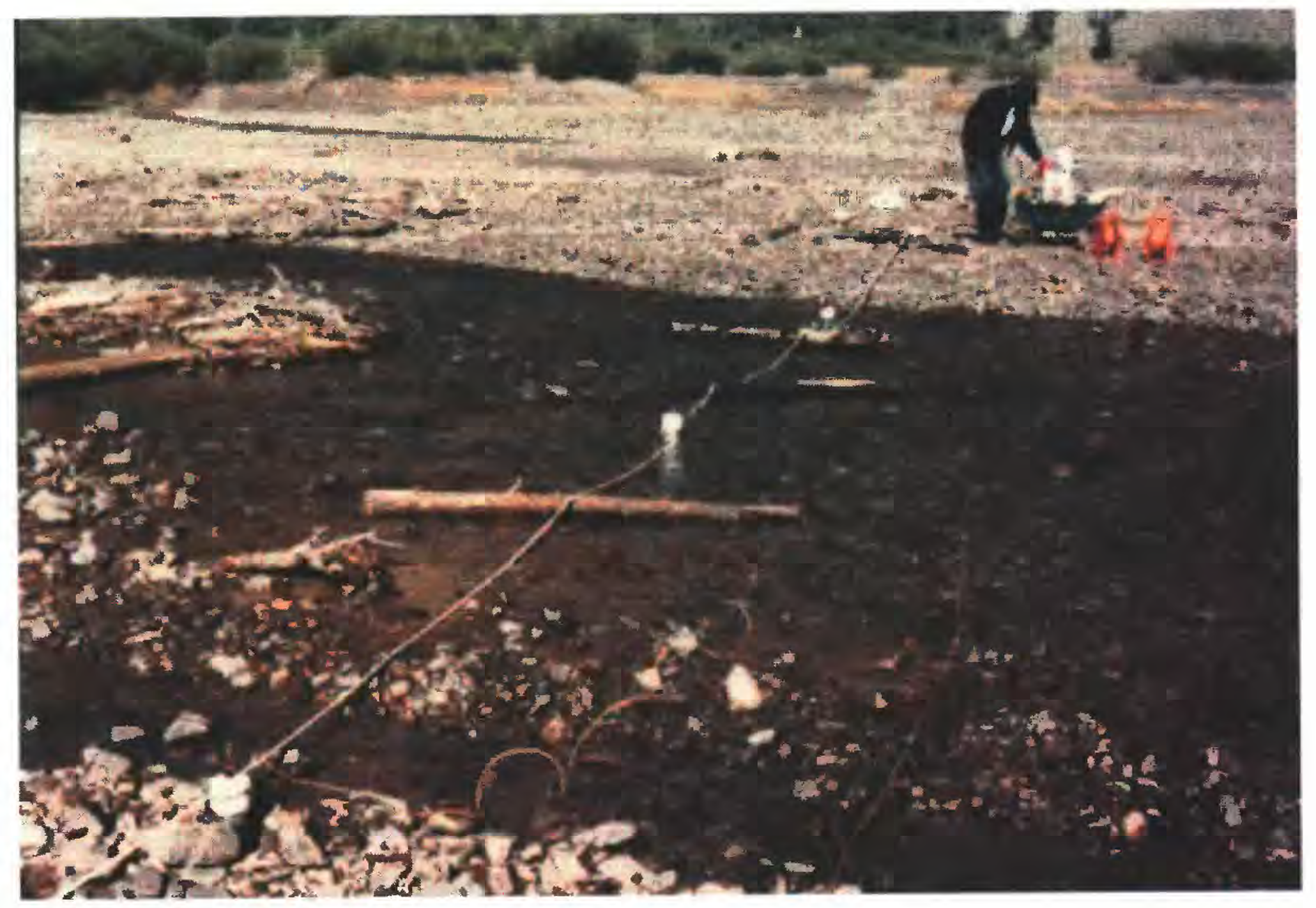

Fig. 9.-- Photograph of SIP field layout crossing shallow stream. 
Fig. 10.-- Spectral pseudosections. These consist of 2 pages directly following this page that show results from the 4 SIP spreads. Note differing scales. Flat or slightly curved signals dominate here, indicating locations where the sediments have little IP effect. The expected signal for sulfide-bearing mine waste is a short concave-down hump, but no such signals were seen here. Signals with long, downward-extending tails result from operator error in taking the measurement, and are not significant. 


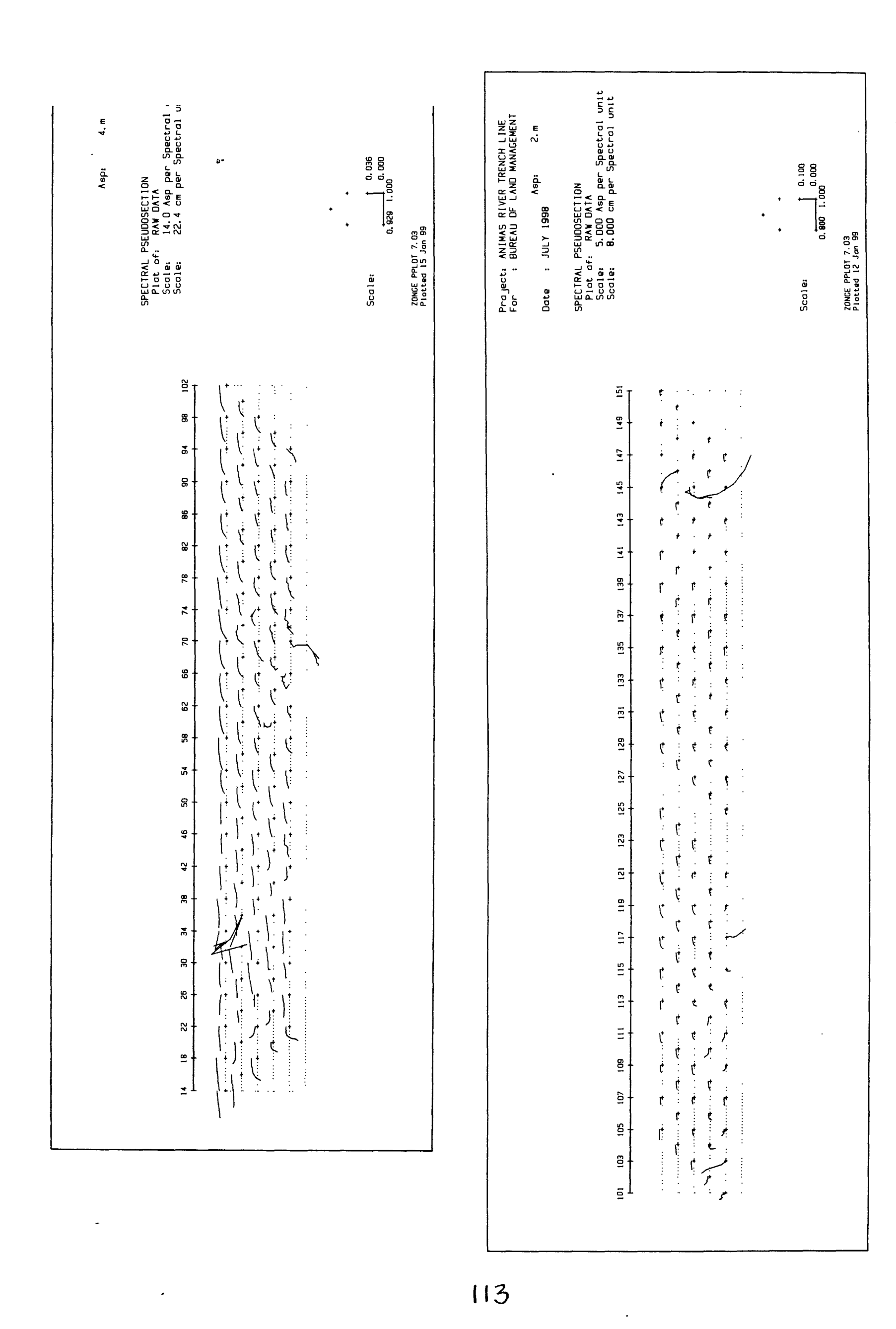



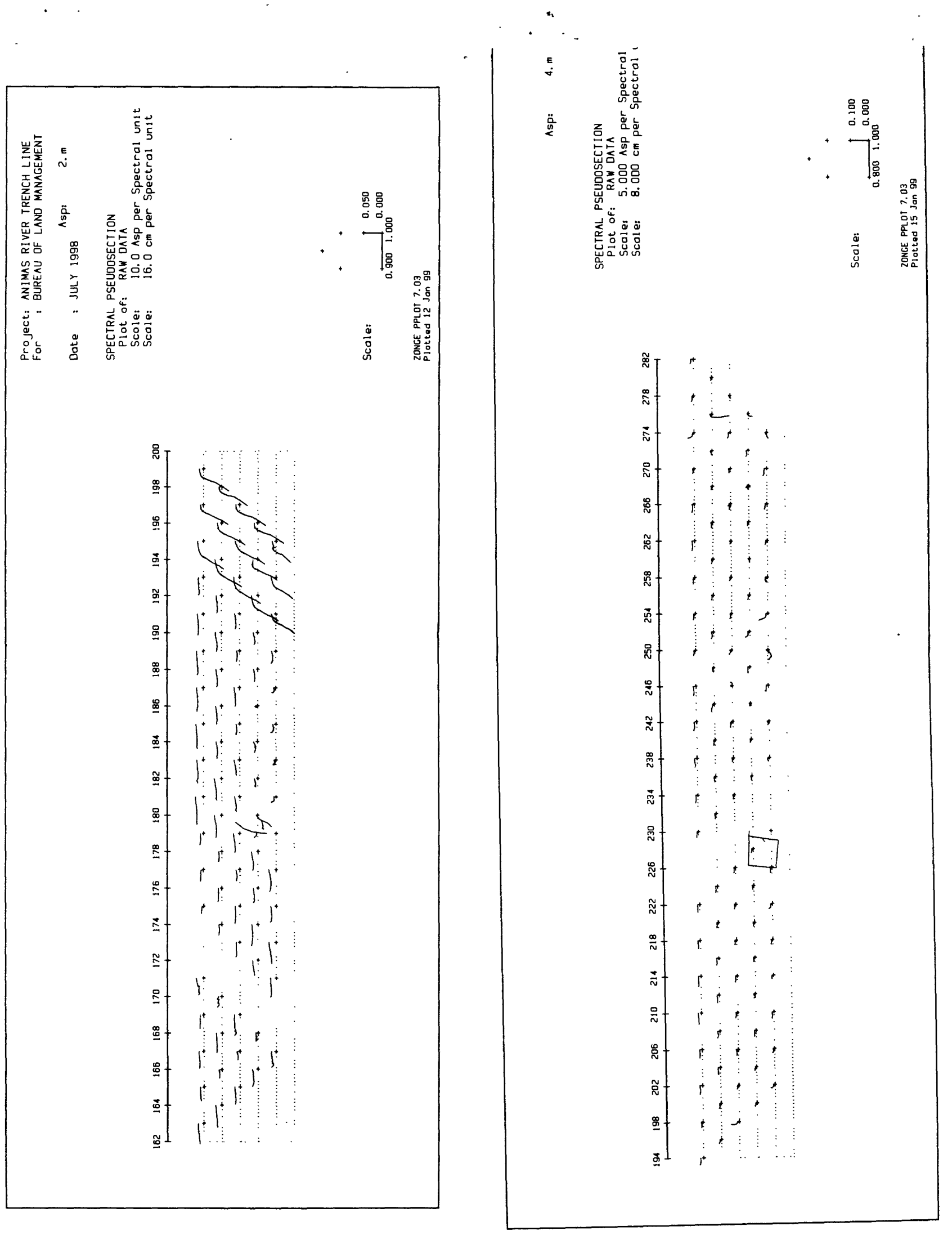